ORNL/TM-2015/142

\title{
Kinetics of Chronic Oxidation of NBG-17 Nuclear Graphite by Water Vapor
}

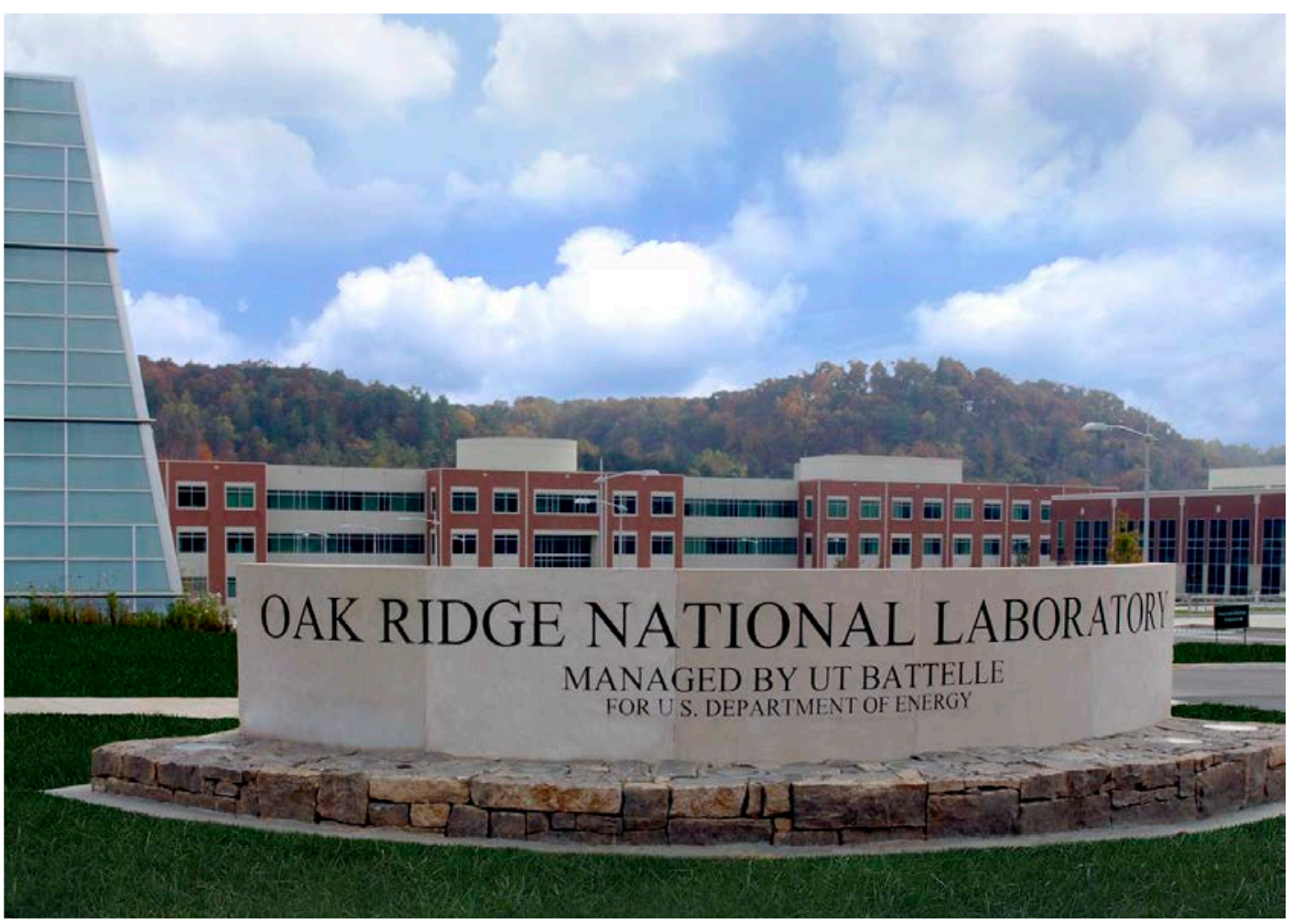

Cristian Contescu

Timothy Burchell

Robert Mee

April 2015 


\section{DOCUMENT AVAILABILITY}

Reports produced after January 1, 1996, are generally available free via US Department of Energy (DOE) SciTech Connect.

Website http://www.osti.gov/scitech/

Reports produced before January 1, 1996, may be purchased by members of the public from the following source:

National Technical Information Service

5285 Port Royal Road

Springfield, VA 22161

Telephone 703-605-6000 (1-800-553-6847)

TDD 703-487-4639

Fax 703-605-6900

E-mail info@ntis.gov

Website http://www.ntis.gov/help/ordermethods.aspx

Reports are available to DOE employees, DOE contractors, Energy Technology Data Exchange representatives, and International Nuclear Information System representatives from the following source:

Office of Scientific and Technical Information

PO Box 62

Oak Ridge, TN 37831

Telephone 865-576-8401

Fax 865-576-5728

E-mail reports@osti.gov

Website http://www.osti.gov/contact.html

This report was prepared as an account of work sponsored by an agency of the United States Government. Neither the United States Government nor any agency thereof, nor any of their employees, makes any warranty, express or implied, or assumes any legal liability or responsibility for the accuracy, completeness, or usefulness of any information, apparatus, product, or process disclosed, or represents that its use would not infringe privately owned rights. Reference herein to any specific commercial product, process, or service by trade name, trademark, manufacturer, or otherwise, does not necessarily constitute or imply its endorsement, recommendation, or favoring by the United States Government or any agency thereof. The views and opinions of authors expressed herein do not necessarily state or reflect those of the United States Government or any agency thereof. 
Advanced Reactor Technology Program

\title{
KINETICS OF CHRONIC OXIDATION OF NBG-17 NUCLEAR GRAPHITE BY WATER VAPOR
}

\author{
Cristian Contescu \\ Timothy Burchell \\ Oak Ridge National Laboratory \\ Robert Mee \\ University of Tennessee, Knoxville
}

April 2015

\author{
Prepared by \\ OAK RIDGE NATIONAL LABORATORY \\ Oak Ridge, Tennessee 37831-6283 \\ managed by \\ UT-BATTELLE, LLC \\ for the \\ US DEPARTMENT OF ENERGY \\ under contract DE-AC05-00OR22725
}


ORNL/TM-2015/142 
ORNL/TM-2015/142

\section{ACKNOWLEDGMENT}

This work is funded by the U.S. Department of Energy, Office of Nuclear Energy Science and Technology, under contract DE-AC05-00OR22725 with Oak Ridge National Laboratory managed by UT-Battelle, LLC. 
ORNL/TM-2015/142 


\section{CONTENTS}

Page

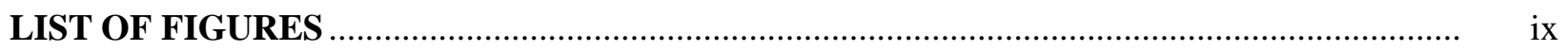

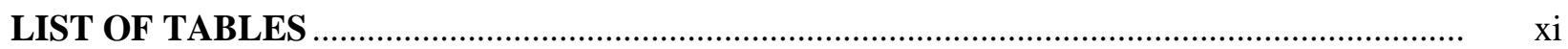

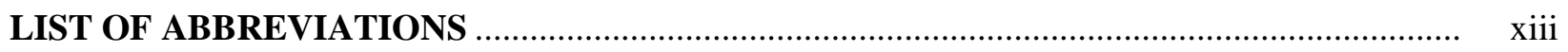

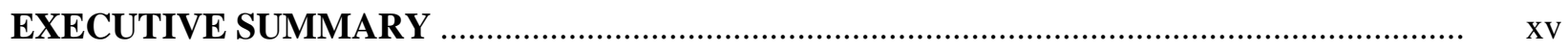

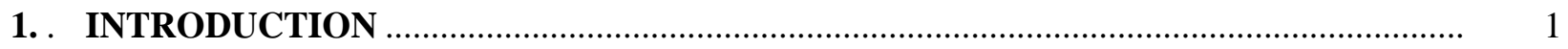

2. EXPERIMENTAL SETUP AND EQUIPMENT PERFORMANCE ............................... 3

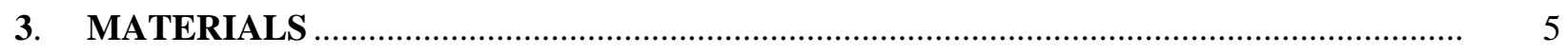

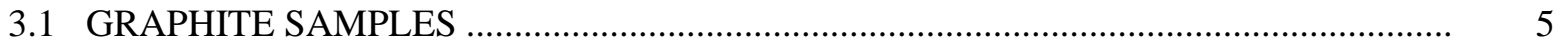

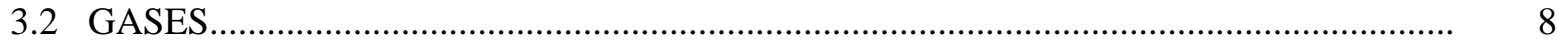

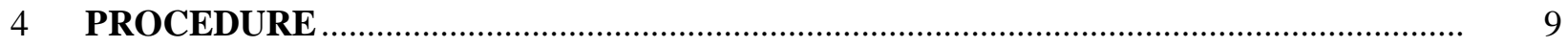

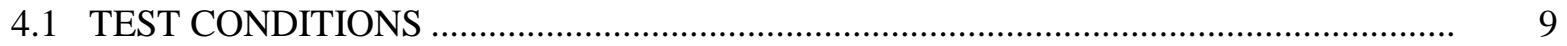

4.2 PREPARATION OF SPECIMENS BEFORE TESTS................................................... 9

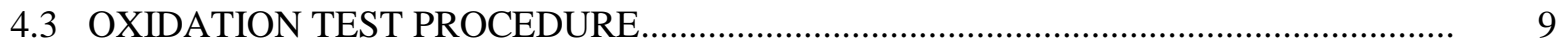

4.4 SPECIMEN CHARACTERIZATION AND DATA SAVING AFTER TESTS ................ 10

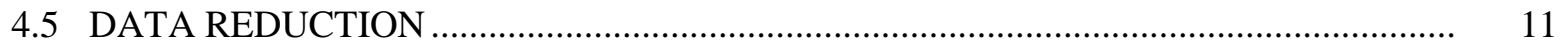

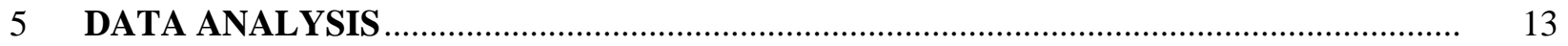

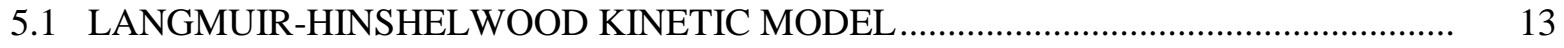

5.2 DETERMINATION OF KINETIC PARAMETERS .......................................................... 14

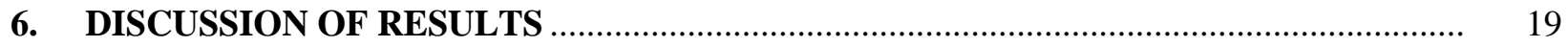

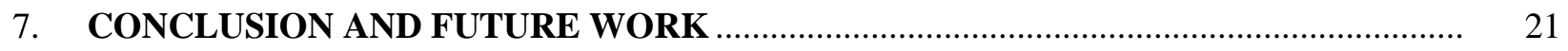

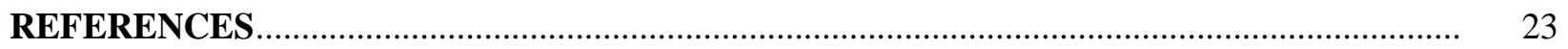

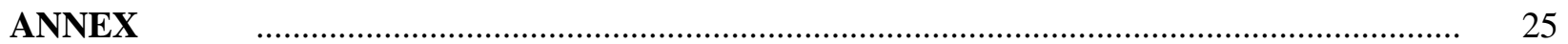

Table A-1 Physical properties of NBG-17 specimens before and after oxidation ..................... 27

Table A-2 Experimental oxidation rates and corresponding conditions $\quad$.................................. 29

Table A-3 Fitted parameter estimates and standard errors provided by SAS .......................... 35 
ORNL/TM-2015/142 


\section{LIST OF FIGURES}

Figure

1. Schematic of experimental setup for oxidation experiments with low concentrations of water in high purity helium.......................................................................................................

2. Cutting diagram of NBG-17 billet ...............................................................................

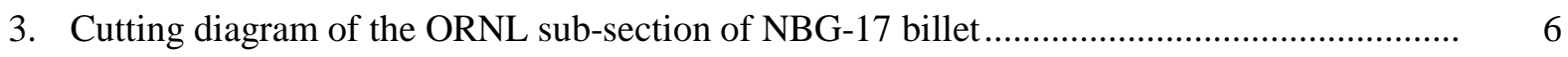

4. Specimen extraction scheme for NBG-17 oxidation by water............................................. 7

5. Example of processed TG data recorded in a 24 hour long run where water pressure was kept constant (30 Pa) and the temperature was increased from 800 to $1100{ }^{\circ} \mathrm{C}$.

6. Example of processed TG data recorded in a 72 hour long run where temperature was kept constant $\left(850{ }^{\circ} \mathrm{C}\right)$ and water vapor pressure and hydrogen pressure were varied....................... 12

7. Oxidation rates predicted with parameters in Table 1 versus observed rates at $\mathrm{P}_{\mathrm{H} 2}=0 \ldots \ldots \ldots \ldots . .16$

8. Oxidation rates predicted with parameters in Table 1 versus observed rates at $\mathrm{P}_{\mathrm{H} 2}=26 \mathrm{~Pa} \ldots . . \quad 16$

9. Comparison between oxidation rates predicted with parameters in Table 1 and actual measured rates 
ORNL/TM-2015/142 


\section{LIST OF TABLES}

Table

Page

1. L-H fitted parameters using all valid 286 observations .................................................... 15

2. Summary of L-H parameters for three nuclear graphites................................................... 19

\section{ANNEX}

Table A-1 Physical properties of NBG-17 specimens before and after oxidation ...................... 27

Table A-2 Experimental oxidation rates and corresponding conditions $\quad$................................. 29

Table A-3 Fitted parameter estimates and standard errors provided by SAS .......................... 35 
ORNL/TM-2015/142 
ORNL/TM-2015/142

\section{LIST OF ABBREVIATIONS}

\begin{tabular}{|c|c|}
\hline AG & against grain \\
\hline CALISTO & software (of TAG instrument) \\
\hline DOE & Department of Energy \\
\hline DTG & derivative of thermogravimetric function (TG curve) \\
\hline $\mathrm{H}-451$ & nuclear graphite grade used in the Fort Vrain reactor (U.S.) \\
\hline HTGR & high temperature gas-cooled reactor \\
\hline HTR & high temperature reactor \\
\hline IG-110 & grade of nuclear graphite manufactured by Toyo Tanso in Japan \\
\hline INL & Idaho National Laboratory \\
\hline L-H & Langmuir-Hinshelwood (kinetic mechanism, equation) \\
\hline NGNP & Next Generation Nuclear Plant \\
\hline MF & mass flow (controller) \\
\hline ML & maximum likelihood \\
\hline MLE & maximum-likelihood estimate \\
\hline NBG-17 & grade of nuclear graphite manufactured by SGL Carbon Group in Germany \\
\hline NBG-18 & grade of nuclear graphite manufactured by SGL Carbon Group in Germany \\
\hline ORNL & Oak Ridge National Laboratory \\
\hline QUADERA & software (of the mass spectrometer) \\
\hline PBMR & Pebble Bed Modular Reactor \\
\hline PCEA & grade of nuclear graphite manufactured by GrafTech International in the U.S. \\
\hline ppm & parts per million (concentration units) \\
\hline ppmv & parts per million (in volume units) \\
\hline ppt & parts per trillion (concentration units) \\
\hline $\mathrm{R} \& \mathrm{D}$ & research and development \\
\hline Ref., ref. & reference \\
\hline TAG & thermo-analyseur gravimetrique (thermogravimetric analyzer) \\
\hline TG & thermogravimetric function (temperature vs weight) \\
\hline UHP & ultra-high purity \\
\hline VHTR & very high temperature reactor \\
\hline WG & with grain \\
\hline
\end{tabular}


ORNL/TM-2015/142 
ORNL/TM-2015/142

\section{EXECUTIVE SUMMARY}

This report presents the results of kinetic measurements during accelerated oxidation tests of NBG-17 nuclear graphite by low concentrations of water vapor and hydrogen in ultra-high purity helium. The objective is to determine the parameters in the Langmuir-Hinshelwood $(\mathrm{L}-\mathrm{H})$ equation describing the oxidation kinetics of nuclear graphite in the helium coolant of high temperature gas-cooled reactors (HTGR). Although the helium coolant chemistry is strictly controlled during normal operating conditions, trace amounts of moisture (predictably $<0.2 \mathrm{ppm}$ ) cannot be avoided. Prolonged exposure of graphite components to water vapor at high temperature will cause very slow (chronic) oxidation over the lifetime of graphite components. This behavior must be understood and predicted for the design and safe operation of gas-cooled nuclear reactors. The results reported here show that, in general, oxidation by water of graphite NBG-17 obeys the L-H mechanism, previously documented for other graphite grades. However, the characteristic kinetic parameters that best describe oxidation rates measured for graphite NBG-17 are different from those reported previously for grades H-451 (General Atomics, 1978) and PCEA (ORNL, 2013). In some specific conditions, certain deviations from the generally accepted L-H model were observed for graphite NBG-17. This graphite is manufactured in Germany by SGL Carbon Group and is a possible candidate for the fuel elements and reflector blocks of HTGR. 
ORNL/TM-2015/142 
ORNL/TM-2015/142

\section{INTRODUCTION}

Nuclear grade graphite is the moderator and a major structural component of High Temperature Gas-Cooled Reactors (HTGR). Graphite is chemically stable at high temperatures in inert helium (He) and reducing environments, but it becomes gasified by oxidizing impurities (oxygen, carbon dioxide, water) that might be present in the HTGR helium coolant. Water is the main oxidizing impurity in He coolant, albeit in very low concentrations. The water partial pressure varies between different HTGR designs but is expected not to exceed 1-1.5 $\mathrm{Pa}$ at total helium pressures of 7-9 MPa [1,2,3,4,5,6]. The oxidation reaction of carbon by water produces carbon monoxide and hydrogen:

$$
\mathrm{C}_{(\mathrm{s})}+\mathrm{H}_{2} \mathrm{O}_{(\mathrm{g})}=\mathrm{CO}_{(\mathrm{g})}+\mathrm{H}_{2(\mathrm{~g})}
$$

This reaction is not energetically favorable at temperatures below $\sim 700{ }^{\circ} \mathrm{C}$ but may play an important role in graphite gasification at higher temperatures, particularly at high water vapor pressures [7].

Under normal operating conditions, oxidation is predictably very slow (chronic) and limited to the surface of graphite components. Predictions show that chronic degradation of graphite properties caused by oxidation by moisture in the coolant circuit will not significantly affect the integrity of graphite components during normal operating conditions. However, these predictions are based on accelerated oxidation measurements made on graphite grade H-451 in 1978 at General Atomics Company [8]. This grade of nuclear graphite is no longer available, and little is known about the oxidation properties of the new grades regarded as candidates for gas-cooled reactors in the United States.

Recent results obtained at Oak Ridge National Laboratory (ORNL) showed that the microstructural characteristics of various graphite grades have significant effects on their chemical reactivity. This has been documented for oxidation by air in conditions that simulate the improbable event of an air-ingress accident [9]. Moreover, an accelerated kinetic study of oxidation by moisture of PCEA graphite produced in the U.S. by GrafTech International showed differences from the results known for the historic grade H-451 [10]. Although the general kinetic mechanism, known as the LangmuirHinshelwood (L-H) mechanism [11,12,13,14], operates for both graphite types, the parameters describing the effects of temperature and gas composition on the reaction rates are different. Extrapolation of accelerated oxidation results to the normal operating conditions in HTGR indicates that PCEA graphite would oxidize slightly faster than $\mathrm{H}-451$ graphite at low temperatures $\left(750-800{ }^{\circ} \mathrm{C}\right)$ and slightly slower at higher temperatures $\left(900-950{ }^{\circ} \mathrm{C}\right)$. Consequently, it can be predicted that at low temperatures, PCEA would develop a narrower oxidation layer on exposed surfaces than what was predicted for graphite $\mathrm{H}$ 451. However, the same predictions show that the oxidation layer would penetrate deeper under the surface of PCEA graphite compared to graphite H-451 $[15,16,17]$. These crude predictions need further confirmation based on results of effective diffusivity measurements of water vapor from He. Recent experimental results on water vapor transport properties of two graphite grades, PCEA and NBG-17, were reported in a parallel study completed at ORNL [18].

This report presents results of accelerated oxidation tests by water vapor of nuclear graphite grade NBG-17. Considered as a candidate for HTGR, this vibrationally molded graphite is manufactured by SGL Carbon (Germany/France). The fuel blocks in prismatic reactors have cooling channels separated by rather small graphite walls; therefore, the optimal graphite material should have small grain size. According to the manufacturer, the maximum grain size in graphite NBG-17 is $0.8 \mathrm{~mm}$. This is similar to the maximum grain size of PCEA $(0.8 \mathrm{~mm})$, half the maximum grain size of NBG-18 $(1.6 \mathrm{~mm})$, and much larger than that of IG-110 $(0.04 \mathrm{~mm})[19,20]$. The average grain size reported for NBG-17 is 0.3 $\mathrm{mm}$ [21]. According to mercury porosity measurements, the pore size distribution in NBG-17 is bimodal, 
with the narrowest pores of about $0.01 \mu \mathrm{m}$ and the largest size pores distributed between 5 and $30 \mu \mathrm{m}$. The cumulative pore volume is about $14 \%$ of the graphite bulk volume [22]. This study followed the same method and experimental setup as previously used for accelerated oxidation studies of graphite PCEA [23]. The experiments were designed to be feasible in laboratory conditions while bearing relevance to normal operation of HTGR, and to provide high quality results with reasonable time and budget resources. 


\section{EXPERIMENTAL SETUP AND EQUIPMENT PERFORMANCE}

The experimental setup diagram is shown in Figure 1. The main components are the gas delivery system of the oxidant gas with controlled composition and flow rate, the thermogravimetric analyzer (TAG 16/18 from SETARAM, France), and the mass spectrometer (DSC 350 from Pfeiffer, USA). A detailed description of these components was provided in a previous report [23].

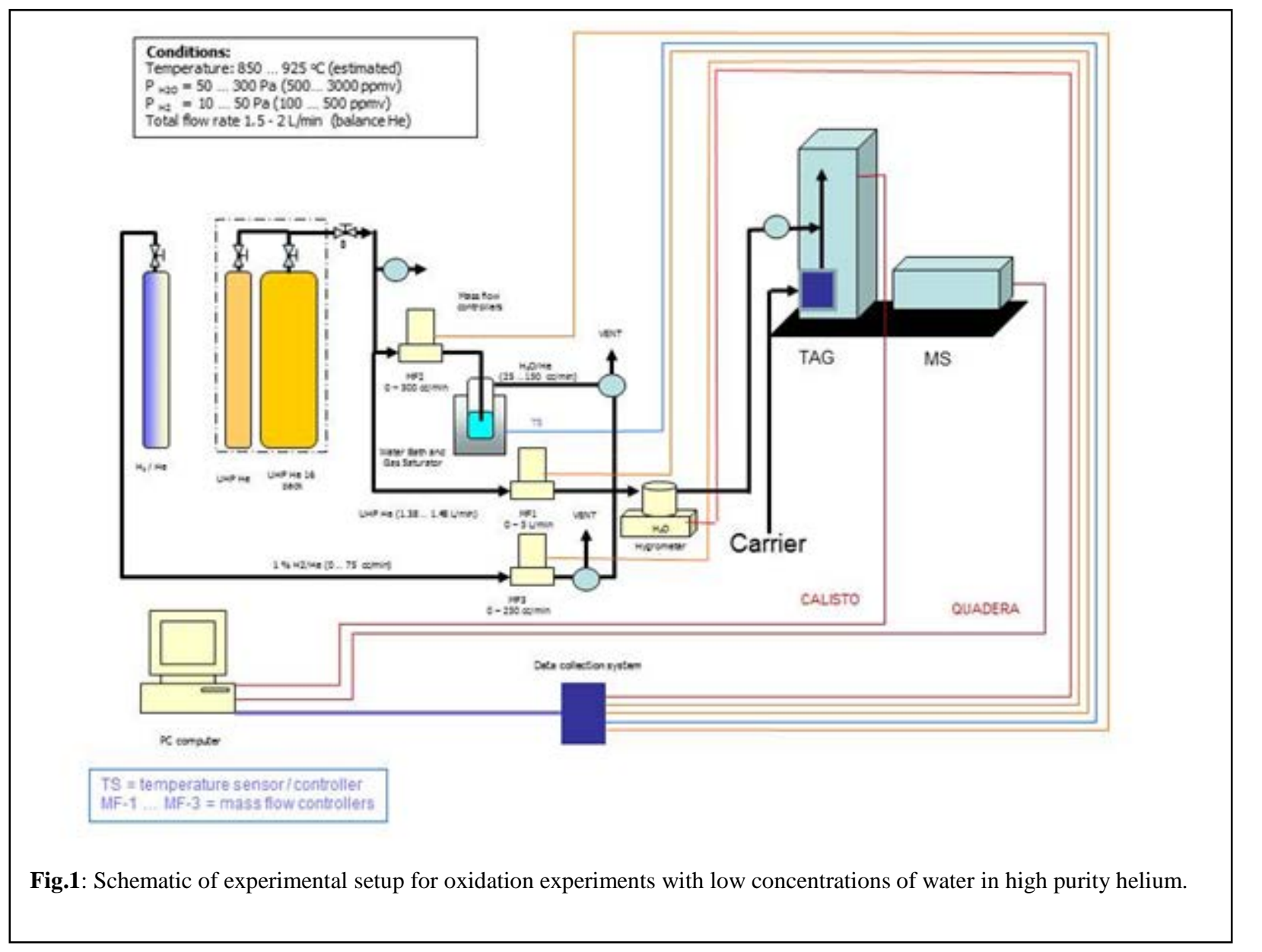

The ultra-high purity (UHP) helium used in this study (Air Liquide, USA) contains $<0.1 \mathrm{ppm}$ water and $<0.5$ ppm oxygen, with balance He ( $>99.999 \%$ ), based on the analysis certificate provided by Air Liquide. Water vapor was introduced by bubbling a split He line through plasma-grade water (Fisher Scientific) maintained at constant $\left( \pm 0.05{ }^{\circ} \mathrm{C}\right)$ temperature. The source of hydrogen added in some experiments was a certified $\mathrm{H}_{2} / \mathrm{He}$ mixture with $1 \%$ by volume $\mathrm{H}_{2}$ (certified by Air Liquide, USA). The water content in the mixed gas obtained by mixing dry $\mathrm{He}$, wet $\mathrm{He}$, and $\mathrm{H}_{2} / \mathrm{He}$ lines was measured by a chilled mirror hygrometer (CR-4 from Buck Research Instruments, LLC, Boulder, CO) placed before the 
thermogravimetric analyzer. The flow rates in the three gas lines (dry He, moist $\mathrm{He}$, and $\mathrm{H}_{2} / \mathrm{He}$ mixture) were regulated by mass flow controllers (Sierra Instruments) and monitored by a LabView application. The same application also collected hygrometer data (dew point temperature and internal pressure), barometric conditions in the lab (temperature, humidity, and atmospheric pressure) measured by a wallmounted instrument (Control Company, USA), and the temperature of the water bath (Fisher Scientific, USA) holding the He bubbler. When corrected for the barometric pressure in the lab, the freeze point and internal pressure data from the hygrometer allow for accurate calculation of the vapor pressure in the TAG oxidation chamber. The partial pressures of water and hydrogen in the reaction were varied by adjusting the water bath temperature and the flow rates on each gas line.

The TAG 16/18 thermogravimetric analyzer is a very sensitive, highly stable microbalance instrument with symmetrical design. Two identical objects (the graphite sample and an inert quartz reference) are suspended by platinum rods and dangle freely into a pair of identical vertical furnace. Buoyancy effects which usually perturb gravimetric measurements at high temperature are much reduced in the symmetrical design. Data collection (sample temperature and weight) was performed by the CALISTO software supplied with the TAG (accuracy of $\pm 0.1{ }^{\circ} \mathrm{C}$ and $\pm 0.10 \mu \mathrm{g}$ ).

The DCS 350 mass spectrometer was intermittently used for analysis of gas composition. Collection and analysis of mass spectra was done by the QUADERA software delivered with the equipment. Some technical issues with this equipment precluded its continuous use. However, when the mass spectrometer became available later in the experiments, it was used to confirm that other oxidizing impurities $\left(\mathrm{O}_{2}, \mathrm{CO}_{2}\right)$ were absent from the reaction chamber of the thermoanalyzer.

The steps taken for accurate calibration of all sensors of the oxidation equipment were detailed in a previous report [23]. Preliminary tests confirmed that the hygrometer responds correctly to flow rate changes of dry and moist He lines and changes of water bath temperature. The hygrometer's operation is based on fundamental thermodynamic properties of water vapors. This instrument is intrinsically capable of long-term accurate and stable operation. The instrument's performance was annually checked by the manufacturer against NIST-certified standards. The equations used for converting mirror's temperature readings into water vapor pressure in the hygrometer chamber were as follows:

$$
\begin{array}{ll}
P_{\mathrm{H} 2 \mathrm{O}}=6.1121 \exp \left[\left(18.678-T_{\mathrm{DP}} / 234.5\right)\left(T_{\mathrm{DP}} /\left(T_{\mathrm{DP}}+257.14\right)\right]\right. & \text { for } T_{\mathrm{DP}}>0{ }^{\circ} \mathrm{C} \\
P_{\mathrm{H} 2 \mathrm{O}}=6.1115 \exp \left[\left(23.036-T_{\mathrm{DP}} / 333.7\right)\left(T_{\mathrm{DP}} /\left(T_{\mathrm{DP}}+279.82\right)\right]\right. & \text { for } T_{\mathrm{DP}}<0{ }^{\circ} \mathrm{C}
\end{array}
$$

where $P_{\mathrm{H} 2 \mathrm{O}}$ is water pressure in mbar and $T_{\mathrm{DP}}$ is the dew point (or frost point) temperature in ${ }^{\circ} \mathrm{C}$ measured by the hygrometer. The actual water vapor pressure in the TAG oxidation chamber was calculated by correcting $P_{H 2 O}$ from Eq. (2b) by the $P_{b a r} / P_{h y g r}$ factor, where $P_{b a r}$ is the current barometric pressure in the lab and $P_{\text {hygr }}$ is the total pressure inside the hygrometer cell:

$$
P_{H 2 O(\text { oxidation })}=P_{H 2 O} \frac{P_{\text {bar }}}{P_{\text {hygr }}}
$$

This result was cross-checked against mass balance calculations using actual flow rates for each gas line and calculated water vapor pressures at the temperature of the water bath. Although the agreement between water vapor pressure values based on hygrometer readings and calculated from flow rates and mass balance was good [23], the values calculated from Eqs. (2b) and (3) and direct hygrometer readings and were preferred because they were affected by lesser errors. 
ORNL/TM-2015/142

\section{MATERIALS}

\subsection{GRAPHITE SAMPLES}

A billet of NBG-17 graphite purchased for the NGNP program was cut according to the diagram in Figure 2 [24]. The billet retained for material characterization at ORNL was cut as shown in Figure 3 [22]. The sub-section labeled Section-A was further used to machine specimen for oxidation by water.

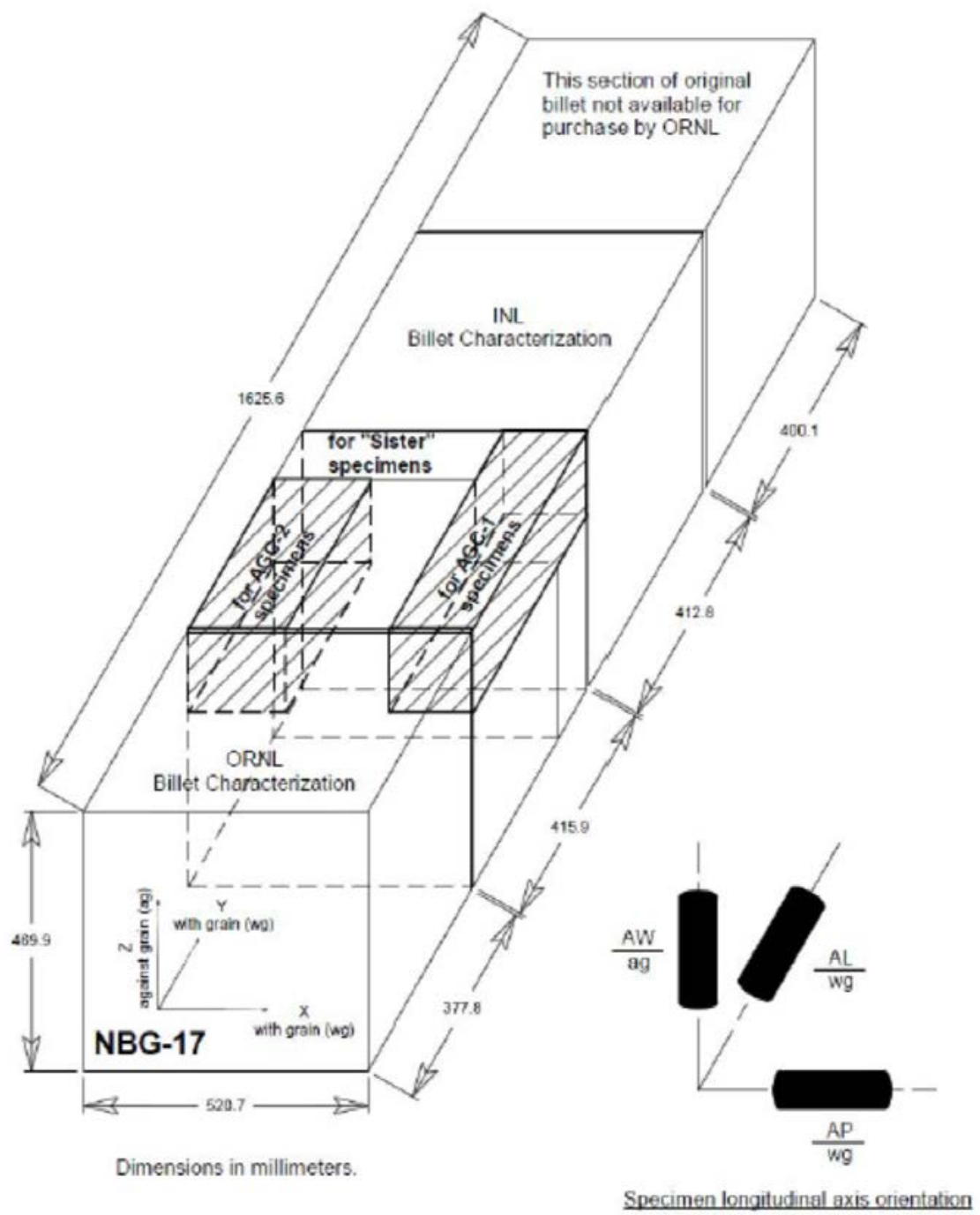

Figure 2: Cutting diagram of NBG-17 billet [24]. 

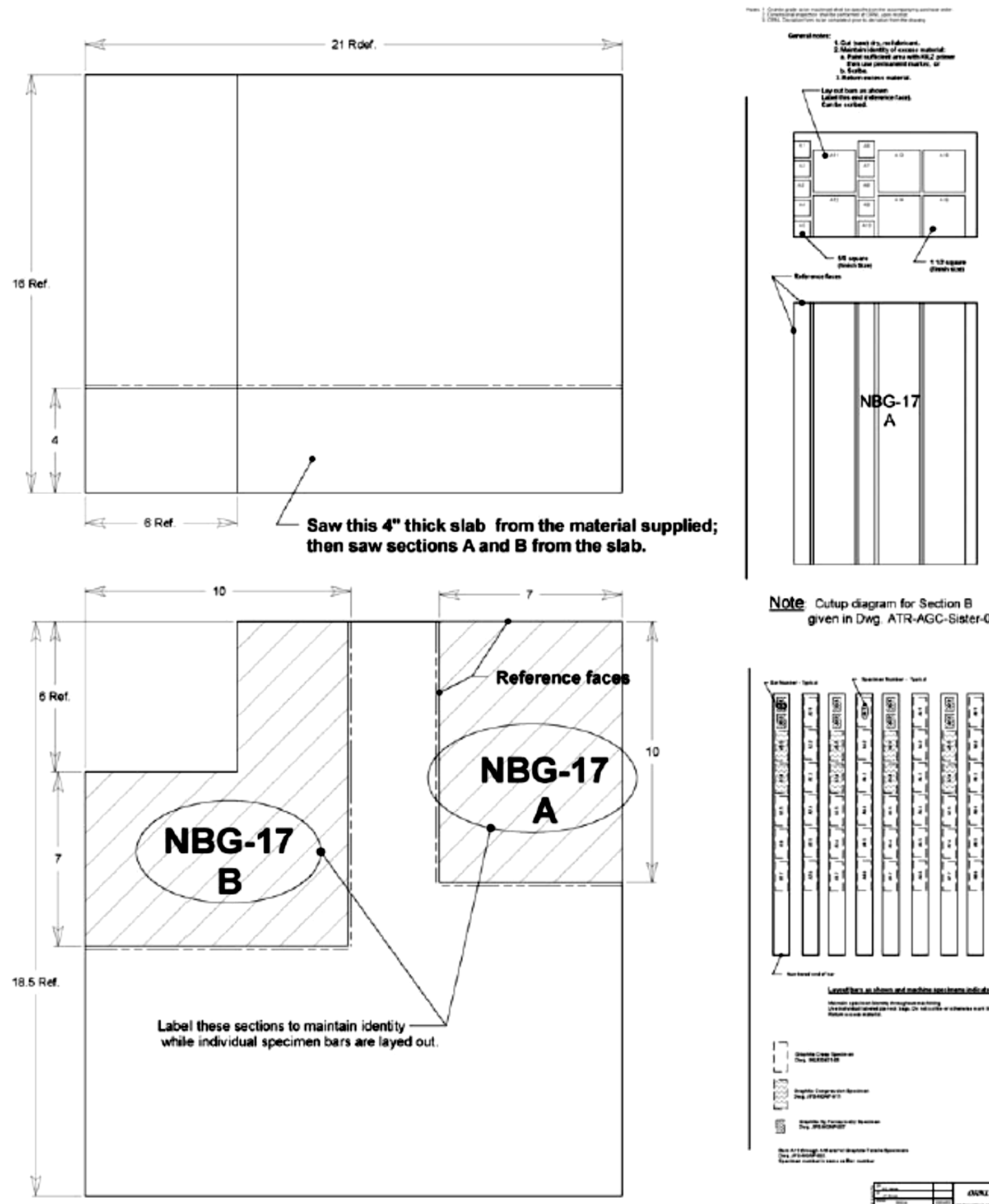

Note Cutup dagram for Section B given in Dig. ATR-AGC-Sister-08

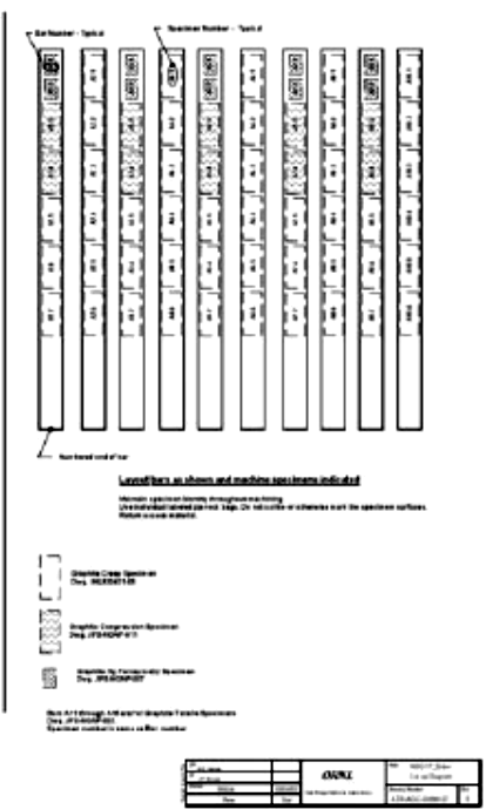

Figure 3: Cutting diagram of the ORNL sub-section of NBG-17 billet [22]. 
All NBG-17 specimens used in this study had identical shapes and dimensions: right cylinders, 20 $\mathrm{mm}$ long $\times 4 \mathrm{~mm}$ diameter. They were cut from subsection A of the NBG-17 billet with two different orientations: against grain (AG) and with grain (WG). The specimen extraction plan is shown in Figure 4. All specimens were machined in dry conditions (no lubricants) and using only non-metal containing cutting tools.

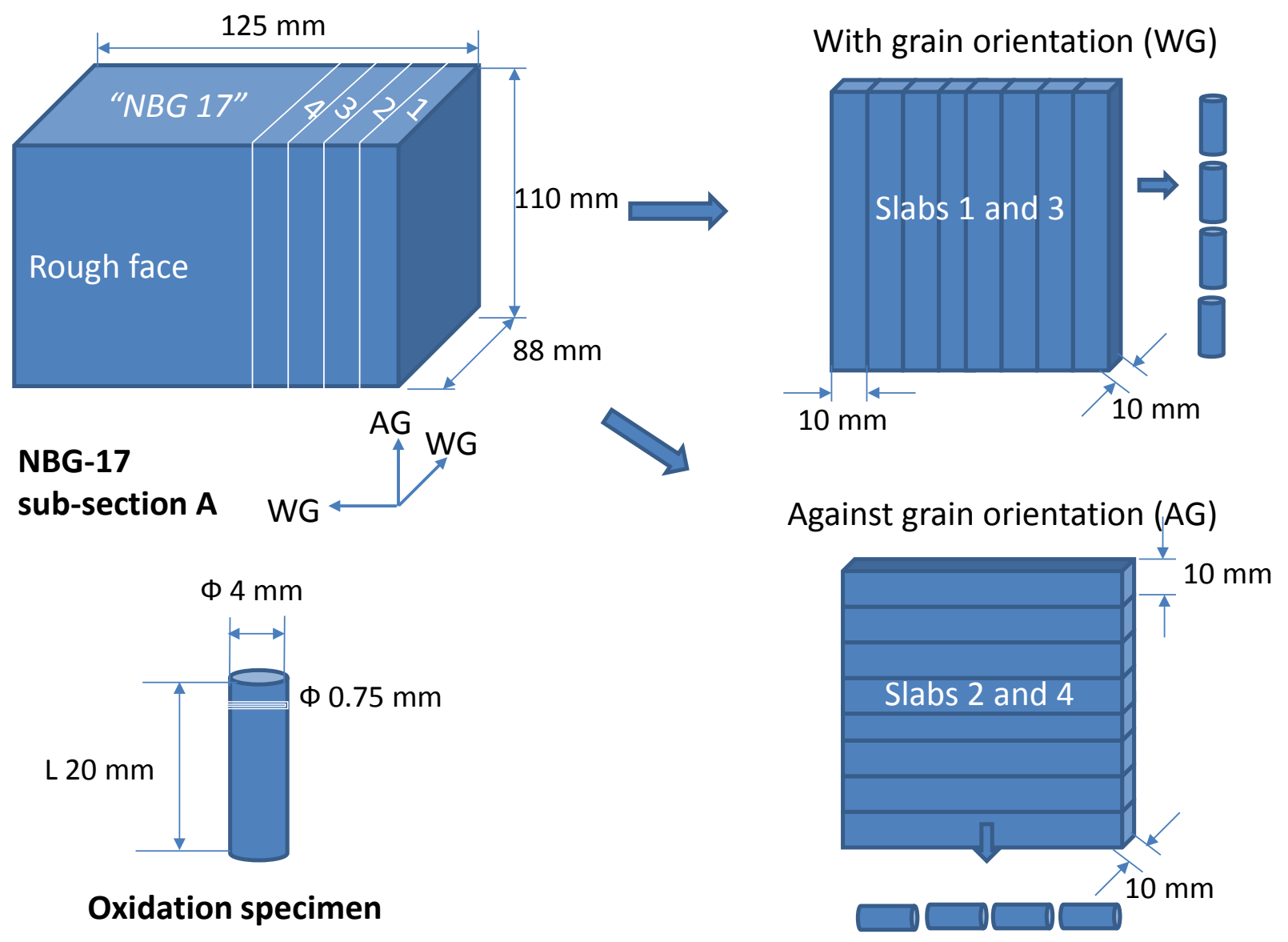

Figure 4: Specimen extraction scheme for NBG-17 oxidation by water.

Graphite anisotropy is usually expressed as the ratio of coefficients of thermal expansion in the AG and WG direction [22]. Compared with the extruded PCEA graphite, the vibrationally-molded grade NBG-17 is more isotropic; therefore, the specimen orientation in the billet is not expected to cause significant property variations. This was confirmed by measurements of oxidation rates of AG and WG oriented specimens performed early in the research program. Data analysis did not show differences that could be confidently attributed to the anisotropy of structural properties. Based on that analysis, in later experiments the orientation (AW or WG) of specimens was disregarded. Specimens with both orientations were randomly used to obtain a non-biased snapshot of mean graphite properties. 
ORNL/TM-2015/142

\subsection{GASES}

Ultra-high purity (UHP) helium was procured from Air Liquide in batches of 16 interconnected pressurized gas cylinders. Each batch was accompanied by lot analysis certifying that the gas corresponds to quality specifications:

\begin{tabular}{|c|c|c|c|}
\hline \multirow{3}{*}{$\begin{array}{l}\text { Major component: } \\
\text { Impurities }\end{array}$} & & Specification & Analysis (several batches) \\
\hline & Helium & $\overline{99.9990 \%}$ & $99.9999 \%$ \\
\hline & Moisture & < 3ppm & $0.2-0.3 \mathrm{ppm}$ \\
\hline & Oxygen & $<2 \mathrm{ppm}$ & $0.8-1.7 \mathrm{ppm}$ \\
\hline & Hydrocarbons & $<0.5 \mathrm{ppm}$ & $<0.1 \mathrm{ppm}$ \\
\hline
\end{tabular}

Hydrogen was delivered from a compressed gas cylinder containing certified mixture of $1 \% \mathrm{H}_{2}$ in UHP helium (Air Liquide). The certificate of accuracy accompanying the gas provides the following information:

\begin{tabular}{lllcc}
$\begin{array}{l}\text { Component } \\
\text { name }\end{array}$ & $\begin{array}{l}\text { Requested } \\
\text { concentration }\end{array}$ & $\begin{array}{l}\text { Certified } \\
\text { concentration }\end{array}$ & $\begin{array}{c}\text { Blend tolerance } \\
(+/-)\end{array}$ & $\begin{array}{l}\text { Certified } \\
\text { accuracy }\end{array}$ \\
\hline $\begin{array}{l}\text { Hydrogen } \\
\text { Helium }\end{array}$ & $\begin{array}{l}1 \text { mole } \% \\
\text { balance }\end{array}$ & $\begin{array}{l}1.00 \text { mole } \% \\
\text { balance }\end{array}$ & $\pm 0.0 \%$ & $\pm 2.00 \%$
\end{tabular}

Water used for adding moisture to the helium line through the saturator bubbler was Plasma Grade Water (Fisher Scientific) with certified analysis of metal impurities (most ions $<0.1-1 \mathrm{ppt}$ ).

For supplemental protection of gas line purity, moisture traps and oxygen traps were used on the dry $\mathrm{He}$ and $\mathrm{H}_{2} / \mathrm{He}$ mixture lines. The oxygen traps (Oxy-purge $\mathrm{N}$ from Fisher Scientific) are rated to remove oxygen from inert gases down to the ppb level (or $\sim 10^{-2} \mathrm{~Pa}$ when delivered at atmospheric pressure). The moisture traps (Drierite, from Fisher Scientific) are rated for drying the air up to a frost point of $-73{ }^{\circ} \mathrm{C}$ at a flow rate of $200 \mathrm{~L} / \mathrm{h}$. The corresponding water vapor pressure is $0.2 \mathrm{~Pa}$. Our experiment used a lower flow rate $(1.5 \mathrm{~L} / \mathrm{min}$ or $90 \mathrm{~L} / \mathrm{h})$ so that the efficiency of the moisture trap was higher. On the other hand, the residual moisture in the UHP He, according to specifications and analysis results, is in the range of $0.02-0.03 \mathrm{~Pa}$ (when delivered at atmospheric pressure). This is much lower than the lowest end-of-scale sensitivity limit for the hygrometer, which cannot measure frost points below about $-55{ }^{\circ} \mathrm{C}$ (corresponding to $2 \mathrm{~Pa}$ water partial pressure). It is reasonable to suspect that hygrometer readings were inaccurate at the lowest end scale (below about $5 \mathrm{~Pa} \mathrm{H}_{2} \mathrm{O}$ ) and the actual water pressures were lower. 
ORNL/TM-2015/142

\section{PROCEDURE}

\subsection{TEST CONDITIONS}

Graphite oxidation by water is extremely slow in normal operating conditions and the rates cannot be measured. The solution is to use accelerated oxidation tests so that the rates can be measured. Accelerated tests were designed to mimic as close as possible the normal operating conditions. The variables were as follow:

- Temperature range:

800 to $1100{ }^{\circ} \mathrm{C}$

- Water pressure:

3 to $1000 \mathrm{~Pa}$

- Hydrogen pressure:

0 to $40 \mathrm{~Pa}$

- Total flow rate

$1.5 \mathrm{~L} / \mathrm{min}$

- Linear flow velocity

$8 \mathrm{~cm} / \mathrm{s}$

- In-situ outgassing temperature before tests $1200{ }^{\circ} \mathrm{C}$

- Duration of in-situ outgassing before tests $1-2 \mathrm{~h}$

\subsection{PREPARATION OF SPECIMENS BEFORE TESTS}

Before tests, each graphite specimen was cleaned for 10 minutes by sonication in acetone and dried in air at $110{ }^{\circ} \mathrm{C}$. Cleaned specimens were handled only with cotton gloves or plastic tweezers.

Physical measurements (weight and dimensions) were taken on each cleaned specimen just before the tests, according to ASTM C559-90 [25]. All physical measurement data are provided in Annex 1.

\subsection{OXIDATION TEST PROCEDURE}

After physical measurements were taken, the specimens were attached with platinum wires to the sample arm of the microgravimetric balance in the TAG and were centered in the furnace. A similar volume quartz reference sample was attached to the reference arm of the TAG, and the furnace was raised to its working position.

The initial weight of each specimen was entered in the test information file and served as the reference weight for weight loss calculations.

The procedure used for most tests consisted of the following steps:

1. Turn on and start simultaneously the LabView software for gas flow control and water bath temperature, the pre-programmed procedure for thermogravimetric analysis (CALISTO) and (in some cases) the mass spectrometer procedure (QUADERA).

2. Flow $1.5 \mathrm{~L} / \mathrm{min}$ dry UHP He for $20 \mathrm{~min}$ at room temperature.

3. Ramp temperature at $10{ }^{\circ} \mathrm{C} / \mathrm{min}$ to $1200{ }^{\circ} \mathrm{C}$.

4. Outgas the specimen at $1200{ }^{\circ} \mathrm{C}$ for 1 or $2 \mathrm{~h}$ while flowing $1.5 \mathrm{~L} / \mathrm{min}$ dry UHP He.

5. Lower temperature at $10{ }^{\circ} \mathrm{C} / \mathrm{min}$ to the first test temperature while flowing $1.5 \mathrm{~L} / \mathrm{min}$ dry UHP He.

6. Introduce water (or water and hydrogen mixture) in the UHP He stream at total flow rate of $1.5 \mathrm{~L} / \mathrm{min}$ and adjust composition to the target partial pressures of $\mathrm{H}_{2} \mathrm{O}$ and $\mathrm{H}_{2}$. 
7. Execute the preselected time- temperature- gas composition program consisting of dwelling segments (2-6 hours) at constant conditions $\left(T, P_{\mathrm{H} 2 \mathrm{O}}\right.$, and $\left.P_{\mathrm{H} 2}\right)$ separated by transitory conditions (temperature ramps at $10{ }^{\circ} \mathrm{C} / \mathrm{min}$ or variations of $P_{\mathrm{H} 2 \mathrm{O}}$ and $P_{\mathrm{H} 2}$ ) while maintaining a total flow rate of $1.5 \mathrm{~L} / \mathrm{min} \mathrm{He}$ with added $\mathrm{H}_{2} \mathrm{O}$ (and $\mathrm{H}_{2}$ in some experiments).

8. Lower the temperature $\left(25^{\circ} \mathrm{C} / \mathrm{min}\right)$ to $25{ }^{\circ} \mathrm{C}$ after last segment while flowing $1.5 \mathrm{~L} / \mathrm{min}$ gas with the last composition.

9. Continue flowing $1.5 \mathrm{~L} / \mathrm{min}$ gas with previous composition for another $10 \mathrm{~min}$ and end the test.

The total duration of most tests was approximately $24 \mathrm{~h}$. Other tests were purposely designed to measure the effect of gas composition at constant temperature. These tests were longer (up to $120 \mathrm{~h}$ ). The gas composition was varied by remote computer control of dry $\mathrm{He}$, moist $\mathrm{He}$, and the $\mathrm{H}_{2} / \mathrm{He}$ mixture.

Some tests at low temperature and low water vapor pressure were affected by the inadvertent oxidation of suspension rods made from a Ni-Cr alloy. This alloy is sensitive to surface oxidation when exposed to water vapor at $800-900{ }^{\circ} \mathrm{C}$. Oxidation caused a weight increase (not decrease, as expected for graphite gasification), which resulted in "negative" rate values. These parasitic effects were particularly significant in conditions in which the oxidation rates were slow (low temperatures, low water vapor pressures). Oxidized rods were recognized by the discoloration that replaced the metallic shine on their surfaces. The problem was corrected by replacing the $\mathrm{Ni}-\mathrm{Cr}$ rods with platinum rods.

After recalibration of the mass spectrometer and replacement of the ion source, several tests were performed in carefully controlled conditions with mass spectrometric analysis of the gas composition. The purpose of these tests was to obtain accurate measurements of very slow oxidation rates. The purity of the gas was controlled by evacuating the whole system, followed by controlled helium introduction, with simultaneous monitoring of gas composition. This procedure led to very clean gas streams, free of residual oxygen and nitrogen, and very low amounts of moisture. Several measurements of slow oxidation rates performed in these conditions proved that the weight increases previously observed were an experimental error. Consequently, all data showing "negative oxidation rates" were discarded before the final analysis of results.

\subsection{SPECIMEN CHARACTERIZATION AND DATA SAVING AFTER TESTS}

Each oxidized specimen was collected after tests and physical measurements were repeated. All results are presented in Annex 1. Oxidized specimens were labeled and stored in plastic bags.

The following data were saved after each test:

- LabView data in text format. Data contain time, flow rates of MF1, MF2, and MF3, dew point and internal pressure from hygrometer, water bath temperature, and ambient conditions in the lab (temperature, humidity, and barometric pressure).

- TAG data processed by CALISTO software. Analysis comprised calculation of weight losses during each segment at constant temperature from the TG curve, calculation of instantaneous weight loss changes from the DTG curve, and graphic representation of data. All data were saved both in graphic and Excel format. See Annex 2 for all oxidation rate data.

- QUADERA data from mass spectrometer. These data were saved (when available) in graphic and ASCII format.

- Excel data files with operator's notes during tests and screen prints of LabView application at the end of experiments, showing plots of hygrometer readings and various flow controller data collected in real time. 


\subsection{DATA REDUCTION}

Instantaneous values of water vapor pressure inside the oxidation furnace were calculated using Eqs. (2b) and (3). The average values calculated for each segment of constant conditions were then correlated with the corresponding average oxidation rates. For each segment, the oxidation rates were calculated as $\Delta w / \Delta t$, where $\Delta w$ is the weight variation and $\Delta t$ is the corresponding duration of each constant conditions segment on TG curves. The absolute weights corresponding to each segment were calculated from the initial specimen weight, the weight loss during high temperature outgassing, and the weight variations in previous segments. Figure 5 shows an example of processed data in a run at constant water vapor pressure and variable temperature. Figure 6 shows an example of a run at constant temperature and variable water vapor pressure and hydrogen pressure.

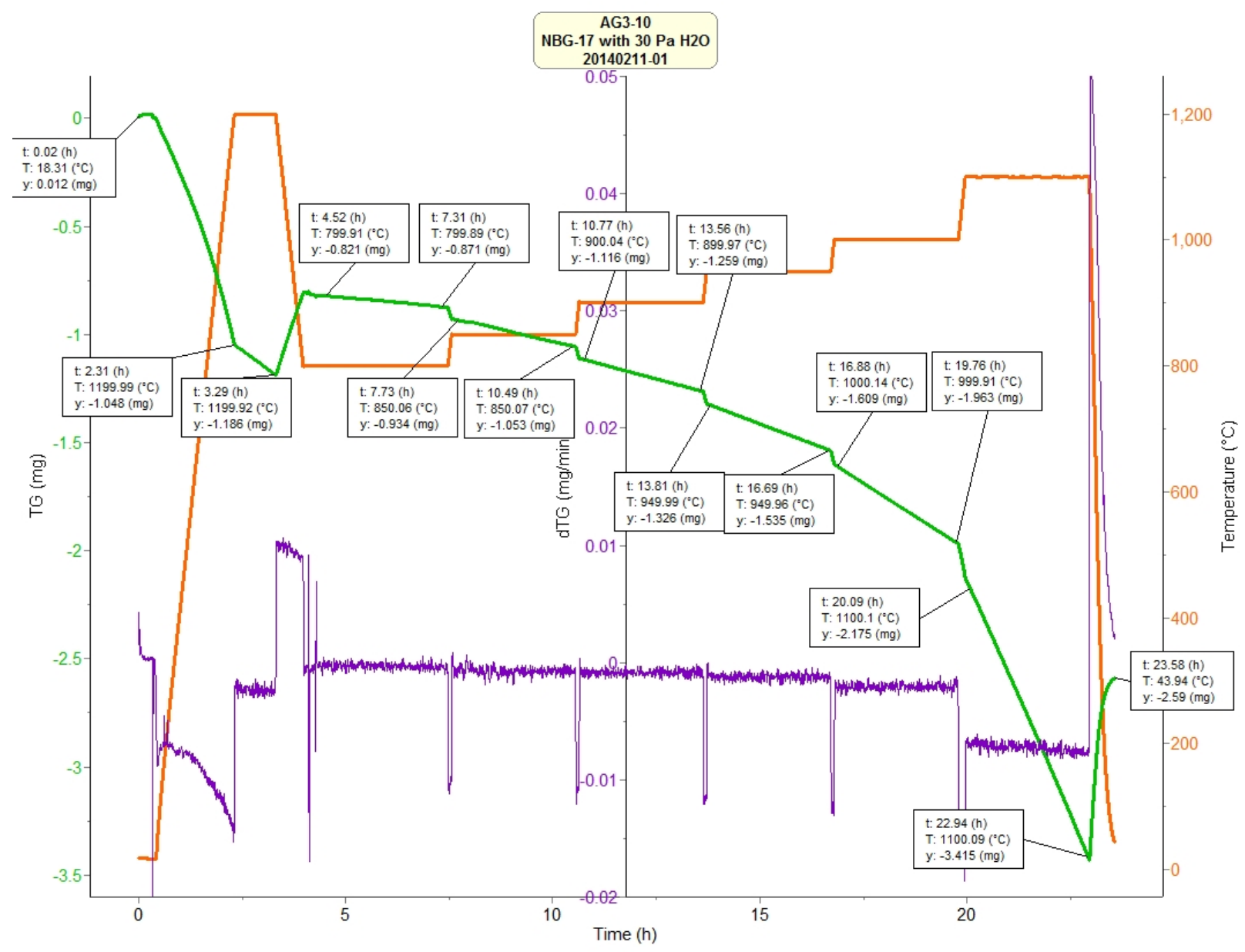

Figure 5: Example of processed TG data recorded in a 24 hour long run where water pressure was kept constant $(30 \mathrm{~Pa})$ and the temperature was increased from 800 to $1100{ }^{\circ} \mathrm{C}$ (red = temperature; green = TG; purple = DTG). 


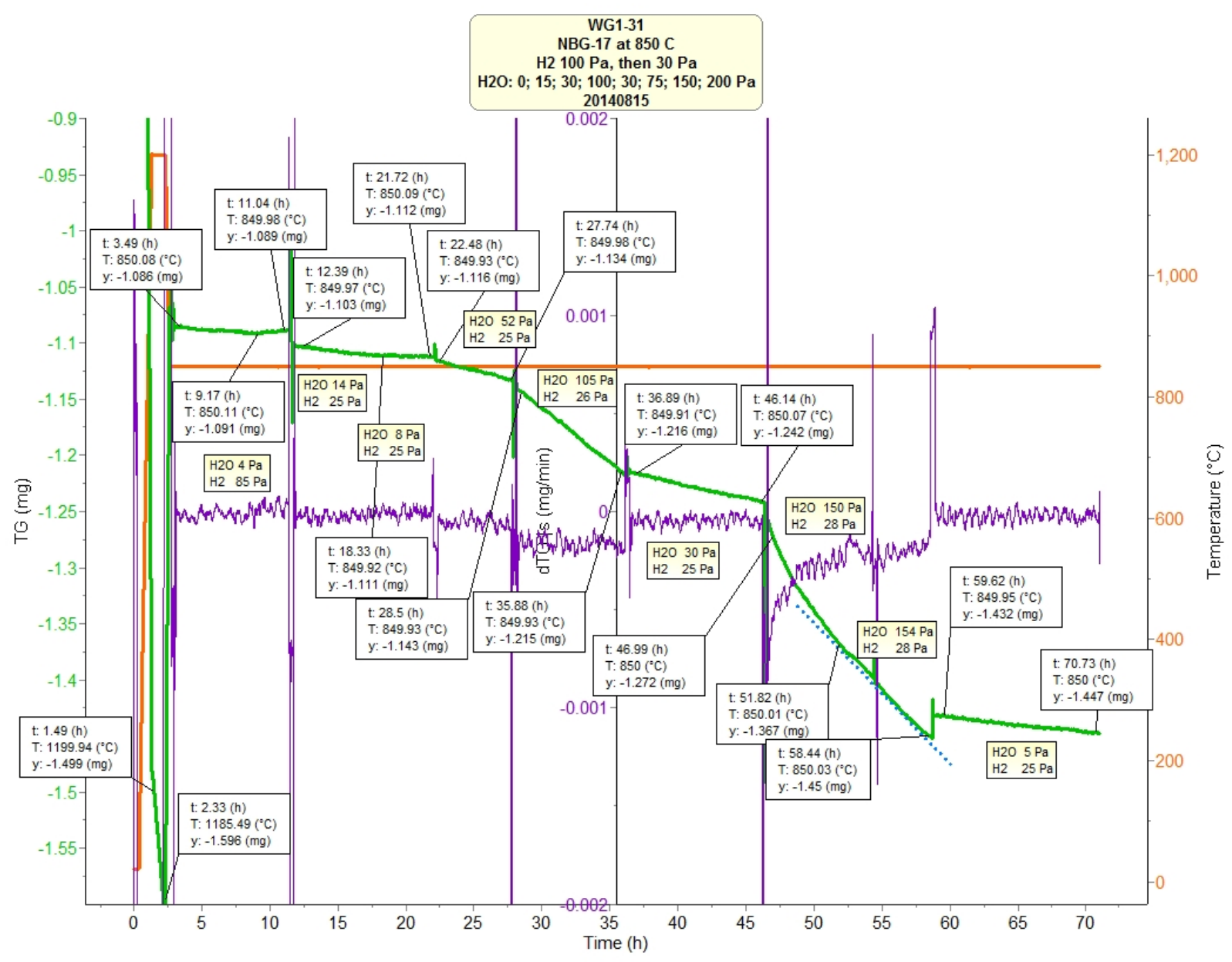

Figure 6: Example of processed TG data recorded in a 72 hour long run where temperature was kept constant $\left(850{ }^{\circ} \mathrm{C}\right)$ and water vapor pressure and hydrogen pressure were varied (red $=$ temperature; green $=\mathrm{TG}$; purple $=$ DTG).

Based on prior experience [23], no attempts were made to correct the variation of oxidation rates caused by graphite "burn-off". $\left.{ }^{*}\right)$ In the model proposed by Su and Perlmutter [26], the increase of oxidation rates with time (or burn-off) is attributed to development of new porosity during extensive oxidation, which is modeled by introducing a graphite-specific structural parameter. While this correction is significant at high oxidation levels in air $[27,28]$ it is not expected to be important in the present experiments where the oxidation level was always $<2 \%$. Prior attempts $[10,23]$ to determine the structural factor for graphite PCEA showed that the empirically found factors that would flatten the weight change profiles were not constant. Rather that introducing another empirical variable, which would randomly affect the oxidation rates, it was decided not to use the burn-off correction for low levels of oxidative weight loss.

\footnotetext{
(*) The expression "burn-off” is used here to keep consistent with the cited publication by Su and Perlmutter. In reality, it is a scientifically demonstrated fact that graphite does not burn.
} 
ORNL/TM-2015/142

\section{DATA ANALYSIS}

\subsection{LANGMUIR-HINSHELWOOD KINETIC MODEL}

The gasification reaction between carbon (graphite) and water becomes thermodynamically possible at temperatures above $\sim 700{ }^{\circ} \mathrm{C}$ :

$$
\mathrm{C}_{(\mathrm{s})}+\mathrm{H}_{2} \mathrm{O}_{(\mathrm{g})}=\mathrm{CO}_{(\mathrm{g})}+\mathrm{H}_{2(\mathrm{~g})}
$$

It has been documented for a long time [11,12,13,14] that graphite oxidation by water follows a complicated mechanism, known as the Langmuir-Hinshelwood (L-H) mechanism, described by the following reaction rate expression:

Rate $=\frac{k_{1} P_{H 2 O}}{1+k_{2}\left(P_{H 2}\right)^{n}+k_{3} P_{H 2 O}} \quad$,

where rate constants $k_{\mathrm{i}}$ obey an Arrhenius type temperature dependence with two parameters, the preexponential (or frequency) factor $A_{i}$ and the activation energy $E_{i}$ :

$k_{i}=A_{i} e^{-\frac{E_{i}}{R T}}$

where $\mathrm{R}$ is the universal gas constant and $T$ is the absolute temperature.

The mechanism of elementary reaction steps for gasification by water is still debated. In the scheme proposed by Gatsby [11,12], the surface sites on graphite are blocked by molecularly adsorbed hydrogen $\left(\mathrm{H}_{2}\right)$; in this case the exponent from Eq. (5) should have the value $n=1$. This mechanism was accepted by Burnette et al. at General Atomic Company, who provided numerical values of all kinetic constants in Eqs. (5) and (6) for oxidation of graphite H-451 by moisture [8]. However, more recent arguments [29] supported by modeling of carbon-hydrogen surface interactions [30,31] suggest a mechanism whereby the blocking of surface sites is caused by atomic $\mathrm{H}$, not molecular $\mathrm{H}_{2}$. This leads to $n$ $=0.5$ in Eq. (5). Previous analysis of accelerated oxidation tests by moisture of PCEA graphite used $n=$ $0.5[10,23]$. The same assumption is used in the present analysis.

In summary, the goal of this study is determination of the six numerical parameters $A_{1}$ and $E_{i}(i=$ $1,2,3)$ in the explicit rate equation obtained by combining eqs. (5) and (6):

$$
\text { Rate }=\frac{A_{1} \exp \left(-\frac{E_{1}}{R T}\right) P_{H 2 O}}{1+A_{2} \exp \left(-\frac{E_{2}}{R T}\right)\left(P_{H 2}\right)^{0.5}+A_{3} \exp \left(-\frac{E_{3}}{R T}\right) P_{H 2 O}}
$$

Knowledge of these six parameters will allow predictions of local oxidation rates of NBG-17 graphite at any given temperature, water vapor partial pressure, and hydrogen partial pressure. A similar modeling 
task was accomplished by Richards [32] using the parameters for graphite $\mathrm{H}-451$ from the General Atomics study cited earlier [8].

Finding the numerical values for the L-H parameters in Eq. (7) is complicated by several factors: (i) the equation is highly nonlinear in pressure; (ii) it has triple exponential dependence of oxidation rates by the reciprocal of absolute temperature; and (iii) its parameters are highly correlated through the Arrhenius relationship, Eq. (6), that links preexponential terms $A_{i}$ with activation energies $E_{i}$. Moreover, the significance of rate constants $k_{i}$ in gas-solid reactions is difficult to ascertain in the absence of a detailed mechanism in the chain of elementary step reactions that compose the overall gasification reaction. The pathway of the oxidation reaction may change with the change in external conditions, because the weight of various elementary reaction steps may be affected by temperature or gas composition. Unlike in the formal kinetics of gas-phase reactions, the presence of porosity, which introduces transport factors in the kinetic equation, complicates the problem even more. For that reason, all $A_{i}$ and $E_{i}$ found by fitting should be regarded as apparent (or mechanism-conditioned) parameters. It is not uncommon for apparent rate constants to have unusual variations. There are examples in the literature on graphite oxidation that show negative values for some apparent activation energies [12], which is quite unusual in the formal chemical kinetics. Such results were also found in the previous study on PCEA oxidation $[10,23]$ and in the current study as well.

\subsection{DETERMNATION OF KINETIC PARAMETERS}

Table A-1 (in the Annex) lists physical properties of 49 NBG-17 specimens analyzed over 52 runs. A total of 302 experimental observations were initially considered. Of these, 33 observations were rejected. Of them, 18 observations returned negative oxidation rates at 800 and $850{ }^{\circ} \mathrm{C}$ (as explained earlier) and 15 measurements were clearly in error compared with the rest of the data. These observations were identified as extreme outliers, based on an empirical response surface model. The rest of the 269 valid observations (89 \% of the total experimental data) were retained for further analysis. Table A-2 (in the Annex) lists the parameters of all observations (valid and rejected).

Data analysis and statistical treatment using the maximum likelihood estimate (MLE) approach was performed by Professor Robert Mee at the University of Tennessee, Knoxville, TN. When applied to a set of data in combination with a statistical model assumed for a particular situation, MLE provides standard errors for the estimates and correlations between the estimates. That is, given data from many runs at different conditions, the MLE approach is to simultaneously estimate the parameters that best represent the data. This is essential for understanding the uncertainty in the parameter estimates.

After the data were validated as explained, the SAS Institute procedure NLMIXED was used to fit the six parameters of the L-H model. The rate equation, Eq. (7), was rewritten in logarithmic form as follows:

$\ln ($ Rate $)=\ln \left(P_{H 2 O}\right)+a_{1}+\frac{b_{1}}{T}-\ln \left[1+P_{H 2 O} \exp \left(a_{3}+\frac{b_{3}}{T}\right)\right]+\varepsilon+\delta$

where $a_{i}=\ln A_{\mathrm{i}}$ and $b_{\mathrm{i}}=E_{\mathrm{i}} / \mathrm{R}$. Taking $\ln ($ Rate $)$ as the response variable, it was assumed that there were two additive sources of random errors, normally distributed: $\varepsilon$ is the error associated with each individual measurement $(n=269)$ and $\delta$ is the error associated with each separate run $(m=52)$. The variability represented by $\delta$ accounts for any material heterogeneity, since a fresh graphite specimen was used in each run (with the exception only of specimen 49 which was used on days 49-52).

A nonlinear mixed model represented by Eq. (8) was assumed. The SAS procedure PROC NLMIXED maximizes an approximation in the likelihood function for the six L-H parameters and the two variance components. PROC MLMIXED also furnishes an approximate $95 \%$ confidence interval for 
each parameter, assuming that the model is correct. The model can also furnish confidence intervals for the average $\ln ($ Rate $)$ for samples of this graphite at any given combination of experimental inputs.

Table A3 (in Annex) shows the fitted parameters provided by SAS along with the standard errors and $95 \%$ confidence intervals. These results were obtained by employing all 269 valid observations over the full range of temperatures investigated $\left(800-1100{ }^{\circ} \mathrm{C}\right)$. The confidence intervals for the preexponential factors $A_{i}$ were calculated by taking the exponential of the endpoints of the corresponding confidence intervals for $a_{i}=\ln \left(A_{i}\right)$; this explains why the ML estimate for each $A_{i}$ is not in the middle of the corresponding confidence interval. The standard errors associated with the activation energies $E_{2}$ and $E_{3}$ are respectively $20 \%$ and $26 \%$ of the estimated values. However, the error affecting the activation energy $E_{1}$ is twice as large (47\%).

The estimates of corresponding parameters of the L-H model are reported in Table 1. Figures 7 and 8 compare measured oxidation rates with predicted rates using these estimates. The two figures detail the effect of temperature and water vapor pressure on the oxidation rates. Figure 7 shows measured data and predicted trends for oxidation caused by water vapor alone (no hydrogen). Data in this figure show a very small temperature effect on oxidation rates at low water vapor pressures. Indeed, the isothermal plots of predicted rates are well separated at high $P_{\mathrm{H} 2 \mathrm{O}}$ and congregate closely toward low $P_{\mathrm{H} 2 \mathrm{O}}$. This is the consequence of the low value of activation energy $E_{1}=61.5 \mathrm{~kJ} / \mathrm{mol}$ found for graphite NBG-17. ${ }^{(\dagger)}$ In contrast, Fig. 8 shows that adding $26 \mathrm{~Pa}$ of hydrogen to the oxidation gas causes strong inhibition of oxidation rates. The rates predicted in the presence of $\mathrm{H}_{2}$ show almost parallel trends and spread over several orders of magnitude. Particularly, when $P_{\mathrm{H} 2} \geq P_{\mathrm{H} 2 \mathrm{O}}$, the inhibition by hydrogen causes a hundred times drop in oxidation rates (compare rates at $3 \mathrm{~Pa} \mathrm{H}_{2} \mathrm{O}$ in the presence of $26 \mathrm{~Pa} \mathrm{H}_{2}$ in Fig. 8 and without $\mathrm{H}_{2}$ in Fig. 7).

Table 1. L-H fitted parameters using all valid 286 observations

\begin{tabular}{|c|c|}
\hline$A_{1}=3.85 \times 10^{-6} \mathrm{~Pa}^{-1} \mathrm{~s}^{-1}$ & $E_{1}=61.5 \mathrm{~kJ} / \mathrm{mol}$ \\
\hline$A_{2}=4.00 \times 10^{-8} \mathrm{~Pa}^{-0.5}$ & $E_{2}=-186.7 \mathrm{~kJ} / \mathrm{mol}$ \\
\hline$A_{3}=5.79 \times 10^{-7} \mathrm{~Pa}^{-1}$ & $E_{3}=-122.9 \mathrm{~kJ} / \mathrm{mol}$ \\
\hline \multicolumn{2}{|c|}{$n=0.5$} \\
\hline
\end{tabular}

${ }^{(} \dagger^{\prime}$ The activation energy $E_{1}$ reported for the first L-H rate constant $k_{1}$ is higher for $\mathrm{H}-451(274 \mathrm{~kJ} / \mathrm{mol})$ and PCEA $(208 \mathrm{~kJ} / \mathrm{mol})$ graphite grades [8,23]. 


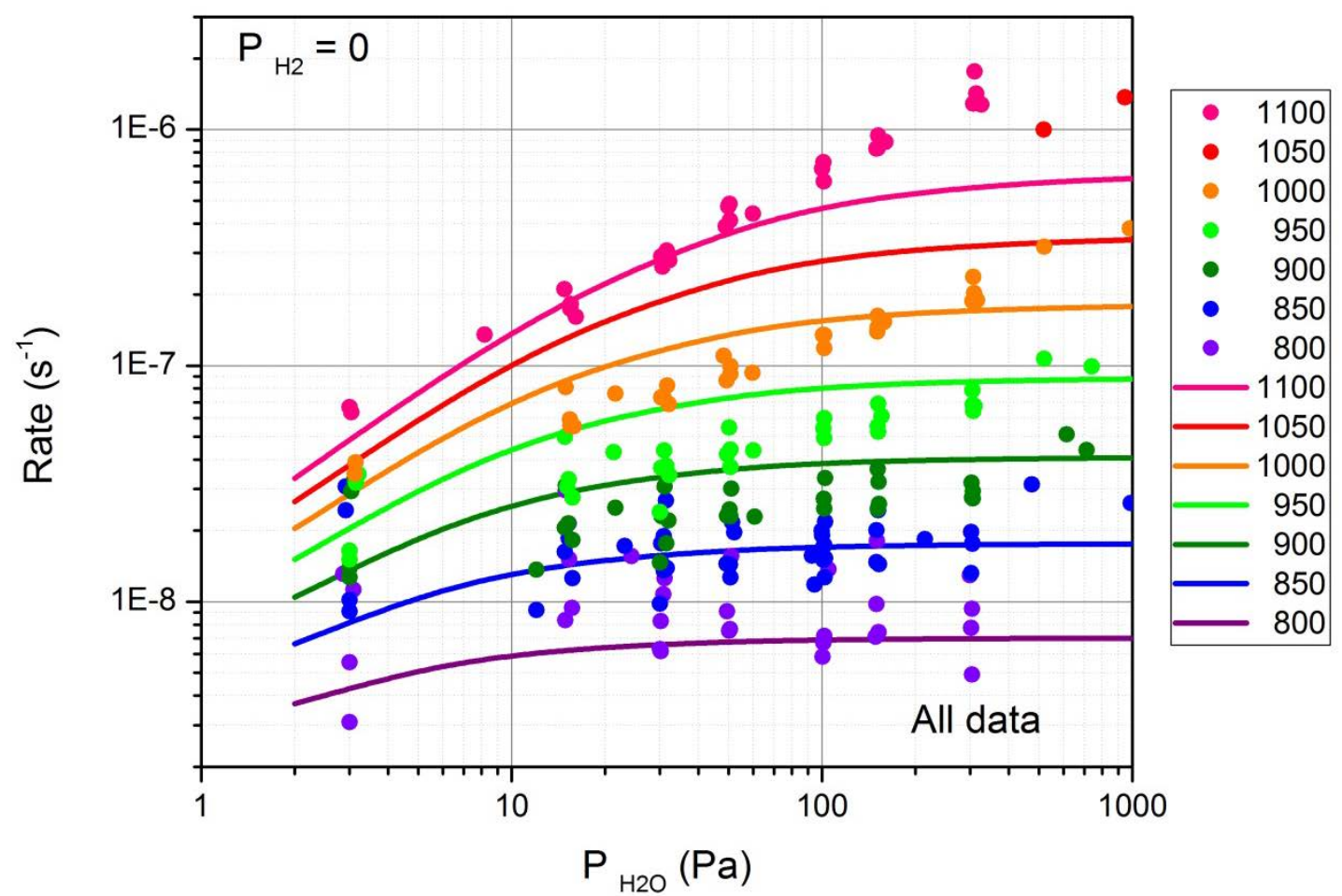

Figure 7: $\quad$ Oxidation rates predicted with parameters in Table 1 versus observed rates at $P_{\mathrm{H} 2}=0$.

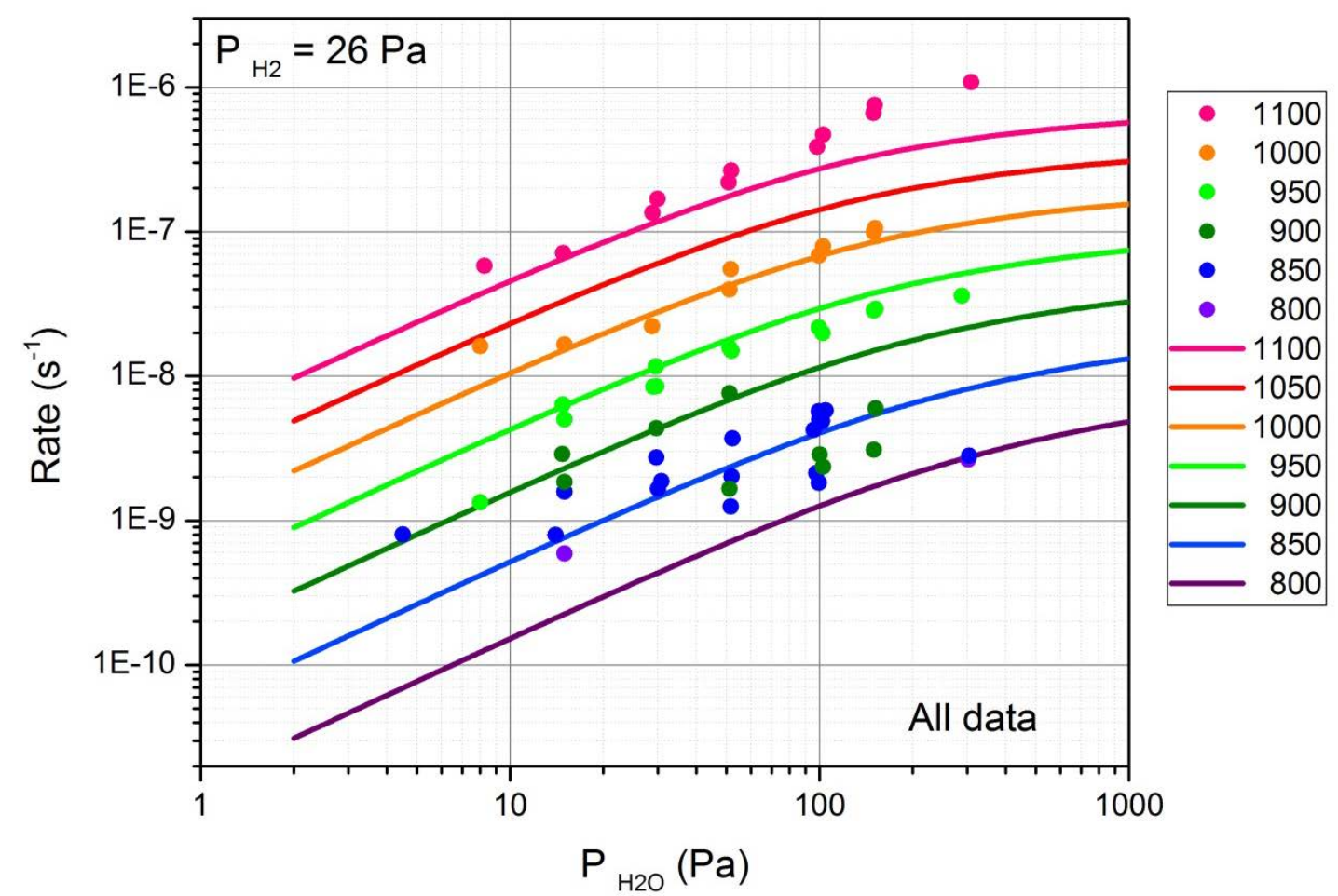

Figure 8: $\quad$ Oxidation rates predicted with parameters in Table 1 versus observed rates at $P_{\mathrm{H} 2}=26 \mathrm{~Pa}$. 
Figure 9 shows a direct comparison between all valid rate measurements and the corresponding rates predicted using parameters from Table 1. The double logarithmic scale was selected to compensate for the large variation (three orders of magnitude) of all data. If predicted rates were identical to the observed values, the plot would be a straight line with the unity slope, the residual sum of squares would be zero, and the correlation coefficient would be one. In fact, a linear fit with slope 1 applied to all 269 valid data points in Fig. 9 indicates a reasonable correlation between predicted and measured rates (adjusted $\mathrm{R}^{2}=0.899$; residual sum of squares $=12.6$ ). However, a second degree polynomial gives a better fit (adjusted $\mathrm{R}^{2}=0.911$; residual sum of squares $=11.0$ ). In fact, the lack of fit of rates higher than $10^{-7} \mathrm{~s}^{-1}$ is easily detected.

Although the parameters in Table 1 appear to provide a reasonable fitting of experimental data over the range of temperatures and pressures investigated, Figs. 7 and 8 show also some evidence of lack of fit. For example, data at 1000 and $1100{ }^{\circ} \mathrm{C}$ and $P_{\mathrm{H} 2 \mathrm{O}}>50 \mathrm{~Pa}$ are clearly underestimated by the fit based on all 269 valid rate measurements. One concludes that the $\mathrm{L}-\mathrm{H}$ model with the best fit parameters from Table 1 underestimates fast oxidation rates.

In an attempt to refine the model, the rate data were split in two groups: low temperature data (191 observables between 800 and $950{ }^{\circ} \mathrm{C}$ ) and high temperature data (166 observables between 900 and $1100{ }^{\circ} \mathrm{C}$ ). The groups were fitted separately, but the statistical parameters (reported in Table A3) did not improve the fit sufficiently to justify using two separate models. Moreover, fitting the L-H model for the low temperature group produced negative values of all three activation energies, which is inconsistent with physical models.

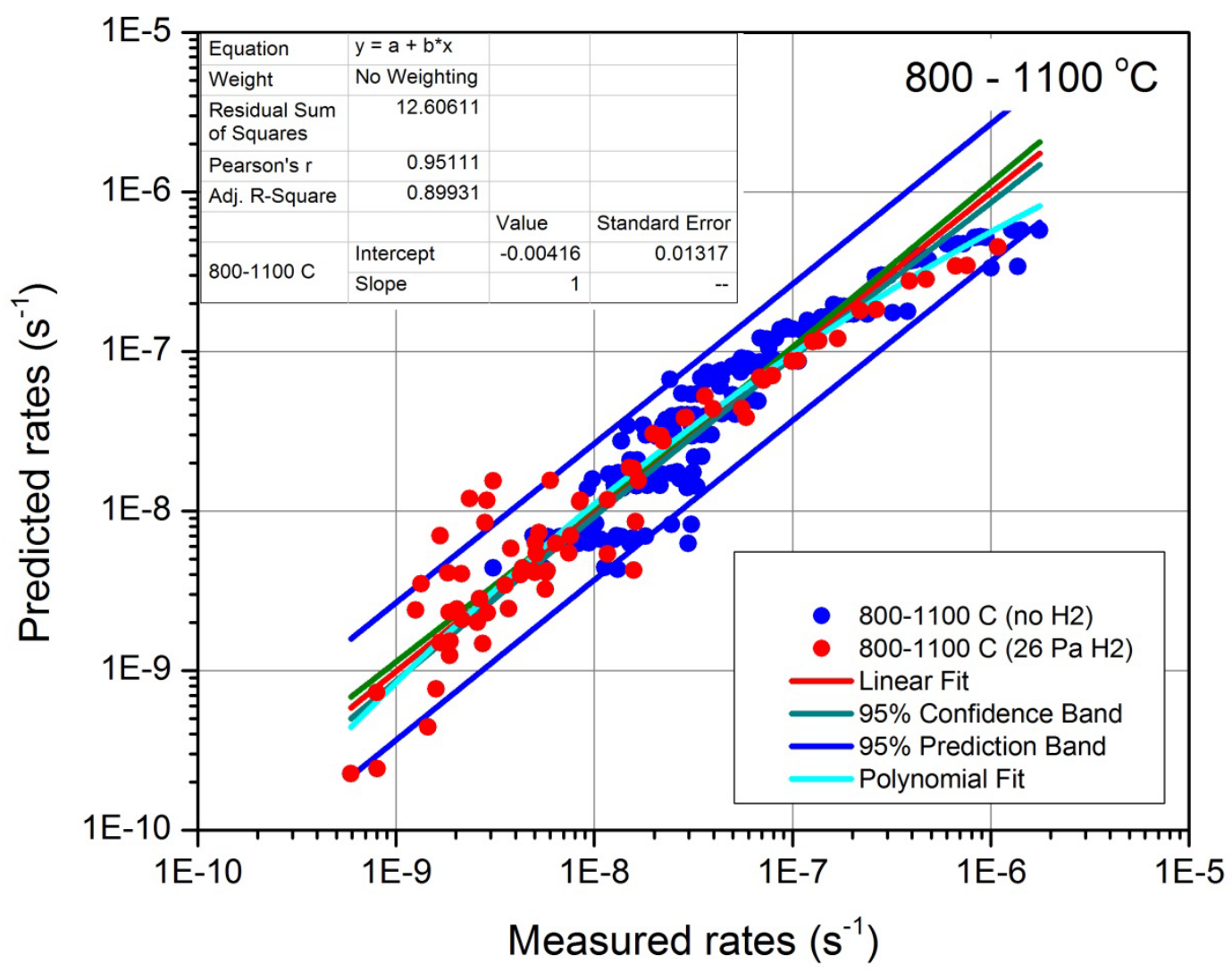

Figure 9: Comparison between oxidation rates predicted with parameters in Table 1 and actual measured rates. The rates observed with and without $\mathrm{H}_{2}$ in the oxidation gas are marked by differently colored symbols. 
ORNL/TM-2015/142

\section{DISCUSSION OF RESULTS}

Fitting the L-H model and finding the kinetic parameters in Eq. (7) is known to pose theoretical difficulties because of the multiple nonlinear form of the equation and the strong correlation between parameters. Ideally, obtaining data over a broad interval of $P_{\mathrm{H} 2 \mathrm{O}}, P_{\mathrm{H} 2}$, and $T$ may improve the accuracy of results. However, this is not possible from the experimental point of view. The temperature range is limited at both ends. Below $700{ }^{\circ} \mathrm{C}$ oxidation of graphite by water is not thermodynamically possible; even at $800{ }^{\circ} \mathrm{C}$ the rates are too slow for accurate determination. On the other hand, the rates are very fast at $1100{ }^{\circ} \mathrm{C}$, and oxidation reactions may become perturbed by slow diffusion of the oxidant. The useful range for measurements is between $800-850$ and $1100{ }^{\circ} \mathrm{C}$.

Despite these difficulties, oxidation rate measurements of two grades of nuclear graphite, PCEA $[10,23]$ and NBG-17 (this work), were shown to obey the L-H model within some reasonable limits. As in the previous work with PCEA graphite, not all oxidation rate data measured for graphite NBG-17 were validated for final analysis of results. Less than $10 \%$ of data identified as extreme outliers had to be rejected for the reasons stated in section 5.

With that correction, the oxidation rate values predicted by the $\mathrm{L}-\mathrm{H}$ model were reasonably well correlated with the experimental measurements, as shown in Fig. 9. The quality of fit for NBG-17 graphite in this work is comparable to that reported previously [10] for PCEA graphite (adjusted correlation coefficients $R^{2}$ is 0.9067 for 190 data points with PCEA and 0.8993 for 269 data points with NBG-17; Pearson's $r$ parameter is 0.95797 for PCEA and 0.95111 for NBG-17).

Table 2: Summary of L-H parameters for three nuclear graphites

\begin{tabular}{|c|c|c|c|c|c|c|}
\hline & $\begin{array}{c}A_{1} \\
\mathrm{~Pa}^{-1} \mathrm{~s}^{-1} \\
\end{array}$ & $\begin{array}{c}E_{1} \\
\mathrm{~kJ} / \mathrm{mol}\end{array}$ & $\begin{array}{c}A_{2} \\
\mathrm{~Pa}^{-0.5}\end{array}$ & $\begin{array}{c}E_{2} \\
\mathrm{~kJ} / \mathrm{mol} \\
\end{array}$ & $\begin{array}{c}A_{3} \\
\mathrm{~Pa}^{-1}\end{array}$ & $\begin{array}{c}E_{3} \\
\mathrm{~kJ} / \mathrm{mol} \\
\end{array}$ \\
\hline \multicolumn{7}{|c|}{ NBG-17 graphite (this work) } \\
\hline & $3.85 \times 10^{-6}$ & 61.5 & $4.00 \times 10^{-8}$ & -186.6 & $5.79 \times 10^{-7}$ & -122.8 \\
\hline $\begin{array}{l}\text { 95\% confidence } \\
\text { intervals } \\
\text { [lower; upper] }\end{array}$ & $\begin{array}{l}{\left[2.6 \times 10^{-6} ;\right.} \\
\left.5.7 \times 10^{-5}\right]\end{array}$ & $\begin{array}{c}{[32.4 ;} \\
90.6]\end{array}$ & $\begin{array}{c}{\left[1.1 \times 10^{-9} ;\right.} \\
\left.1.5 \times 10^{6}\right]\end{array}$ & $\begin{array}{l}{[-149.2 ;} \\
-224.0]\end{array}$ & $\begin{array}{c}{\left[2.7 \times 10^{-8} ;\right.} \\
\left.1.2 \times 10^{-5}\right]\end{array}$ & $\begin{array}{l}{[-90.8 ;} \\
-155.0]\end{array}$ \\
\hline \multicolumn{7}{|c|}{ PCEA graphite [10] } \\
\hline $\begin{array}{l}\text { 95\% confidence } \\
\text { intervals } \\
\text { [lower; upper] }\end{array}$ & {$[0.06 ; 8.34]$} & $\begin{array}{r}{[175 ;} \\
227] \\
\end{array}$ & {$\left[9.1 \times 10^{-14} ; 7.1 \times 10^{34}\right]$} & {$[-321 ; 942]$} & $\begin{array}{c}{\left[9.8 \times 10^{-6} ;\right.} \\
\left.2.1 \times 10^{-2}\right]\end{array}$ & $\begin{array}{r}{[-76 ;} \\
3.3]\end{array}$ \\
\hline \multicolumn{7}{|l|}{ H-451 graphite [8] } \\
\hline 0-300 $\mathrm{Pa} \mathrm{H}_{2} \mathrm{O}$ & 2000 & 274 & 1100 & 74.6 & 200 & 95.8 \\
\hline 300-3500 $\mathrm{Pa} \mathrm{H}_{2} \mathrm{O}$ & 0.11 & 195 & $7.9 \times 10^{-8}$ & 119.7 & $1.3 \times 10^{-9}$ & 131.4 \\
\hline 0-3500 $\mathrm{Pa} \mathrm{H}_{2} \mathrm{O}$ & 900 & 274 & $1.1 \times 10^{2}$ & 74.66 & 30 & 95.85 \\
\hline
\end{tabular}


Table 2 compares the L-H parameters for slow oxidation by water of three graphite grades for which detailed kinetic analysis is now available: H-451 [8], PCEA [10] and NBG-17 (this work). The parameters differ considerably between graphite grades. This finding does not come as a surprise: it is known that fitting of a complicated nonlinear equation such as the L-H model may produce multiple sets of local optimal parameters, depending on the initial "guess" introduced in the fitting algorithm. The problem is further complicated by the inherent experimental errors and the likely inhomogeneity of the material [33]. In addition, the use of linearization methods with non-linear models may provide point estimates of parameters, but their exact value remains uncertain because of the assumption that the model is linear in the neighborhood of these point estimates. This is certainly the case with the results reported for graphite $\mathrm{H}-451$, where the $\mathrm{L}-\mathrm{H}$ parameters were obtained by a successive linearization algorithm. In this method, the errors from successive linearization steps compound with one another and result in greater uncertainty of the parameters found. Analysis of PCEA and NBG-17 oxidation data was carried out using the more powerful MLE approach. In this statistical method, all parameters are fitted simultaneously on a large set of experimental observations, and the final selection is based on the maximum likelihood with the observables. Inherent to this approach is the assumption that the original model, as expressed by Eq. (7), is valid over the whole range of pressures and temperatures. The stability of the model is based, in turn, on the tacit assumption that each individual elementary reaction step of the overall complex kinetic mechanism does not change with pressure and temperature. This is difficult to justify, especially for gas-solid reactions that might be affected by significant diffusion perturbations as the external conditions vary. Nonetheless, the fact that a multitude of experimental oxidation rate data, spanning three orders of magnitude, can be reasonably reproduced by the $\mathrm{L}-\mathrm{H}$ model with a set of six parameters justifies, in general, the applicability of this model for graphite oxidation by water. This is the best that can be done at this time. In the near future, when more information becomes available for graphite grades with significant differences in microstructure, a fresh look at the limits of the L-H model will be worthwhile. A more flexible approach, although pragmatic and perhaps remote from the assumptions of the L-H model, might allow more accurate prediction of long term graphite oxidation behavior. 
ORNL/TM-2015/142

\section{CONCLUSION AND FUTURE WORK}

This kinetic study of oxidation by water of nuclear graphite NBG-17 follows a similar study completed in 2013 on graphite PCEA [10,23]. Both graphite grades are possible candidates for manufacturing of components in HTGR systems. A third study of oxidation kinetics by water of graphite IG-110 is now in progress. The purpose of these studies is to obtain material-specific information needed to develop predictive models for evaluation of the extremely slow, but continuous structural damage that will occur in normal operating conditions when graphite components are exposed to very low concentrations of water in the helium coolant. A similar study was performed in 1978 by Velasquez, Hightower, and Burnette for General Atomic Company on the American graphite H-451 [8]. Based on the results for graphite H-451, Richards [32] calculated the density profile under the surface of wateroxidized graphite after prolonged exposure to moisture. He concluded that oxidation of graphite $\mathrm{H}-451$ will be limited to 1-2 mm under the surface of components, provided the water concentration is kept below $0.1 \mathrm{ppm}$. The model predictions compared favorably with measurements on water-oxidized graphite 2020 (a different grade from $\mathrm{H}-451$ ) oxidized at $1000{ }^{\circ} \mathrm{C}$ in 55 bar of He with $9090 \mathrm{ppm}_{2} \mathrm{O}$ and $455 \mathrm{ppm} \mathrm{H}_{2}$ [32]. The conclusion that graphite oxidation will not affect the reactor integrity during long time HTGR operation was based on this comparison. However, graphite H-451 (used in the Fort St. Vrain reactor) is no longer available. New experimental reactors built in China (HTR-10) and Japan (HTTR) use graphite IG-110. Because no specific information on chronic oxidation by water of this graphite is available, it was assumed that all nuclear graphite grades will reproduce the kinetic behavior of grade $\mathrm{H}$ $451[27,34,35]$. Given the known effects of microstructure on the oxidation behavior of various graphite grades [9], the assumption that oxidation rate parameters of graphite grade H-451 can be safely transferred to other graphite grades is questionable.

Investigation of long term oxidation resistance in conditions relevant for normal operation of nuclear reactors is a requirement for qualification of new grades of nuclear graphite for the Advanced Reactor Technology program in the United States. The results obtained with graphites NBG-17 and PCEA show that the L-H model for graphite oxidation by moisture is valid within some reasonable limits. Both graphite grades show deviations from the model at extreme conditions. On the one hand, observed oxidation rates were slower than predicted at low temperatures, low water vapor pressure, and in the presence of hydrogen. On the other hand, they were faster than predicted by the model at high temperatures and high water vapor pressures. Moreover, results for the two graphite grades suggest strongly that the microstructures of particular graphite grades have a strong influence on the kinetic behavior during oxidation by traces of water. This observation corroborates the recent result showing the effect of microstructure on the diffusivity and permeability of graphite for water vapor and helium [18].

This project must continue with examination of the combined effects of kinetic and transport (diffusion) characteristics of graphite grades on oxidant penetration profiles in the subsurface of graphite components. The analysis will use the parameters of the L-H model determined for PCEA and NBG-17 graphites and the water effective diffusivity measurements for the same grades [18]. The expected result is to predict the density profiles of the oxidation layer produced by reactions with water at several temperatures. The predictions will then be compared with the measured oxidation profiles in known experimental conditions. Oxidation profile data for graphite PCEA measured by optical microscopy (at ORNL) and X-ray tomography (at Idaho National Laboratory) are already available A similar set of measurements should be performed on NBG-17 specimens oxidized by moisture. 
ORNL/TM-2015/142 
ORNL/TM-2015/142

\section{REFERENCES}

1 M P Kissane, A review of radionuclide behavior in the primary system of a very-high temperature reactor, Nucl. Eng. Design, 239 (2009) 3076-3091.

$2 \mathrm{X}$ Yu, S Yu, Analysis of fuel element matrix graphite corrosion in HTR-PM for normal operating conditions, Nucl. Eng. Design, 240 (2010) 738-743.

3 E R Corwin, Generation IV Reactors Integrated Materials Technology Program Plan: Focus on Very High Temperature Reactor Materials, ORNL/TM-2008/129 (2008).

4 M Fechter, Graphite Oxidation Modeling for a 250 MW Pebble Bed Reactor, ORNL presentation, July 2010.

5 B Castle, NGNP Reactor Coolant Chemistry Control Study, INL/EXT-10-10533.

6 R N Wright, Kinetics of Gas Reactions and Environmental Degradation in NGNP Helium, INL/EXT06-11494 .

7 T J Clark, R E Woodley, D R de Halas, Gas-graphite systems, in Nuclear Graphite, ed. R E Nightingale, Academic Press (1962), p. 387-444.

8 C Velasquez, G Hightower, R Burnette, The Oxidation of H-451 Graphite by Steam. Part 1: Reaction Kinetics, General Atomic Company, GA-A14951 (1978).

9 C I Contescu, T Guldan, P Wang, T D Burchell, The effect of microstructure on air oxidation resistance of nuclear graphite, Carbon, 50 (2012) 3354-3366.

10 C I Contescu, R W Mee, P Wang, A V Romanova, T D Burchell, Oxidation of PCEA nuclear graphite by low water concentrations in helium, J. Nucl. Mater., 453 (2014) 225-232.

11 J Gadsby, C N Hinshelwood, K W Sykes, Kinetics of the reactions of steam-carbon system, Proc. Roy. Soc. (London) A, 187 (1946) 129-151.

12 J Gadsby, F J Long, P Sleightholmm K W Sykes, Proc. Roy. Soc. (London) A, 193 (1949) 357.

13 L G Overholser, J P Blakely, Oxidation of graphite by low concentrations of water vapor and carbon dioxide in helium, Carbon, 2 (1965) 385-394.

$14 \mathrm{~J}$ P Blakely, L G Overholser, Oxidation of ATJ graphite by low concentrations of water vapor and carbon dioxide in helium, Carbon, 3 (1965) 269-275.

15 R P Wichner, T D Burchell, C I Contescu, Penetration depths and transient oxidation of graphite by oxygen and water vapor, J. Nucl. Mater., 393 (2009) 518-521.

16 R P Wichner, T D Burchell, C I Contescu, A Note on the Oxidation of Graphite by $\mathrm{O}_{2}$ and Moisture, ORNL/TM-2008/230 (2008).

17 C I Contescu, Graphite oxidation: Analysis and modeling results, Advanced Materials R\&D program review, Advanced Reactor Technologies Program, May 6-8, 2014, Oak Ridge, TN (2014).

18 C I Contescu, T D Burchell, Water Vapor Transport in Nuclear Graphite, ORNL/TM-2015/88 (2015).

19 P Beghein, G Berlioux, B du Mesnildot, F Hiltmann, M Melin, NBG-17 - An improved graphite grade for HTRs and VHTRs, Nucl. Eng. Design, 251 (2012) 146-49.

20 J Kane, C Karthik, D P Butt, W E Windes, R Ubic, Microstructural characterization and pore 
ORNL/TM-2015/142

structure analysis of nuclear graphite, J. Nucl. Mater., 415 (2011) 189-197.

21 Q-K Choi, N-J Kim, E-S Kim, S-H Chi, S-J Park, Oxidation behavior of IG and NBG nuclear graphites, Nucl. Eng. Design, 241 (2011) 82-87.

22 T Burchell, S Nunn, J Strizak, M Williams, AGC-1 Sister Specimen Testing Data Report, ORNL/TM-2009/025 (2009).

23 C I Contescu, T D Burchell, R Mee, Accelerated Oxidation Studies of PCEA Nuclear Graphite by Low Concentration of Water and Hydrogen in Helium, ORNL/TM-2013/524 (2013).

24 T Burchell, J Strizak, M Williams, AGC-1 Specimen Pre-irradiation Data Report, ORNL/TM2010/285 (2010).

25 Standard test method for bulk density by physical measurements of manufactured carbon and graphite articles, ASTM C559-90 (Reapproved 2010).

26 J-L Su, D D Perlmutter, Effect of pore structure on char oxidation kinetics, AIChE Journal, 31 (1985) 973-981.

27 X Yu, L Brissoneau, C Bourdeloie, S Yu,The modeling of graphite oxidation behavior for HTGR fuel coolant channels under normal operating conditions, Nucl, Eng, Design, 238 (2008) 2230-2238.

28 M S El-Genk, J-M Tournier, Comparison of oxidation model predictions with gasification data of IG110, IG-430 and NBG-25 nuclear graphite, J. Nucl. Mater., 420 (2012) 141-158.

29 R C Giberson, J P Walker, Reaction of nuclear graphite with water vapor. Part I: Effect of hydrogen and water vapor partial pressure, Carbon, 3 (1966) 521-525.

30 T X Nguyen, J-S Bae, Y Wang, S K Bhatia, On the strength of hydrogen-carbon interactions as deduced from physisorption, Langmuir, 25 (2009) 4314-4319.

31 F H Yang, R T Yang, Ab initio molecular orbital study of adsorption of atomic hydrogen on graphite, Carbon 40 (2002) 437-444.

32 M B Richards, Reaction of nuclear grade graphite with low concentrations of steam in the helium coolant of an MHTGR, Energy, 15 (1990) 729-739.

33 S-H Hsu, S D Stamatis, J M Carruthers, W N Delgass, V Venkatasubramanian, Bayesian framework for building kinetic models of catalytic systems, Ind. Eng. Chem. Res., 48 (2009) 4768-4790.

$34 \mathrm{X}$ Luo, J-C Robin, S Yu, Theoretical analysis of mass transfer and reaction in a porous medium applied to gasification of graphite by water vapor, Nucl. Eng. Design, 238 (2008) 2230-2238.

35 M Eto, T Kurosawa, Estimation of graphite materials corrosion with water-vapor in coolant VHTR and oxidation effect on the materials' properties, Specialists meeting on Graphite Component Structural Design, JAERI Tokai (Japan), September 8-11, 1996, IWGGR-11: 189-194. 
ORNL/TM-2015/142 
ORNL/TM-2015/142

ANNEX 
ORNL/TM-2015/142 
Table A-1: $\quad$ Physical properties of NBG-17 specimens before and after oxidation

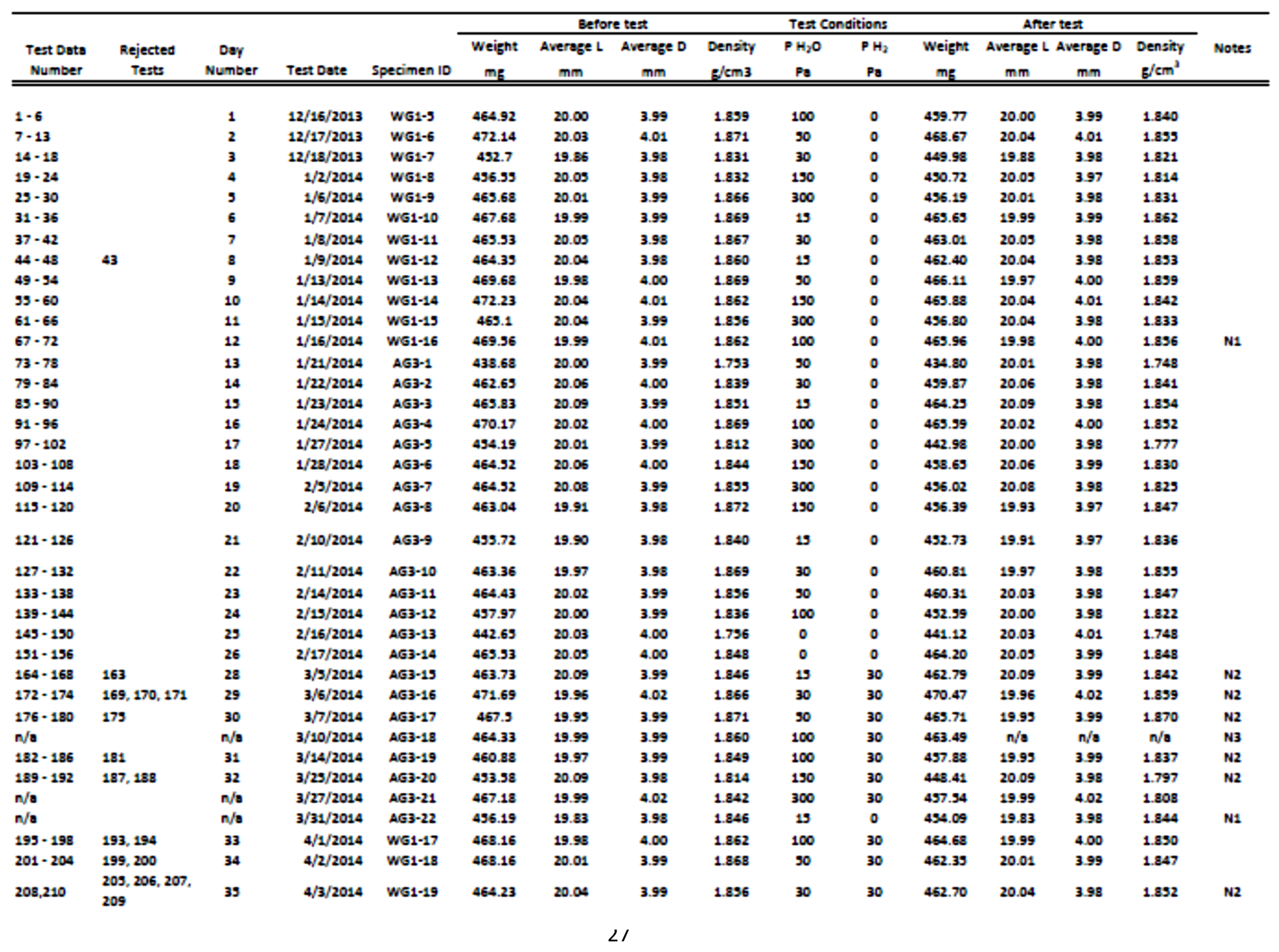


ORNL/TM-2015/142

\begin{tabular}{|c|c|c|c|c|c|c|c|c|c|c|c|c|c|c|c|}
\hline \multirow{3}{*}{$\begin{array}{l}\text { Test Dsts } \\
\text { Number }\end{array}$} & \multirow{3}{*}{$\begin{array}{c}\text { Rejected } \\
\text { Tests }\end{array}$} & \multirow{3}{*}{$\begin{array}{c}\text { Day } \\
\text { Number }\end{array}$} & \multirow[b]{3}{*}{ Test Date } & \multirow[b]{3}{*}{ Specimen ID } & \multicolumn{4}{|c|}{ Before test } & \multicolumn{2}{|c|}{ Test Conditions } & \multicolumn{4}{|c|}{ After test } & \multirow{3}{*}{ Note: } \\
\hline & & & & & Weight & Average L & Average D & Density & $\mathrm{PH}_{2} \mathrm{O}$ & $\mathrm{PH}_{2}$ & Weight & Aversge L & Averoge D & Density & \\
\hline & & & & & $\mathrm{mg}$ & $\mathrm{mm}$ & $\mathrm{mm}$ & $\mathrm{g} / \mathrm{cm}^{3}$ & $\mathrm{~Pa}$ & $\mathrm{~Pa}$ & $\mathrm{mg}$ & $\mathrm{mm}$ & $\mathrm{mm}$ & $\mathrm{E} / \mathrm{cm}^{2}$ & \\
\hline $213-216$ & 211,212 & 36 & $4 / 4 / 2014$ & WG1-20 & 465.3 & 20.03 & 3.98 & 1.865 & 190 & 30 & 460.74 & 20.04 & 3.98 & 1.846 & \\
\hline \multirow[t]{2}{*}{$225 \cdot 227$} & 223,224 & 38 & $4 / 3 / 2014$ & WG1-22 & 497.51 & 19.80 & 3.99 & 1.844 & 13 & 30 & 496.71 & 19.81 & 3.99 & 1.845 & N1 \\
\hline & $228-233$ & 39 & 4/9/2014 & WG1-23 & 470.38 & 20.01 & 4.00 & 1.871 & 3 & 100 & 469.74 & 20.02 & 4.01 & 1.863 & N9 \\
\hline $234 \cdot 239$ & 239 & 40 & $6 / 30 / 2014$ & WG1-24 & 465.29 & 20.07 & 3.99 & 1.853 & 500 & 0 & 442.02 & 20.07 & 3.98 & 1.774 & \\
\hline $240-244$ & 249,246 & 41 & $7 / 1 / 2014$ & WG1-25 & 465.38 & 20.05 & 3.98 & 1.868 & 1000 & 0 & 430.71 & 20.04 & 3.96 & 1.742 & $\mathrm{~N} 1$ \\
\hline $247-251$ & & 42 & $7 / 29 / 2014$ & WG1-27 & 467.87 & 20.02 & 3.99 & 1.865 & 100 & 30 & 465.72 & 20.01 & 3.99 & 1.861 & N6 \\
\hline $252-255$ & & 43 & $8 / 4 / 2014$ & WG1-28 & 466.22 & 20.01 & 3.99 & 1.863 & 100 & 30 & 454.77 & 20.02 & 3.98 & 1.864 & N6 \\
\hline $256 \cdot 263$ & & 44 & $8 / 8 / 2014$ & WG1-29 & 466.01 & 20.03 & 3.98 & 1.868 & $100-200$ & very & 454.60 & 20.04 & 3.99 & 1.853 & \\
\hline $264-272$ & & 49 & $8 / 12 / 2014$ & WG1-30 & 466.83 & 20.04 & 4.00 & 1.859 & $30-50$ & vary & 455.87 & 20.03 & 3.99 & 1.860 & \\
\hline $272-282$ & $273,274,276$ & 46 & $8 / 15 / 2014$ & WG1-31 & 470.25 & 19.99 & 4.01 & 1.868 & vary & 25 & 469.98 & 19.99 & 4.01 & 1.861 & \\
\hline $283-286$ & & 47 & $8 / 25 / 2014$ & WG1-32 & 456.9 & 20.02 & 4.00 & 1.818 & 19 & 26 & 456.34 & 20.03 & 4.00 & 1.816 & \\
\hline $287-290$ & & 48 & $9 / 3 / 2014$ & WG1-33 & 463.92 & 20.06 & 3.98 & 1.857 & 30 & 26 & 463.15 & 20.09 & 3.98 & 1.861 & \\
\hline $291-294$ & & 49 & $12 / 30 / 2014$ & WG1-34-1 & 468.3 & 20.01 & 3.99 & 1.869 & 30 & 0 & $\mathrm{n} / \mathrm{s}$ & $n / a$ & $\mathrm{n} / \mathrm{s}$ & $\mathrm{n} / \mathrm{s}$ & No \\
\hline $291-296$ & & 50 & $1 / 1 / 2015$ & WG1-34-2 & $\mathrm{n} / \mathrm{a}$ & $n / a$ & $\mathrm{n} / \mathrm{s}$ & $\mathrm{n} / \mathrm{a}$ & 15 & 0 & $\mathrm{n} / \mathrm{s}$ & $\mathrm{n} / \mathrm{a}$ & $\mathrm{n} / \mathrm{a}$ & $\mathrm{n} / \mathrm{s}$ & NS \\
\hline $297 \cdot 300$ & & 51 & $1 / 5 / 2015$ & WG1-34-3 & $\mathrm{n} / \mathrm{s}$ & $\mathrm{n} / \mathrm{a}$ & $\mathrm{n} / \mathrm{s}$ & $\mathrm{n} / \mathrm{s}$ & 3 & 0 & $\mathrm{n} / \mathrm{s}$ & $\mathrm{n} / \mathrm{a}$ & $\mathrm{n} / \mathrm{a}$ & $\mathrm{n} / \mathrm{a}$ & \\
\hline & Notes: & N1 & Poor control or & $P_{M C O}$ & & & & & & & & & & & \\
\hline & & N2 & Errors in slow o & widsiton rates & & & & & & & & & & & \\
\hline & & N3 & Helium flow sto & opped during tes & & & & & & & & & & & \\
\hline & & N4 & Hygrometer ms & Ifunction & & & & & & & & & & & \\
\hline & & N5 & Fluctustions in & helium fow & & & & & & & & & & & \\
\hline & & N5 & No $\mathrm{H}_{2} \mathrm{O}, 100 \mathrm{~Pa}$ & $\mathrm{H}_{2}$ in $\mathrm{He}$ & & & & & & & & & & & \\
\hline & & N6 & $\mathrm{H}_{2}$ on st off at 8 & $890 \circ \mathrm{C}$ & & & & & & & & & & & \\
\hline
\end{tabular}


Table A-2: Experimental oxidation rates and corresponding conditions

\begin{tabular}{|c|c|c|c|c|c|c|c|c|c|c|c|c|c|c|c|c|c|c|c|}
\hline \multirow{3}{*}{$\begin{array}{l}\text { Test Data } \\
\text { Number }\end{array}$} & \multirow{3}{*}{$\begin{array}{c}\text { Day } \\
\text { Number }\end{array}$} & \multirow{3}{*}{ Test Date } & \multirow{3}{*}{ Specimen ID } & \multicolumn{2}{|c|}{ Water Pressure } & \multirow{2}{*}{$\begin{array}{c}\text { H2 } \\
\text { Pressure }\end{array}$} & \multicolumn{2}{|c|}{ Temperature } & \multicolumn{2}{|c|}{ Weight } & \multicolumn{2}{|c|}{ Time in the Test } & \multirow{2}{*}{$\begin{array}{l}\text { Oxidation } \\
\text { Rate }\end{array}$} & \multicolumn{2}{|c|}{ Burn off \% } & \multicolumn{2}{|c|}{ Sample Preparaton } & Weight Loss on & \\
\hline & & & & target & actual & & target & actual & before & after & before & after & & before & after & duration & temperature & & Notes \\
\hline & & & & $\mathrm{Pa}$ & $\mathrm{Pa}$ & $\mathrm{Pa}$ & ${ }^{\circ} \mathrm{C}$ & oc & $\mathrm{mg}$ & $\mathrm{mg}$ & $\mathrm{hr}$ & $\mathrm{hr}$ & $s^{-1}$ & $\%$ & $\%$ & $h$ & ${ }^{\circ} \mathrm{C}$ & $\mathrm{mg}$ & \\
\hline 1 & 1 & $12 / 16 / 2013$ & WG1-5 & 100 & 100 & 0 & 800 & 800 & 465.07 & 465.04 & 4.60 & 7.36 & $5.84 E-09$ & -0.03 & -0.03 & 1 & 1200 & 0.18 & \\
\hline 2 & 1 & $12 / 16 / 2013$ & WG1-5 & 100 & 101 & 0 & 850 & 850 & 464.99 & 464.91 & 7.70 & 10.46 & $1.71 E-08$ & -0.01 & 0.00 & 1 & 1200 & 0.18 & \\
\hline 3 & 1 & $12 / 16 / 2013$ & WG1-5 & 100 & 101 & 0 & 900 & 900 & 464.84 & 464.72 & 10.91 & 13.56 & $2.73 E-08$ & 0.02 & 0.04 & 1 & 1200 & 0.18 & \\
\hline 4 & 1 & $12 / 16 / 2013$ & WG1-5 & 100 & 101 & 0 & 950 & 950 & 464.66 & 464.41 & 13.78 & 16.55 & $5.42 E-08$ & 0.06 & 0.11 & 1 & 1200 & 0.18 & \\
\hline 5 & 1 & $12 / 16 / 2013$ & WG1-5 & 100 & 101 & 0 & 1000 & 1000 & 464.30 & 463.68 & 16.94 & 19.68 & $1.35 E-07$ & 0.13 & 0.27 & 1 & 1200 & 0.18 & \\
\hline 6 & 1 & $12 / 16 / 2013$ & WG1-5 & 100 & 100 & 0 & 1100 & 1100 & 463.29 & 460.17 & 20.12 & 22.86 & $6.81 E-07$ & 0.35 & 1.02 & 1 & 1200 & 0.18 & \\
\hline 7 & 2 & $12 / 17 / 2013$ & WG1-6 & 50 & 50 & 0 & 800 & 800 & 471.18 & 471.14 & 4.21 & 7.34 & $7.53 E-09$ & 0.17 & 0.18 & 1 & 1200 & 0.15 & \\
\hline 8 & 2 & $12 / 17 / 2013$ & WG1-6 & 50 & 51 & 0 & 850 & 850 & 471.07 & 471.02 & 7.81 & 10.46 & $1.27 E-08$ & 0.19 & 0.21 & 1 & 1200 & 0.15 & \\
\hline 9 & 2 & $12 / 17 / 2013$ & WG1-6 & 50 & 50 & 0 & 900 & 900 & 470.96 & 470.85 & 10.82 & 13.51 & $2.46 E-08$ & 0.22 & 0.24 & 1 & 1200 & 0.15 & \\
\hline 10 & 2 & $12 / 17 / 2013$ & WG1-6 & 50 & 51 & 0 & 950 & 950 & 470.74 & 470.57 & 13.90 & 16.57 & $3.71 E-08$ & 0.27 & 0.30 & 1 & 1200 & 0.15 & \\
\hline 11 & 2 & $12 / 17 / 2013$ & WG1-6 & so & 51 & 0 & 1000 & 1000 & 470.46 & 470.05 & 17.02 & 19.68 & $9.21 E-08$ & 0.32 & 0.41 & 1 & 1200 & 0.15 & \\
\hline 12 & 2 & $12 / 17 / 2013$ & WG1-6 & 50 & 51 & 0 & 1100 & 1100 & 469.75 & 467.86 & 20.15 & 22.86 & 4.11E-07 & 0.47 & 0.87 & 1 & 1200 & 0.15 & \\
\hline 13 & 3 & $12 / 18 / 2013$ & WG1-7 & 30 & 30 & 0 & 800 & 800 & 451.65 & 451.63 & 4.52 & 6.61 & $6.18 E-09$ & 0.20 & 0.20 & 2 & 1200 & 0.15 & \\
\hline 14 & 3 & $12 / 18 / 2013$ & WG1-7 & 30 & 30 & 0 & 850 & 850 & 451.54 & 451.47 & 7.89 & 10.43 & $1.77 E-08$ & 0.22 & 0.24 & 2 & 1200 & 0.15 & \\
\hline 15 & 3 & $12 / 18 / 2013$ & WG1-7 & 30 & 30 & 0 & 900 & 900 & 451.40 & 451.31 & 10.94 & 13.48 & $2.30 E-08$ & 0.25 & 0.27 & 2 & 1200 & 0.15 & \\
\hline 16 & 3 & $12 / 18 / 2013$ & WG1-7 & 30 & 30 & 0 & 950 & 950 & 451.24 & 451.08 & 13.95 & 16.57 & $3.69 E-08$ & 0.29 & 0.32 & 2 & 1200 & 0.15 & \\
\hline 17 & 3 & $12 / 18 / 2013$ & WG1-7 & 30 & 30 & 0 & 1000 & 1000 & 450.99 & 450.67 & 17.02 & 19.70 & $7.33 E-08$ & 0.34 & 0.42 & 2 & 1200 & 0.15 & \\
\hline 18 & 3 & $12 / 18 / 2013$ & WG1-7 & 30 & 30 & 0 & 1100 & 1100 & 450.48 & 449.25 & 20.04 & 22.66 & $2.90 E-07$ & 0.46 & 0.73 & 2 & 1200 & 0.15 & \\
\hline 19 & 4 & $1 / 2 / 2014$ & WG1-8 & 150 & 152 & 0 & 800 & 800 & 455.29 & 455.26 & 4.85 & 7.39 & $7.45 E-09$ & 0.23 & 0.23 & 2 & 1200 & 0.22 & \\
\hline 20 & 4 & $1 / 2 / 2014$ & WG1-8 & 150 & 153 & 0 & 850 & 850 & 455.21 & 455.15 & 7.84 & 10.38 & $1.44 E-08$ & 0.25 & 0.26 & 2 & 1200 & 0.22 & \\
\hline 21 & 4 & $1 / 2 / 2014$ & WG1-8 & 150 & 153 & 0 & 900 & 900 & 455.08 & 454.97 & 10.85 & 13.51 & $2.59 E-08$ & 0.27 & 0.30 & 2 & 1200 & 0.22 & \\
\hline 22 & 4 & $1 / 2 / 2014$ & WG1-8 & 150 & 152 & 0 & 950 & 950 & 454.90 & 454.67 & 13.93 & 16.57 & $5.25 E-08$ & 0.31 & 0.36 & 2 & 1200 & 0.22 & \\
\hline 23 & 4 & $1 / 2 / 2014$ & WG1-8 & 150 & 151 & 0 & 1000 & 1000 & 454.57 & 453.93 & 16.94 & 19.73 & $1.40 E-07$ & 0.39 & 0.53 & 2 & 1200 & 0.22 & \\
\hline 24 & 4 & $1 / 2 / 2014$ & WG1-8 & 150 & 150 & 0 & 1100 & 1100 & 453.47 & 449.73 & 20.18 & 22.94 & $8.30 E-07$ & 0.63 & 1.45 & 2 & 1200 & 0.22 & \\
\hline 25 & 5 & $1 / 6 / 2014$ & WG1-9 & 300 & 303 & 0 & 800 & 800 & 464.463 & 464.427 & 4.46 & 7.24 & $7.74 E-09$ & 0.21 & 0.22 & 2 & 1200 & 0.22 & \\
\hline 26 & 5 & $1 / 6 / 2014$ & WG1-9 & 300 & 302 & 0 & 850 & 850 & 464.367 & 464.31 & 7.80 & 10.38 & $1.32 E-08$ & 0.24 & 0.25 & 2 & 1200 & 0.22 & \\
\hline 27 & 5 & $1 / 6 / 2014$ & WG1-9 & 300 & 304 & 0 & 900 & 900 & 464.248 & 464.125 & 10.80 & 13.47 & $2.76 E-08$ & 0.26 & 0.29 & 2 & 1200 & 0.22 & \\
\hline 28 & 5 & $1 / 6 / 2014$ & WG1-9 & 300 & 307 & 0 & 950 & 950 & 464.045 & 463.729 & 13.69 & 16.64 & $6.41 E-08$ & 0.30 & 0.37 & 2 & 1200 & 0.22 & \\
\hline 29 & 5 & $1 / 6 / 2014$ & WG1-9 & 300 & 309 & 0 & 1000 & 1000 & 463.582 & 462.677 & 17.03 & 19.70 & $2.03 E-07$ & 0.40 & 0.60 & 2 & 1200 & 0.22 & \\
\hline 30 & 5 & $1 / 6 / 2014$ & WG1-9 & 300 & 314 & 0 & 1100 & 1100 & 462.139 & 455.456 & 20.09 & 22.92 & $1.42 E-06$ & 0.71 & 2.15 & 2 & 1200 & 0.22 & \\
\hline 31 & 6 & $1 / 7 / 2014$ & WG1-10 & 15 & 15 & 0 & 800 & 800 & 466.664 & 466.628 & 4.71 & 7.28 & $8.34 E-09$ & 0.18 & 0.19 & 2 & 1200 & 0.16 & \\
\hline 32 & 6 & $1 / 7 / 2014$ & WG1-10 & 15 & 15 & 0 & 850 & 850 & 466.571 & 466.5 & 7.81 & 10.41 & $1.63 E-08$ & 0.20 & 0.22 & 2 & 1200 & 0.16 & \\
\hline 33 & 6 & $1 / 7 / 2014$ & WG1-10 & 15 & 15 & 0 & 900 & 900 & 466.44 & 466.348 & 10.85 & 13.51 & $2.06 E-08$ & 0.23 & 0.25 & 2 & 1200 & 0.16 & \\
\hline 34 & 6 & $1 / 7 / 2014$ & WG1-10 & 15 & 15 & 0 & 950 & 950 & 466.279 & 466.141 & 13.95 & 16.63 & $3.07 E-08$ & 0.27 & 0.29 & 2 & 1200 & 0.16 & \\
\hline 35 & 6 & $1 / 7 / 2014$ & WG1-10 & 15 & 15 & 0 & 1000 & 1000 & 466.07 & 465.81 & 16.91 & 19.70 & $5.55 E-08$ & 0.31 & 0.37 & 2 & 1200 & 0.16 & \\
\hline 36 & 6 & $1 / 7 / 2014$ & WG1-10 & 15 & 15 & 0 & 1100 & 1100 & 465.629 & 464.813 & 20.07 & 22.86 & $1.74 E-07$ & 0.40 & 0.58 & 2 & 1200 & 0.16 & \\
\hline 37 & 7 & $1 / 8 / 2014$ & WG1-11 & 30 & 30 & 0 & 800 & 800 & 464.557 & 464.518 & 4.63 & 7.45 & $8.27 E-09$ & 0.18 & 0.19 & 2 & 1200 & 0.14 & \\
\hline 38 & 7 & $1 / 8 / 2014$ & WG1-11 & 30 & 30 & 0 & 850 & 850 & 464.465 & 464.398 & 7.73 & 10.49 & $1.45 E-08$ & 0.20 & 0.21 & 2 & 1200 & 0.14 & \\
\hline 39 & 7 & $1 / 8 / 2014$ & WG1-11 & 30 & 32 & 0 & 900 & 900 & 464.339 & 464.234 & 10.80 & 13.64 & $2.21 E-08$ & 0.23 & 0.25 & 2 & 1200 & 0.14 & \\
\hline 40 & 7 & $1 / 8 / 2014$ & WG1-11 & 30 & 32 & 0 & 950 & 950 & 464.176 & 464.012 & 13.81 & 16.66 & $3.44 E-08$ & 0.26 & 0.30 & 2 & 1200 & 0.14 & \\
\hline 41 & 7 & $1 / 8 / 2014$ & WG1-11 & 30 & 32 & 0 & 1000 & 1000 & 463.939 & 463.613 & 16.88 & 19.73 & $6.85 E-08$ & 0.31 & 0.38 & 2 & 1200 & 0.14 & \\
\hline 42 & 7 & $1 / 8 / 2014$ & WG1-11 & 30 & 32 & 0 & 1100 & 1100 & 463.406 & 462.082 & 20.07 & 22.91 & $2.79 E-07$ & 0.43 & 0.71 & 2 & 1200 & 0.14 & \\
\hline 44 & 8 & $1 / 9 / 2014$ & WG1-12 & 15 & 15 & 0 & 850 & 850 & 463.261 & 463.181 & 7.87 & 10.46 & 1.85E-08 & 0.20 & 0.22 & 2 & 1200 & 0.14 & \\
\hline 45 & 8 & $1 / 9 / 2014$ & WG1-12 & 15 & 15 & 0 & 900 & 900 & 463.123 & 463.021 & 10.77 & 13.62 & $2.15 E-08$ & 0.23 & 0.26 & 2 & 1200 & 0.14 & \\
\hline 46 & 8 & $1 / 9 / 2014$ & WG1-12 & 15 & 15 & 0 & 950 & 950 & 462.956 & 462.812 & 13.90 & 16.52 & $3.30 E-08$ & 0.27 & 0.30 & 2 & 1200 & 0.14 & \\
\hline 47 & 8 & $1 / 9 / 2014$ & WG1-12 & 15 & 15 & 0 & 1000 & 1000 & 462.727 & 462.455 & 16.94 & 19.70 & $5.92 E-08$ & 0.32 & 0.38 & 2 & 1200 & 0.14 & \\
\hline 48 & 8 & $1 / 9 / 2014$ & WG1-12 & 15 & 16 & 0 & 1100 & 1100 & 462.185 & 461.413 & 20.34 & 22.89 & $1.82 E-07$ & 0.44 & 0.60 & 2 & 1200 & 0.14 & \\
\hline 49 & 9 & $1 / 13 / 2014$ & WG1-13 & 50 & 49 & 0 & 800 & 800 & 468.56 & 468.515 & 4.54 & 7.47 & $9.10 E-09$ & 0.20 & 0.21 & 2 & 1200 & 0.16 & \\
\hline 50 & 9 & $1 / 13 / 2014$ & WG1-13 & 50 & 49 & 0 & 850 & 850 & 468.461 & 468.393 & 7.67 & 10.46 & $1.45 E-08$ & 0.22 & 0.24 & 2 & 1200 & 0.16 & \\
\hline 51 & 9 & $1 / 13 / 2014$ & WG1-13 & 50 & 49 & 0 & 900 & 900 & 468.334 & 468.224 & 10.74 & 13.56 & $2.31 E-08$ & 0.25 & 0.28 & 2 & 1200 & 0.16 & \\
\hline 52 & 9 & $1 / 13 / 2014$ & WG1-13 & so & 49 & 0 & 950 & 950 & 468.158 & 467.956 & 13.81 & 16.66 & 4.21E-08 & 0.29 & 0.33 & 2 & 1200 & 0.16 & \\
\hline 53 & 9 & $1 / 13 / 2014$ & WG1-13 & so & 49 & 0 & 1000 & 1000 & 467.881 & 467.458 & 16.86 & 19.76 & $8.66 E-08$ & 0.35 & 0.44 & 2 & 1200 & 0.16 & \\
\hline
\end{tabular}




\begin{tabular}{|c|c|c|c|c|c|c|c|c|c|c|c|c|c|c|c|c|c|c|c|}
\hline \multirow{3}{*}{$\begin{array}{l}\text { Test Data } \\
\text { Number }\end{array}$} & \multirow{3}{*}{$\begin{array}{c}\text { Day } \\
\text { Number }\end{array}$} & \multirow{3}{*}{ Test Date } & \multirow{3}{*}{ Specimen ID } & \multicolumn{2}{|c|}{ Water Pressure } & \multirow{2}{*}{$\begin{array}{c}\text { H2 } \\
\text { Pressure }\end{array}$} & \multicolumn{2}{|c|}{ Temperature } & \multicolumn{2}{|c|}{ Weight } & \multicolumn{2}{|c|}{ Time in the Test } & \multirow{2}{*}{$\begin{array}{l}\text { Oxidation } \\
\text { Rate }\end{array}$} & \multicolumn{2}{|c|}{ Burn off \% } & Sample & reparaton & Weight Loss on & \\
\hline & & & & target & actual & & target & actual & before & after & before & after & & before & after & duration & temperature & & Notes \\
\hline & & & & $\mathrm{Pa}_{\mathrm{a}}$ & $\mathrm{Pa}$ & $\mathrm{Pa}$ & ${ }^{\circ} \mathrm{C}$ & $o C$ & $\mathrm{mg}$ & $\mathrm{mg}$ & $\mathrm{hr}$ & $\mathrm{hr}$ & $s^{-1}$ & $\%$ & $\%$ & $h$ & ${ }^{\circ} \mathrm{C}$ & $\mathrm{mg}$ & \\
\hline 54 & 9 & $1 / 13 / 2014$ & WG1-13 & 50 & 49 & 0 & 1100 & 1100 & 467.205 & 465.372 & 20.09 & 22.89 & $3.89 E-07$ & 0.49 & 0.88 & 2 & 1200 & 0.16 & \\
\hline 55 & 10 & $1 / 14 / 2014$ & WG1-14 & 150 & 149 & 0 & 800 & 800 & 471.241 & 471.21 & 4.82 & 7.39 & $7.11 E-09$ & 0.18 & 0.19 & 2 & 1200 & 0.15 & \\
\hline 56 & 10 & $1 / 14 / 2014$ & WG1-14 & 150 & 150 & 0 & 850 & 850 & 471.156 & 471.062 & 7.67 & 10.43 & $2.01 E-08$ & 0.20 & 0.22 & 2 & 1200 & 0.15 & \\
\hline 57 & 10 & $1 / 14 / 2014$ & WG1-14 & 150 & 152 & 0 & 900 & 900 & 470.999 & 470.845 & 10.74 & 13.56 & $3.22 E-08$ & 0.23 & 0.26 & 2 & 1200 & 0.15 & \\
\hline 58 & 10 & $1 / 14 / 2014$ & WG1-14 & 150 & 155 & 0 & 950 & 950 & 470.771 & 470.485 & 13.84 & 16.60 & $6.11 E-08$ & 0.28 & 0.34 & 2 & 1200 & 0.15 & \\
\hline 59 & 10 & $1 / 14 / 2014$ & WG1-14 & 150 & 158 & 0 & 1000 & 1000 & 470.358 & 469.646 & 16.99 & 19.73 & $1.53 E-07$ & 0.37 & 0.52 & 2 & 1200 & 0.15 & \\
\hline 60 & 10 & $1 / 14 / 2014$ & WG1-14 & 150 & 160 & 0 & 1100 & 1100 & 469.237 & 465.093 & 20.09 & 22.86 & $8.86 E-07$ & 0.60 & 1.48 & 2 & 1200 & 0.15 & \\
\hline 61 & 11 & $1 / 15 / 2014$ & WG1-15 & 300 & 304 & 0 & 800 & 800 & 464.077 & 464.053 & 4.36 & 7.28 & $4.92 E-09$ & 0.19 & 0.19 & 2 & 1200 & 0.15 & \\
\hline 62 & 11 & $1 / 15 / 2014$ & WG1-15 & 300 & 306 & 0 & 850 & 850 & 463.994 & 463.914 & 7.75 & 10.45 & $1.77 E-08$ & 0.21 & 0.22 & 2 & 1200 & 0.15 & \\
\hline 63 & 11 & $1 / 15 / 2014$ & WG1-15 & 300 & 306 & 0 & 900 & 900 & 463.846 & 463.726 & 10.89 & 13.51 & $2.74 E-08$ & 0.24 & 0.26 & 2 & 1200 & 0.15 & \\
\hline 64 & 11 & $1 / 15 / 2014$ & WG1-15 & 300 & 310 & 0 & 950 & 950 & 463.648 & 463.337 & 13.84 & 16.60 & $6.75 E-08$ & 0.28 & 0.35 & 2 & 1200 & 0.15 & \\
\hline 65 & 11 & $1 / 15 / 2014$ & WG1-15 & 300 & 316 & 0 & 1000 & 1000 & 463.207 & 462.319 & 16.96 & 19.77 & $1.90 E-07$ & 0.37 & 0.57 & 2 & 1200 & 0.15 & \\
\hline 66 & 11 & $1 / 15 / 2014$ & WG1-15 & 300 & 327 & 0 & 1100 & 1100 & 461.341 & 456.033 & 20.37 & 22.88 & $1.27 \mathrm{E}-06$ & 0.78 & 1.92 & 2 & 1200 & 0.15 & \\
\hline 67 & 12 & $1 / 16 / 2014$ & WG1-16 & 100 & 101 & 0 & 800 & 800 & 468.502 & 468.471 & 4.60 & 7.34 & $6.71 E-09$ & 0.19 & 0.20 & 2 & 1200 & 0.16 & \\
\hline 68 & 12 & $1 / 16 / 2014$ & WG1-16 & 100 & 101 & 0 & 850 & 850 & 468.417 & 468.344 & 7.61 & 10.49 & $1.50 E-08$ & 0.21 & 0.22 & 2 & 1200 & 0.16 & \\
\hline 69 & 12 & $1 / 16 / 2014$ & WG1-16 & 100 & 61 & 0 & 900 & 900 & 468.286 & 468.177 & 10.74 & 13.56 & $2.29 E-08$ & 0.24 & 0.26 & 2 & 1200 & 0.16 & \\
\hline 70 & 12 & $1 / 16 / 2014$ & WG1-16 & 100 & 60 & 0 & 950 & 950 & 468.109 & 467.901 & 13.81 & 16.63 & 4.38E- 08 & 0.28 & 0.32 & 2 & 1200 & 0.16 & \\
\hline 71 & 12 & $1 / 16 / 2014$ & WG1-16 & 100 & 60 & 0 & 1000 & 1000 & 467.825 & 467.375 & 16.86 & 19.73 & $9.31 E-08$ & 0.34 & 0.43 & 2 & 1200 & 0.16 & \\
\hline 72 & 12 & $1 / 16 / 2014$ & WG1-16 & 100 & 60 & 0 & 1100 & 1100 & 467.09 & 465.026 & 20.12 & 22.91 & 4.40E- -07 & 0.49 & 0.93 & 2 & 1200 & 0.16 & \\
\hline 73 & 13 & $1 / 21 / 2014$ & AG3-1 & so & 51 & 0 & 800 & 800 & 437.532 & 437.501 & 4.82 & 7.39 & $7.66 \mathrm{E}-09$ & 0.22 & 0.23 & 2 & 1200 & 0.19 & \\
\hline 74 & 13 & $1 / 21 / 2014$ & AG3-1 & 50 & 51 & 0 & 850 & 850 & 437.447 & 437.384 & 7.73 & 10.52 & $1.43 E-08$ & 0.24 & 0.25 & 2 & 1200 & 0.19 & \\
\hline 75 & 13 & $1 / 21 / 2014$ & AG3-1 & 50 & 51 & 0 & 900 & 900 & 437.327 & 437.226 & 10.77 & 13.56 & $2.30 E-08$ & 0.27 & 0.29 & 2 & 1200 & 0.19 & \\
\hline 76 & 13 & $1 / 21 / 2014$ & AG3-1 & 50 & 51 & 0 & 950 & 950 & 437.166 & 436.967 & 13.76 & 16.63 & $4.41 E-08$ & 0.30 & 0.35 & 2 & 1200 & 0.19 & \\
\hline 77 & 13 & $1 / 21 / 2014$ & AG3-1 & 50 & 51 & 0 & 1000 & 1000 & 436.877 & 436.445 & 16.94 & 19.70 & 9.95E-08 & 0.37 & 0.47 & 2 & 1200 & 0.19 & \\
\hline 78 & 13 & $1 / 21 / 2014$ & AG3-1 & 50 & 50 & 0 & 1100 & 1100 & 436.103 & 434.047 & 20.21 & 22.91 & 4.85E- -07 & 0.54 & 1.01 & 2 & 1200 & 0.19 & \\
\hline 79 & 14 & $1 / 22 / 2014$ & AG3-2 & 30 & 31 & 0 & 800 & 800 & 461.685 & 461.629 & 4.79 & 7.47 & $1.26 E-08$ & 0.18 & 0.19 & 2 & 1200 & 0.13 & \\
\hline 80 & 14 & $1 / 22 / 2014$ & AG3-2 & 30 & 32 & 0 & 850 & 850 & 461.578 & 461.513 & 7.70 & 10.52 & $1.39 E-08$ & 0.20 & 0.22 & 2 & 1200 & 0.13 & \\
\hline 81 & 14 & $1 / 22 / 2014$ & AG3-2 & 30 & 32 & 0 & 900 & 900 & 461.436 & 461.355 & 10.80 & 13.56 & $1.77 E-08$ & 0.23 & 0.25 & 2 & 1200 & 0.13 & \\
\hline 82 & 14 & $1 / 22 / 2014$ & AG3-2 & 30 & 31 & 0 & 950 & 950 & 461.296 & 461.113 & 13.76 & 16.69 & $3.76 E-08$ & 0.26 & 0.30 & 2 & 1200 & 0.13 & \\
\hline 83 & 14 & $1 / 22 / 2014$ & AG3-2 & 30 & 32 & 0 & 1000 & 1000 & 461.038 & 460.649 & 16.91 & 19.76 & $8.22 E-08$ & 0.32 & 0.40 & 2 & 1200 & 0.13 & \\
\hline 84 & 14 & $1 / 22 / 2014$ & AG3-2 & 30 & 32 & 0 & 1100 & 1100 & 460.432 & 458.989 & 20.07 & 22.91 & $3.07 E-07$ & 0.45 & 0.76 & 2 & 1200 & 0.13 & \\
\hline 85 & 15 & $1 / 23 / 2014$ & AG3-3 & 15 & 16 & 0 & 800 & 800 & 464.874 & 464.831 & 4.61 & 7.34 & $9.41 E-09$ & 0.18 & 0.19 & 2 & 1200 & 0.13 & \\
\hline 86 & 15 & $1 / 23 / 2014$ & AG3-3 & 15 & 16 & 0 & 850 & 850 & 464.774 & 464.714 & 7.71 & 10.56 & $1.26 E-08$ & 0.20 & 0.21 & 2 & 1200 & 0.13 & \\
\hline 87 & 15 & $1 / 23 / 2014$ & AG3-3 & 15 & 16 & 0 & 900 & 900 & 464.659 & 464.573 & 10.77 & 13.59 & $1.82 E-08$ & 0.22 & 0.24 & 2 & 1200 & 0.13 & \\
\hline 88 & 15 & $1 / 23 / 2014$ & AG3-3 & 15 & 16 & 0 & 950 & 950 & 464.511 & 464.381 & 13.86 & 16.68 & $2.76 E-08$ & 0.26 & 0.28 & 2 & 1200 & 0.13 & \\
\hline 89 & 15 & $1 / 23 / 2014$ & AG3-3 & 15 & 16 & 0 & 1000 & 1000 & 464.311 & 464.053 & 16.91 & 19.70 & $5.53 E-08$ & 0.30 & 0.35 & 2 & 1200 & 0.13 & \\
\hline 90 & 15 & $1 / 23 / 2014$ & AG3-3 & 15 & 16 & 0 & 1100 & 1100 & 463.865 & 463.312 & 20.10 & 22.16 & $1.61 E-07$ & 0.39 & 0.51 & 2 & 1200 & 0.13 & \\
\hline 91 & 16 & $1 / 24 / 2014$ & AG3-4 & 100 & 102 & 0 & 800 & 800 & 469.193 & 469.17 & 5.49 & 7.39 & $7.17 \varepsilon-09$ & 0.18 & 0.19 & 2 & 1200 & 0.12 & \\
\hline 92 & 16 & $1 / 24 / 2014$ & AG3-4 & 100 & 102 & 0 & 850 & 850 & 469.117 & 469.058 & 7.76 & 10.52 & $1.27 \varepsilon-08$ & 0.20 & 0.21 & 2 & 1200 & 0.12 & \\
\hline 93 & 16 & $1 / 24 / 2014$ & AG3-4 & 100 & 102 & 0 & 900 & 900 & 468.994 & 468.883 & 10.91 & 13.56 & $2.48 E-08$ & 0.23 & 0.25 & 2 & 1200 & 0.12 & \\
\hline 94 & 16 & $1 / 24 / 2014$ & AG3-4 & 100 & 102 & 0 & 950 & 950 & 468.812 & 468.577 & 13.87 & 16.69 & 4.94E- 08 & 0.26 & 0.31 & 2 & 1200 & 0.12 & \\
\hline 95 & 16 & $1 / 24 / 2014$ & AG3-4 & 100 & 102 & 0 & 1000 & 1000 & 468.489 & 467.919 & 16.91 & 19.76 & 1.19E- -07 & 0.33 & 0.45 & 2 & 1200 & 0.12 & \\
\hline 96 & 16 & $1 / 24 / 2014$ & AG3-4 & 100 & 101 & 0 & 1100 & 1100 & 467.573 & 464.765 & 20.12 & 22.89 & $6.02 E-07$ & 0.53 & 1.12 & 2 & 1200 & 0.12 & \\
\hline 97 & 17 & $1 / 27 / 2014$ & AG3-5 & 300 & 299 & 0 & 800 & 800 & 453.06 & 453.005 & 4.77 & 7.38 & $1.29 E-08$ & 0.20 & 0.22 & 2 & 1200 & 0.20 & \\
\hline 98 & 17 & $1 / 27 / 2014$ & AG3-5 & 300 & 302 & 0 & 850 & 850 & 452.941 & 452.858 & 7.86 & 10.44 & $1.97 E-08$ & 0.23 & 0.25 & 2 & 1200 & 0.20 & \\
\hline 99 & 17 & $1 / 27 / 2014$ & AG3-5 & 300 & 303 & 0 & 900 & 900 & 452.797 & 452.651 & 10.74 & 13.55 & $3.19 E-08$ & 0.26 & 0.29 & 2 & 1200 & 0.20 & \\
\hline 100 & 17 & $1 / 27 / 2014$ & AG3-5 & 300 & 306 & 0 & 950 & 950 & 452.579 & 452.211 & 13.80 & 16.67 & $7.87 E-08$ & 0.31 & 0.39 & 2 & 1200 & 0.20 & \\
\hline 101 & 17 & $1 / 27 / 2014$ & AG3-5 & 300 & 308 & 0 & 1000 & 1000 & 452.083 & 450.983 & 16.94 & 19.78 & $2.38 E-07$ & 0.42 & 0.66 & 2 & 1200 & 0.20 & \\
\hline 102 & 17 & $1 / 27 / 2014$ & AG3-5 & 300 & 310 & 0 & 1100 & 1100 & 450.657 & 442.425 & 19.98 & 22.86 & $1.76 E-06$ & 0.73 & 2.55 & 2 & 1200 & 0.20 & \\
\hline 103 & 18 & $1 / 28 / 2014$ & AG3-6 & 150 & 150 & 0 & 800 & 800 & 463.513 & 463.468 & 4.63 & 7.39 & $9.77 E-09$ & 0.19 & 0.20 & 2 & 1200 & 0.15 & \\
\hline 104 & 18 & $1 / 28 / 2014$ & AG3-6 & 150 & 150 & 0 & 850 & 850 & 463.416 & 463.346 & 7.61 & 10.46 & $1.47 E-08$ & 0.21 & 0.22 & 2 & 1200 & 0.15 & \\
\hline 105 & 18 & $1 / 28 / 2014$ & AG3-6 & 150 & 151 & 0 & 900 & 900 & 463.289 & 463.175 & 10.74 & 13.51 & $2.47 E-08$ & 0.23 & 0.26 & 2 & 1200 & 0.15 & \\
\hline 106 & 18 & $1 / 28 / 2014$ & AG3-6 & 150 & 151 & 0 & 950 & 950 & 463.107 & 462.841 & 13.78 & 16.66 & $5.54 E-08$ & 0.27 & 0.33 & 2 & 1200 & 0.15 & \\
\hline
\end{tabular}




\begin{tabular}{|c|c|c|c|c|c|c|c|c|c|c|c|c|c|c|c|c|c|c|c|}
\hline \multirow{3}{*}{$\begin{array}{l}\text { Test Data } \\
\text { Number }\end{array}$} & \multirow{3}{*}{$\begin{array}{c}\text { Day } \\
\text { Number }\end{array}$} & \multirow{3}{*}{ Test Date } & \multirow{3}{*}{ Specimen ID } & \multicolumn{2}{|c|}{ Water Pressure } & \multirow{2}{*}{$\begin{array}{c}\text { H2 } \\
\text { Pressure }\end{array}$} & \multicolumn{2}{|c|}{ Temperature } & \multicolumn{2}{|c|}{ Weight } & \multicolumn{2}{|c|}{ Time in the Test } & \multirow{2}{*}{$\begin{array}{l}\text { Oxidation } \\
\text { Rate }\end{array}$} & \multicolumn{2}{|c|}{ Burn off $\%$} & Sample & reparaton & Weight Loss on & \\
\hline & & & & target & actual & & target & actual & before & after & before & after & & before & after & duration & temperature & & Notes \\
\hline & & & & $\mathrm{Pa}_{\mathrm{a}}$ & $\mathrm{Pa}$ & $\mathrm{Pa}$ & ${ }^{\circ} \mathrm{C}$ & $o C$ & $\mathrm{mg}$ & $\mathrm{mg}$ & $\mathrm{hr}$ & $\mathrm{hr}$ & $s^{-1}$ & $\%$ & $\%$ & $h$ & ${ }^{\circ} \mathrm{C}$ & $\mathrm{mg}$ & \\
\hline 107 & 18 & $1 / 28 / 2014$ & AG3-6 & 150 & 151 & 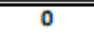 & 1000 & 1000 & 4462.763 & 462.042 & 16.83 & 19.81 & $\begin{array}{l}1.45 E-07 \\
\end{array}$ & 0.35 & 0.50 & 2 & 1200 & 0.15 & \\
\hline 108 & 18 & $1 / 28 / 2014$ & AG3-6 & 150 & 151 & 0 & 1100 & 1100 & 461.647 & 457.782 & 20.12 & 22.91 & $8.34 E-07$ & 0.59 & 1.42 & 2 & 1200 & 0.15 & \\
\hline 109 & 19 & $2 / 5 / 2014$ & AG3-7 & 300 & 305 & 0 & 800 & 800 & 463.67 & 463.623 & 4.33 & 7.34 & $9.35 E-09$ & 0.20 & 0.21 & 2 & 1200 & 0.16 & \\
\hline 110 & 19 & $2 / 5 / 2014$ & AG3-7 & 300 & 306 & 0 & 850 & 850 & 463.565 & 463.484 & 7.67 & 10.43 & $1.76 E-08$ & 0.22 & 0.24 & 2 & 1200 & 0.16 & \\
\hline 111 & 19 & $2 / 5 / 2014$ & AG3-7 & 300 & 306 & 0 & 900 & 900 & 463.42 & 463.286 & 10.81 & 13.54 & $2.94 E-08$ & 0.25 & 0.28 & 2 & 1200 & 0.16 & \\
\hline 112 & 19 & $2 / 5 / 2014$ & AG3-7 & 300 & 306 & 0 & 950 & 950 & 463.206 & 462.891 & 13.87 & 16.63 & $6.84 E-08$ & 0.30 & 0.36 & 2 & 1200 & 0.16 & \\
\hline 113 & 19 & $2 / 5 / 2014$ & AG3-7 & 300 & 305 & 0 & 1000 & 1000 & 462.783 & 461.878 & 16.90 & 19.79 & $1.88 E-07$ & 0.39 & 0.58 & 2 & 1200 & 0.16 & \\
\hline 114 & 19 & $2 / 5 / 2014$ & AG3-7 & 300 & 307 & 0 & 1100 & 1100 & 461.696 & 455.617 & 19.93 & 22.77 & $1.29 E-06$ & 0.62 & 1.93 & 2 & 1200 & 0.16 & \\
\hline 115 & 20 & $2 / 6 / 2014$ & AG3-8 & 150 & 150 & 0 & 800 & 800 & 461.912 & 461.838 & 4.88 & 7.34 & $1.81 E-08$ & 0.20 & 0.22 & 2 & 1200 & 0.20 & \\
\hline 116 & 20 & $2 / 6 / 2014$ & AG3-8 & 150 & 152 & 0 & 850 & 850 & 461.778 & 461.666 & 7.70 & 10.46 & $2.44 E-08$ & 0.23 & 0.25 & 2 & 1200 & 0.20 & \\
\hline 117 & 20 & $2 / 6 / 2014$ & AG3-8 & 150 & 151 & 0 & 900 & 900 & 461.601 & 461.432 & 10.77 & 13.56 & $3.65 E-08$ & 0.27 & 0.30 & 2 & 1200 & 0.20 & \\
\hline 118 & 20 & $2 / 6 / 2014$ & AG3-8 & 150 & 152 & 0 & 950 & 950 & 461.353 & 461.04 & 13.87 & 16.60 & $6.90 E-08$ & 0.32 & 0.39 & 2 & 1200 & 0.20 & \\
\hline 119 & 20 & $2 / 6 / 2014$ & AG3-8 & 150 & 151 & 0 & 1000 & 1000 & 460.937 & 460.182 & 16.88 & 19.68 & $1.62 E-07$ & 0.41 & 0.57 & 2 & 1200 & 0.20 & \\
\hline 120 & 20 & $2 / 6 / 2014$ & AG3-8 & 150 & 152 & 0 & 1100 & 1100 & 459.642 & 455.378 & 20.18 & 22.91 & $9.44 E-07$ & 0.69 & 1.61 & 2 & 1200 & 0.20 & \\
\hline 121 & 21 & $2 / 10 / 2014$ & AG3-9 & 15 & 15 & 0 & 800 & 800 & 460.261 & 460.211 & 5.35 & 7.34 & $1.52 E-08$ & 0.25 & 0.26 & 2 & 1200 & 0.32 & \\
\hline 122 & 21 & $2 / 10 / 2014$ & AG3-9 & 15 & 15 & 0 & 850 & 850 & 460.149 & 460.049 & 7.70 & 10.52 & $2.14 E-08$ & 0.27 & 0.29 & 2 & 1200 & 0.32 & \\
\hline 123 & 21 & $2 / 10 / 2014$ & AG3-9 & 15 & 15 & 0 & 900 & 900 & 459.986 & 459.846 & 10.80 & 13.53 & $3.10 E-08$ & 0.31 & 0.34 & 2 & 1200 & 0.32 & \\
\hline 124 & 21 & $2 / 10 / 2014$ & AG3-9 & 15 & 15 & 0 & 950 & 950 & 459.777 & 459.533 & 13.78 & 16.74 & 4.98E-08 & 0.35 & 0.40 & 2 & 1200 & 0.32 & \\
\hline 125 & 21 & $2 / 10 / 2014$ & AG3-9 & 15 & 15 & 0 & 1000 & 1000 & 459.462 & 459.092 & 16.97 & 19.73 & $8.10 E-08$ & 0.42 & 0.50 & 2 & 1200 & 0.32 & \\
\hline 126 & 21 & $2 / 10 / 2014$ & AG3-9 & 15 & 15 & 0 & 1100 & 1100 & 458.882 & 457.906 & 20.09 & 22.89 & $2.11 E-07$ & 0.55 & 0.76 & 2 & 1200 & 0.32 & \\
\hline 127 & 22 & $2 / 11 / 2014$ & AG3-10 & 30 & 31 & 0 & 800 & 800 & 462.401 & 462.351 & 4.52 & 7.31 & $1.08 E-08$ & 0.18 & 0.19 & 2 & 1200 & 0.14 & \\
\hline 128 & 22 & $2 / 11 / 2014$ & AG3-10 & 30 & 31 & 0 & 850 & 850 & 462.288 & 462.166 & 7.76 & 10.49 & $2.69 E-08$ & 0.20 & 0.23 & 2 & 1200 & 0.14 & \\
\hline 129 & 22 & $2 / 11 / 2014$ & AG3-10 & 30 & 31 & 0 & 900 & 900 & 462.106 & 461.963 & 10.77 & 13.56 & $3.08 E-08$ & 0.24 & 0.27 & 2 & 1200 & 0.14 & \\
\hline 130 & 22 & $2 / 11 / 2014$ & AG3-10 & 30 & 31 & 0 & 950 & 950 & 461.896 & 461.687 & 13.81 & 16.69 & $4.36 E-08$ & 0.29 & 0.33 & 2 & 1200 & 0.14 & \\
\hline 131 & 22 & $2 / 11 / 2014$ & AG3-10 & 30 & 31 & 0 & 1000 & 1000 & 461.613 & 461.259 & 16.88 & 19.76 & $7.40 E-08$ & 0.35 & 0.42 & 2 & 1200 & 0.14 & \\
\hline 132 & 22 & $2 / 11 / 2014$ & AG3-10 & 30 & 31 & 0 & 1100 & 1100 & 461.047 & 459.807 & 20.09 & 22.94 & $2.62 E-07$ & 0.47 & 0.74 & 2 & 1200 & 0.14 & \\
\hline 133 & 23 & $2 / 14 / 2014$ & AG3-11 & 50 & 51 & 0 & 800 & 800 & 463.228 & 463.159 & 4.77 & 7.42 & $1.56 E-08$ & 0.22 & 0.23 & 2 & 1200 & 0.20 & \\
\hline 134 & 23 & $2 / 14 / 2014$ & AG3-11 & 50 & 51 & 0 & 850 & 850 & 463.099 & 463.003 & 7.76 & 10.41 & $2.17 E-08$ & 0.24 & 0.26 & 2 & 1200 & 0.20 & \\
\hline 135 & 23 & $2 / 14 / 2014$ & $A G 3-11$ & 50 & 51 & 0 & 900 & 900 & 462.932 & 462.8 & 10.88 & 13.51 & $3.01 E-08$ & 0.28 & 0.31 & 2 & 1200 & 0.20 & \\
\hline 136 & 23 & $2 / 14 / 2014$ & AG3-11 & 50 & 50 & 0 & 950 & 950 & 462.723 & 462.472 & 13.84 & 16.60 & $5.46 E-08$ & 0.33 & 0.38 & 2 & 1200 & 0.20 & \\
\hline 137 & 23 & $2 / 14 / 2014$ & AG3-11 & 50 & 48 & 0 & 1000 & 1000 & 462.379 & 461.866 & 16.88 & 19.68 & $1.10 E-07$ & 0.40 & 0.51 & 2 & 1200 & 0.20 & \\
\hline 138 & 23 & $2 / 14 / 2014$ & AG3-11 & 50 & 50 & 0 & 1100 & 1100 & 461.565 & 459.353 & 20.09 & 22.91 & $4.72 E-07$ & 0.57 & 1.05 & 2 & 1200 & 0.20 & \\
\hline 139 & 24 & $2 / 15 / 2014$ & AG3-12 & 100 & 105 & 0 & 800 & 800 & 456.892 & 456.821 & 4.24 & 7.39 & $1.37 E-08$ & 0.19 & 0.21 & 2 & 1200 & 0.20 & \\
\hline 140 & 24 & $2 / 15 / 2014$ & AG3-12 & 100 & 102 & 0 & 850 & 850 & 456.767 & 456.665 & 7.64 & 10.49 & $2.18 E-08$ & 0.22 & 0.24 & 2 & 1200 & 0.20 & \\
\hline 141 & 24 & $2 / 15 / 2014$ & AG3-12 & 100 & 102 & 0 & 900 & 900 & 456.603 & 456.445 & 10.74 & 13.62 & $3.34 E-08$ & 0.26 & 0.29 & 2 & 1200 & 0.20 & \\
\hline 142 & 24 & $2 / 15 / 2014$ & AG3-12 & 100 & 102 & 0 & 950 & 950 & 456.373 & 456.093 & 13.84 & 16.69 & 5.98E-08 & 0.31 & 0.37 & 2 & 1200 & 0.20 & \\
\hline 143 & 24 & $2 / 15 / 2014$ & AG3-12 & 100 & 102 & 0 & 1000 & 1000 & 455.999 & 455.387 & 16.91 & 19.68 & $1.35 E-07$ & 0.39 & 0.52 & 2 & 1200 & 0.20 & \\
\hline 144 & 24 & $2 / 15 / 2014$ & AG3-12 & 100 & 101 & 0 & 1100 & 1100 & 454.91 & 451.662 & 20.21 & 22.94 & $7.26 E-07$ & 0.63 & 1.34 & 2 & 1200 & 0.20 & \\
\hline 145 & 25 & $2 / 16 / 2014$ & AG3-13 & 3 & 3 & 0 & 800 & 800 & 441.532 & 441.472 & 4.04 & 7.39 & $1.13 E-08$ & 0.22 & 0.23 & 2 & 1200 & 0.15 & \\
\hline 146 & 25 & $2 / 16 / 2014$ & AG3-13 & 3 & 3 & 0 & 850 & 850 & 441.414 & 441.273 & 7.61 & 10.49 & $3.08 E-08$ & 0.25 & 0.28 & 2 & 1200 & 0.15 & \\
\hline 147 & 25 & $2 / 16 / 2014$ & AG3-13 & 3 & 3 & 0 & 900 & 900 & 441.207 & 441.06 & 10.74 & 13.56 & $3.28 E-08$ & 0.29 & 0.33 & 2 & 1200 & 0.15 & \\
\hline 148 & 25 & $2 / 16 / 2014$ & AG3-13 & 3 & 3 & 0 & 950 & 950 & 440.988 & 440.848 & 13.87 & 16.63 & $3.20 E-08$ & 0.34 & 0.37 & 2 & 1200 & 0.15 & \\
\hline 149 & 25 & $2 / 16 / 2014$ & AG3-13 & 3 & 3 & 0 & 1000 & 1000 & 440.774 & 440.6 & 16.94 & 19.76 & $3.89 E-08$ & 0.39 & 0.43 & 2 & 1200 & 0.15 & \\
\hline 150 & 25 & $2 / 16 / 2014$ & AG3-13 & 3 & 3 & 0 & 1100 & 1100 & 440.452 & 440.148 & 20.07 & 22.94 & $6.68 E-08$ & 0.46 & 0.53 & 2 & 1200 & 0.15 & \\
\hline 151 & 26 & $2 / 17 / 2014$ & AG3-14 & 3 & 3 & 0 & 800 & 800 & 464.54 & 464.468 & 4.07 & 7.36 & $1.31 E-08$ & 0.18 & 0.20 & 2 & 1200 & 0.15 & \\
\hline 152 & 26 & $2 / 17 / 2014$ & AG3-14 & 3 & 3 & 0 & 850 & 850 & 464.406 & 464.291 & 7.70 & 10.52 & $2.44 E-08$ & 0.21 & 0.24 & 2 & 1200 & 0.15 & \\
\hline 153 & 26 & $2 / 17 / 2014$ & AG3-14 & 3 & 3 & 0 & 900 & 900 & 464.24 & 464.096 & 10.71 & 13.64 & $2.94 E-08$ & 0.25 & 0.28 & 2 & 1200 & 0.15 & \\
\hline 154 & 26 & $2 / 17 / 2014$ & AG3-14 & 3 & 3 & 0 & 950 & 950 & 464.033 & 463.873 & 13.81 & 16.57 & $3.47 E-08$ & 0.29 & 0.32 & 2 & 1200 & 0.15 & \\
\hline 155 & 26 & $2 / 17 / 2014$ & AG3-14 & 3 & 3 & 0 & 1000 & 1000 & 463.795 & 463.636 & 16.91 & 19.65 & $3.48 E-08$ & 0.34 & 0.38 & 2 & 1200 & 0.15 & \\
\hline 156 & 26 & $2 / 17 / 2014$ & AG3-14 & 3 & 3 & 0 & 1100 & 1100 & 463.477 & 463.178 & 20.07 & 22.89 & $6.35 E-08$ & 0.41 & 0.47 & 2 & 1200 & 0.15 & \\
\hline 157 & 27 & $3 / 31 / 2014$ & AG3-22 & 15 & 24 & 0 & 800 & 800 & 454.981 & 454.911 & 4.68 & 7.42 & $1.56 E-08$ & 0.22 & 0.23 & 2 & 1200 & 0.21 & \\
\hline 158 & 27 & $3 / 31 / 2014$ & AG3-22 & 15 & 23 & 0 & 850 & 850 & 454.85 & 454.772 & 7.73 & 10.49 & $1.73 E-08$ & 0.25 & 0.27 & 2 & 1200 & 0.21 & \\
\hline 159 & 27 & $3 / 31 / 2014$ & AG3-22 & 15 & 22 & 0 & 900 & 900 & 454.707 & 454.595 & 10.88 & 13.62 & $2.50 E-08$ & 0.28 & 0.30 & 2 & 1200 & 0.21 & \\
\hline
\end{tabular}




\begin{tabular}{|c|c|c|c|c|c|c|c|c|c|c|c|c|c|c|c|c|c|c|c|}
\hline \multirow{3}{*}{$\begin{array}{l}\text { Test Data } \\
\text { Number }\end{array}$} & \multirow{3}{*}{$\begin{array}{c}\text { Day } \\
\text { Number }\end{array}$} & \multirow{3}{*}{ Test Date } & \multirow{3}{*}{ Specimen ID } & \multicolumn{2}{|c|}{ Water Pressure } & \multirow{2}{*}{$\begin{array}{c}\text { H2 } \\
\text { Pressure }\end{array}$} & \multicolumn{2}{|c|}{ Temperature } & \multicolumn{2}{|c|}{ Weight } & \multicolumn{2}{|c|}{ Time in the Test } & \multirow{2}{*}{$\begin{array}{l}\text { Oxidation } \\
\text { Rate }\end{array}$} & \multicolumn{2}{|c|}{ Burn off $\%$} & Sample & reparaton & Weight Loss on & \\
\hline & & & & target & actual & & target & actual & before & after & before & after & & before & after & duration & temperature & & Notes \\
\hline & & & & $\mathrm{Pa}$ & $\mathrm{Pa}$ & $\mathrm{Pa}$ & ${ }^{\circ} \mathrm{C}$ & $o C$ & $\mathrm{mg}$ & $\mathrm{mg}$ & $\mathrm{hr}$ & $\mathrm{hr}$ & $s^{-1}$ & $\%$ & $\%$ & $h$ & ${ }^{\circ} \mathrm{C}$ & $\mathrm{mg}$ & \\
\hline 160 & 27 & $3 / 31 / 2014$ & AG3-22 & 15 & $\overline{221}$ & 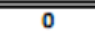 & 950 & 9950 & 4454.524 & $4 \quad 454.33$ & $\begin{array}{l}13.87 \\
\end{array}$ & 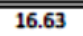 & $4 \quad 4.30 E-08$ & 0.32 & 0.36 & $\overline{2 \overline{2}}$ & 1200 & 0.21 & \\
\hline 161 & 27 & $3 / 31 / 2014$ & AG3-22 & 15 & 22 & 0 & 1000 & 1000 & 454.249 & 453.891 & 16.88 & 19.76 & $7.60 E-08$ & 0.38 & 0.46 & 2 & 1200 & 0.21 & \\
\hline 162 & 27 & $3 / 31 / 2014$ & AG3-22 & 15 & 8 & 0 & 1100 & 1100 & 453.658 & 453.042 & 20.12 & 22.91 & $1.35 E-07$ & 0.51 & 0.64 & 2 & 1200 & 0.21 & \\
\hline 164 & 28 & $3 / 5 / 2014$ & AG3-15 & 30 & 15 & 26 & 850 & 850 & 462.701 & 462.703 & 7.78 & 10.43 & $-4.53 E-10$ & 0.19 & 0.19 & 2 & 1200 & 0.16 & \\
\hline 165 & 28 & $3 / 5 / 2014$ & AG3-15 & 30 & 15 & 26 & 900 & 900 & 462.652 & 462.639 & 10.85 & 13.56 & $2.88 E-09$ & 0.20 & 0.20 & 2 & 1200 & 0.16 & \\
\hline 166 & 28 & $3 / 5 / 2014$ & AG3-15 & 30 & 15 & 26 & 950 & 950 & 462.584 & 462.555 & 13.87 & 16.60 & $6.38 E-09$ & 0.21 & 0.22 & 2 & 1200 & 0.16 & \\
\hline 167 & 28 & $3 / 5 / 2014$ & AG3-15 & 30 & 15 & 26 & 1000 & 1000 & 462.494 & 462.419 & 16.97 & 19.68 & $1.66 \mathrm{E}-08$ & 0.23 & 0.25 & 2 & 1200 & 0.16 & \\
\hline 168 & 28 & $3 / 5 / 2014$ & AG3-15 & 30 & 15 & 26 & 1100 & 1100 & 462.271 & 461.95 & 20.12 & 22.83 & $7.12 E-08$ & 0.28 & 0.35 & 2 & 1200 & 0.16 & \\
\hline 172 & 29 & $3 / 6 / 2014$ & AG3-16 & 30 & 29 & 26 & 950 & 950 & 470.614 & 470.576 & 13.98 & 16.63 & $8.46 E-09$ & 0.20 & 0.21 & 2 & 1200 & 0.12 & \\
\hline 173 & 29 & $3 / 6 / 2014$ & AG3-16 & 30 & 29 & 26 & 1000 & 1000 & 470.51 & 470.406 & 16.99 & 19.76 & $2.22 E-08$ & 0.22 & 0.25 & 2 & 1200 & 0.12 & \\
\hline 174 & 29 & $3 / 6 / 2014$ & AG3-16 & 30 & 29 & 26 & 1100 & 1100 & 470.222 & 469.564 & 20.07 & 22.94 & $1.35 E-07$ & 0.29 & 0.42 & 2 & 1200 & 0.12 & \\
\hline 176 & 30 & $3 / 7 / 2014$ & AG3-17 & so & 52 & 26 & 850 & 850 & 466.444 & 466.438 & 7.70 & 10.55 & $1.25 E-09$ & 0.19 & 0.19 & 2 & 1200 & 0.15 & \\
\hline 177 & 30 & $3 / 7 / 2014$ & AG3-17 & 50 & 51 & 26 & 900 & 900 & 466.385 & 466.35 & 10.77 & 13.51 & $7.61 E-09$ & 0.21 & 0.21 & 2 & 1200 & 0.15 & \\
\hline 178 & 30 & $3 / 7 / 2014$ & AG3-17 & 50 & 51 & 26 & 950 & 950 & 466.29 & 466.215 & 13.84 & 16.69 & $1.57 E-08$ & 0.23 & 0.24 & 2 & 1200 & 0.15 & \\
\hline 179 & 30 & $3 / 7 / 2014$ & AG3-17 & 50 & 51 & 26 & 1000 & 1000 & 466.148 & 465.958 & 16.91 & 19.76 & $3.97 E-08$ & 0.26 & 0.30 & 2 & 1200 & 0.15 & \\
\hline 180 & 30 & $3 / 7 / 2014$ & AG3-17 & 50 & 51 & 26 & 1100 & 1100 & 465.767 & 464.757 & 20.09 & 22.84 & $2.19 \mathrm{E}-07$ & 0.34 & 0.55 & 2 & 1200 & 0.15 & \\
\hline 182 & 31 & $3 / 14 / 2014$ & AG3-19 & 100 & 100 & 26 & 850 & 850 & 459.711 & 459.703 & 7.87 & 10.52 & $1.82 \mathrm{E}-09$ & 0.21 & 0.21 & 2 & 1200 & 0.22 & \\
\hline 183 & 31 & $3 / 14 / 2014$ & AG3-19 & 100 & 100 & 26 & 900 & 900 & 459.652 & 459.639 & 10.77 & 13.51 & $2.87 E-09$ & 0.22 & 0.22 & 2 & 1200 & 0.22 & \\
\hline 184 & 31 & $3 / 14 / 2014$ & AG3-19 & 100 & 99 & 26 & 950 & 950 & 459.575 & 459.478 & 13.95 & 16.66 & $2.16 E-08$ & 0.24 & 0.26 & 2 & 1200 & 0.22 & \\
\hline 185 & 31 & $3 / 14 / 2014$ & AG3-19 & 100 & 99 & 26 & 1000 & 1000 & 459.401 & 459.086 & 16.94 & 19.73 & $6.83 E-08$ & 0.27 & 0.34 & 2 & 1200 & 0.22 & \\
\hline 186 & 31 & $3 / 14 / 2014$ & AG3-19 & 100 & 98 & 26 & 1100 & 1100 & 458.788 & 458.109 & 20.18 & 21.24 & 3.88E-07 & 0.41 & 0.55 & 2 & 1200 & 0.22 & \\
\hline 189 & 32 & $3 / 25 / 2014$ & AG3-20 & 150 & 152 & 26 & 900 & 900 & 452.222 & 452.195 & 10.74 & 13.51 & 5.99E- 09 & 0.25 & 0.26 & 2 & 1200 & 0.22 & \\
\hline 190 & 32 & $3 / 25 / 2014$ & AG3-20 & 150 & 151 & 26 & 950 & 950 & 452.137 & 451.999 & 13.78 & 16.69 & $2.91 E-08$ & 0.27 & 0.30 & 2 & 1200 & 0.22 & \\
\hline 191 & 32 & $3 / 25 / 2014$ & AG3-20 & 150 & 151 & 26 & 1000 & 1000 & 451.926 & 451.421 & 16.86 & 19.79 & $1.06 E-07$ & 0.32 & 0.43 & 2 & 1200 & 0.22 & \\
\hline 192 & 32 & $3 / 25 / 2014$ & AG3-20 & 150 & 151 & 26 & 1100 & 1100 & 451.018 & 447.52 & 20.15 & 23.00 & $7.56 E-07$ & 0.52 & 1.29 & 2 & 1200 & 0.22 & \\
\hline 195 & 33 & $4 / 1 / 2014$ & WG1-17 & 100 & 103 & 26 & 900 & 900 & 466.935 & 466.924 & 10.80 & 13.58 & 2. $35 E-09$ & 0.22 & 0.22 & 2 & 1200 & 0.17 & \\
\hline 196 & 33 & $4 / 1 / 2014$ & WG1-17 & 100 & 102 & 26 & 950 & 950 & 466.865 & 466.77 & 13.78 & 16.63 & $1.98 E-08$ & 0.23 & 0.25 & 2 & 1200 & 0.17 & \\
\hline 197 & 33 & $4 / 1 / 2014$ & WG1-17 & 100 & 103 & 26 & 1000 & 1000 & 466.697 & 466.318 & 16.88 & 19.73 & $7.92 E-08$ & 0.27 & 0.35 & 2 & 1200 & 0.17 & \\
\hline 198 & 33 & $4 / 1 / 2014$ & WG1-17 & 100 & 103 & 26 & 1100 & 1100 & 466.064 & 463.773 & 20.07 & 22.97 & $4.71 E-07$ & 0.41 & 0.90 & 2 & 1200 & 0.17 & \\
\hline 201 & 34 & $4 / 2 / 2014$ & WG1-18 & so & 51 & 26 & 900 & 900 & 463.309 & 463.301 & 10.71 & 13.59 & $1.67 E-09$ & 0.22 & 0.22 & 2 & 1200 & 0.18 & \\
\hline 202 & 34 & $4 / 2 / 2014$ & WG1-18 & 50 & 52 & 26 & 950 & 950 & 463.244 & 463.173 & 13.84 & 16.69 & $1.49 E-08$ & 0.23 & 0.25 & 2 & 1200 & 0.18 & \\
\hline 203 & 34 & $4 / 2 / 2014$ & WG1-18 & 50 & 52 & 26 & 1000 & 1000 & 463.103 & 462.838 & 16.91 & 19.79 & $5.52 E-08$ & 0.27 & 0.32 & 2 & 1200 & 0.18 & \\
\hline 204 & 34 & $4 / 2 / 2014$ & WG1-18 & 50 & 52 & 26 & 1100 & 1100 & 462.635 & 461.385 & 20.07 & 22.91 & $2.64 E-07$ & 0.37 & 0.64 & 2 & 1200 & 0.18 & \\
\hline 208 & 35 & $4 / 3 / 2014$ & WG1-19 & 30 & 30 & 26 & 950 & 950 & 463.009 & 462.969 & 13.82 & 16.64 & $8.51 E-09$ & 0.23 & 0.24 & 2 & 1200 & 0.17 & \\
\hline 210 & 35 & $4 / 3 / 2014$ & WG1-19 & 30 & 30 & 26 & 1100 & 1100 & 462.525 & 461.739 & 20.10 & 22.89 & $1.69 E-07$ & 0.33 & 0.50 & 2 & 1200 & 0.17 & \\
\hline 213 & 36 & $4 / 4 / 2014$ & WG1-20 & 150 & 150 & 26 & 900 & 900 & 464.163 & 464.149 & 10.85 & 13.56 & $3.09 E-09$ & 0.21 & 0.21 & 2 & 1200 & 0.15 & \\
\hline 214 & 36 & $4 / 4 / 2014$ & WG1-20 & 150 & 150 & 26 & 950 & 950 & 464.086 & 463.955 & 13.87 & 16.63 & $2.84 E-08$ & 0.23 & 0.26 & 2 & 1200 & 0.15 & \\
\hline 215 & 36 & $4 / 4 / 2014$ & WG1-20 & 150 & 150 & 26 & 1000 & 1000 & 463.875 & 463.425 & 16.88 & 19.59 & 9.94E-08 & 0.27 & 0.37 & 2 & 1200 & 0.15 & \\
\hline 216 & 36 & $4 / 4 / 2014$ & WG1-20 & 150 & 149 & 26 & 1100 & 1100 & 462.8 & 459.953 & 20.37 & 22.94 & $6.65 E-07$ & 0.50 & 1.12 & 2 & 1200 & 0.15 & \\
\hline 217 & 37 & $4 / 7 / 2014$ & WG1-21 & 300 & 303 & 26 & 800 & 800 & 464.971 & 464.961 & 5.13 & 7.39 & $2.64 E-09$ & 0.21 & 0.22 & 2 & 1200 & 0.19 & \\
\hline 218 & 37 & $4 / 7 / 2014$ & WG1-21 & 300 & 304 & 26 & 850 & 850 & 464.906 & 464.893 & 7.67 & 10.43 & $2.81 E-09$ & 0.23 & 0.23 & 2 & 1200 & 0.19 & \\
\hline 220 & 37 & $4 / 7 / 2014$ & WG1-21 & 300 & 289 & 26 & 950 & 950 & 464.763 & 464.589 & 13.84 & 16.72 & $3.61 \mathrm{E}-08$ & 0.26 & 0.30 & 2 & 1200 & 0.19 & \\
\hline 221 & 37 & $4 / 7 / 2014$ & WG1-21 & 300 & 284 & 26 & 1000 & 1000 & 464.502 & 463.907 & 16.91 & 19.73 & $1.26 E-07$ & 0.32 & 0.44 & 2 & 1200 & 0.19 & \\
\hline 222 & 37 & $4 / 7 / 2014$ & WG1-21 & 300 & 309 & 26 & 1100 & 1100 & 463.309 & 458.402 & 20.23 & 22.94 & $1.09 E-06$ & 0.57 & 1.62 & 2 & 1200 & 0.19 & \\
\hline 225 & 38 & $4 / 8 / 2014$ & WG1-22 & 15 & 8 & 26 & 950 & 950 & 456.228 & 456.222 & 13.87 & 16.60 & 1.34E- 09 & 0.24 & 0.24 & 2 & 1200 & 0.17 & \\
\hline 226 & 38 & $4 / 8 / 2014$ & WG1-22 & 15 & 8 & 26 & 1000 & 1000 & 456.161 & 456.086 & 16.97 & 19.81 & $1.61 E-08$ & 0.26 & 0.27 & 2 & 1200 & 0.17 & \\
\hline 227 & 38 & $4 / 8 / 2014$ & WG1-22 & 15 & 8 & 25 & 1100 & 1100 & 455.946 & 455.677 & 20.07 & 22.89 & $5.81 E-08$ & 0.30 & 0.36 & 2 & 1200 & 0.17 & \\
\hline 234 & 40 & $6 / 30 / 2014$ & WG1-24 & 500 & 475 & 0 & 850 & 850 & 463.864 & 463.718 & 3.99 & 6.77 & $3.14 E-08$ & 0.25 & 0.28 & 2 & 1200 & 0.25 & \\
\hline 235 & 40 & $6 / 30 / 2014$ & WG1-24 & 500 & 614 & 0 & 900 & 900 & 463.645 & 463.403 & 7.07 & 9.90 & $5.12 E-08$ & 0.30 & 0.35 & 2 & 1200 & 0.25 & \\
\hline 236 & 40 & $6 / 30 / 2014$ & WG1-24 & 500 & 520 & 0 & 950 & 950 & 463.316 & 462.816 & 10.12 & 12.93 & $1.07 E-07$ & 0.37 & 0.48 & 2 & 1200 & 0.25 & \\
\hline 237 & 40 & $6 / 30 / 2014$ & WG1-24 & 500 & 520 & 0 & 1000 & 1000 & 462.648 & 461.181 & 13.25 & 16.01 & 3.19E- 07 & 0.51 & 0.83 & 2 & 1200 & 0.25 & \\
\hline 238 & 40 & $6 / 30 / 2014$ & WG1-24 & 500 & 519 & 0 & 1050 & 1050 & 460.878 & 456.168 & 16.27 & 19.11 & $1.00 E-06$ & 0.89 & 1.91 & 2 & 1200 & 0.25 & \\
\hline 240 & 41 & $7 / 1 / 2014$ & WG1-25 & 1000 & 988 & 0 & 850 & 850 & 464.032 & 463.951 & 4.46 & 6.31 & $2.62 E-08$ & 0.25 & 0.27 & 2 & 1200 & 0.18 & \\
\hline
\end{tabular}




\begin{tabular}{|c|c|c|c|c|c|c|c|c|c|c|c|c|c|c|c|c|c|c|c|}
\hline \multirow{2}{*}{$\begin{array}{l}\text { Test Data } \\
\text { Number }\end{array}$} & \multirow{2}{*}{$\begin{array}{c}\text { Day } \\
\text { Number }\end{array}$} & \multirow{2}{*}{ Test Date } & \multirow[b]{2}{*}{ Specimen ID } & \multicolumn{2}{|c|}{ Water Pressure } & \multirow{2}{*}{$\begin{array}{c}\mathrm{H} 2 \\
\text { Pressure }\end{array}$} & \multicolumn{2}{|c|}{ Temperature } & \multicolumn{2}{|c|}{ Weight } & \multicolumn{2}{|c|}{ Time in the Test } & \multirow{2}{*}{$\begin{array}{l}\text { Oxidation } \\
\text { Rate }\end{array}$} & \multicolumn{2}{|c|}{ Burn off $\%$} & Sample & reparaton & Weight Loss on & \\
\hline & & & & target & actual & & target & actual & before & after & before & after & & before & after & $\begin{array}{l}\text { duration } \\
\end{array}$ & temperature & & Notes \\
\hline & & & & $\mathrm{Pa}$ & $\mathrm{Pa}$ & $\mathrm{Pa}$ & ${ }^{\circ} \mathrm{C}$ & $o C$ & $\mathrm{mg}$ & $\mathrm{mg}$ & $\mathrm{hr}$ & $\mathrm{hr}$ & $s^{-1}$ & $\%$ & $\%$ & $h$ & ${ }^{\circ} \mathrm{C}$ & $\mathrm{mg}$ & \\
\hline 241 & $4 \overline{41}$ & $7 / 1 / 2014$ & WG1-25 & 1000 & 712 & $=0$ & 900 & 9900 & $4 \quad 464.156$ & $\begin{array}{l}463.95 \\
\end{array}$ & $=7.58$ & 10.39 & $\begin{array}{l}4.395-08 \\
\end{array}$ & 0.22 & 0.27 & $\overline{22}$ & 1200 & 0.18 & \\
\hline 242 & 41 & $7 / 1 / 2014$ & WG1-25 & 1000 & 738 & 0 & 950 & 950 & 463.683 & 463.353 & 11.44 & 13.43 & $9.93 E-08$ & 0.33 & 0.40 & 2 & 1200 & 0.18 & \\
\hline 243 & 41 & $7 / 1 / 2014$ & WG1-25 & 1000 & 981 & 0 & 1000 & 1000 & 463.183 & 461.502 & 13.76 & 16.41 & $3.80 E-07$ & 0.43 & 0.79 & 2 & 1200 & 0.18 & \\
\hline 244 & 41 & $7 / 1 / 2014$ & WG1-25 & 1000 & 944 & 0 & 1050 & 1050 & 460.798 & 454.859 & 16.99 & 19.61 & $1.37 E-06$ & 0.95 & 2.22 & 2 & 1200 & 0.18 & \\
\hline 247 & 42 & $7 / 30 / 2014$ & WG1-27 & 100 & 95 & 0 & 850 & 850 & 466.431 & 466.355 & 4.17 & 8.00 & $1.18 E-08$ & 0.25 & 0.20 & 1 & 1200 & 0.26 & \\
\hline 248 & 42 & $7 / 30 / 2014$ & WG1-27 & 100 & 98 & 26 & 850 & 850 & 465.3 & 465.263 & 10.39 & 20.73 & $2.14 E-09$ & 0.49 & 0.50 & 1 & 1200 & 0.26 & \\
\hline 249 & 42 & $7 / 30 / 2014$ & WG1-27 & 100 & 96 & 22 & 850 & 850 & 465.253 & 465.137 & 21.64 & 26.02 & $1.58 E-08$ & 0.50 & 0.56 & 1 & 1200 & 0.26 & \\
\hline 250 & 42 & $7 / 30 / 2014$ & WG1-27 & 100 & 96 & 25 & 850 & 850 & 465.093 & 465.033 & 28.92 & 37.39 & $4.23 E-09$ & 0.54 & 0.55 & 1 & 1200 & 0.26 & \\
\hline 251 & 42 & $7 / 30 / 2014$ & WG1-27 & 100 & 93 & 0 & 850 & 850 & 465.014 & 464.769 & 38.64 & 48.00 & $1.56 E-08$ & 0.56 & 0.61 & 1 & 1200 & 0.26 & \\
\hline 252 & 43 & $8 / 6 / 2014$ & WG1-28 & 100 & 100 & 0 & 850 & 850 & 464.83 & 464.582 & 3.22 & 10.97 & $1.91 E-08$ & 0.26 & 0.31 & 2 & 1200 & 0.17 & \\
\hline 253 & 43 & $8 / 6 / 2014$ & WG1-28 & 100 & 100 & 25 & 850 & 850 & 464.511 & 464.435 & 12.35 & 21.41 & $5.02 E-09$ & 0.33 & 0.35 & 2 & 1200 & 0.17 & \\
\hline 254 & 43 & $8 / 6 / 2014$ & WG1-28 & 100 & 100 & 0 & 850 & 850 & 464.428 & 464.312 & 21.88 & 25.35 & $2.00 E-08$ & 0.35 & 0.37 & 2 & 1200 & 0.17 & \\
\hline 255 & 43 & $8 / 6 / 2014$ & WG1-28 & 100 & 99 & 26 & 850 & 850 & 464.3 & 464.229 & 25.78 & 33.22 & $5.71 E-09$ & 0.37 & 0.39 & 2 & 1200 & 0.17 & \\
\hline 256 & 44 & $8 / 8 / 2014$ & WG1-29 & 100 & 102 & 0 & 850 & 850 & 466.76 & 466.582 & 3.26 & 10.19 & $1.53 E-08$ & 0.22 & 0.26 & 1 & 1200 & 0.07 & \\
\hline 257 & 44 & $8 / 8 / 2014$ & WG1-29 & 100 & 102 & 13 & 850 & 850 & 466.544 & 466.454 & 12.07 & 22.56 & $5.11 E-09$ & 0.27 & 0.29 & 1 & 1200 & 0.07 & \\
\hline 258 & 44 & $8 / 8 / 2014$ & WG1-29 & 100 & 102 & 25 & 850 & 850 & 466.444 & 466.414 & 24.44 & 28.09 & 4.89E-09 & 0.29 & 0.30 & 1 & 1200 & 0.07 & \\
\hline 259 & 44 & $8 / 8 / 2014$ & WG1-29 & 100 & 102 & 42 & 850 & 850 & 466.407 & 466.368 & 28.93 & 35.49 & $3.54 E-09$ & 0.30 & 0.31 & 1 & 1200 & 0.07 & \\
\hline 260 & 44 & $8 / 8 / 2014$ & WG1-29 & 100 & 102 & 0 & 850 & 850 & 466.351 & 466.078 & 36.90 & 46.27 & $1.74 E-08$ & 0.31 & 0.37 & 1 & 1200 & 0.07 & \\
\hline 261 & 44 & $8 / 8 / 2014$ & WG1-29 & 200 & 215 & 0 & 850 & 850 & 466.024 & 465.787 & 47.49 & 55.17 & $1.84 E-08$ & 0.38 & 0.43 & 1 & 1200 & 0.07 & \\
\hline 262 & 44 & $8 / 8 / 2014$ & WG1-29 & 200 & 213 & 44 & 850 & 850 & 465.753 & 465.682 & 56.95 & 68.10 & $3.80 E-09$ & 0.44 & 0.45 & 1 & 1200 & 0.07 & \\
\hline 263 & 44 & $8 / 8 / 2014$ & WG1-29 & 200 & 212 & 21 & 850 & 850 & 465.661 & 465.59 & 70.72 & 78.78 & $5.25 E-09$ & 0.46 & 0.47 & 1 & 1200 & 0.07 & \\
\hline 264 & 45 & $8 / 12 / 2014$ & WG1-30 & 100 & 31 & 0 & 850 & 850 & 465.485 & 465.392 & 3.15 & 7.24 & $1.36 E-08$ & 0.26 & 0.28 & 1 & 1200 & 0.144 & \\
\hline 265 & 45 & $8 / 12 / 2014$ & WG1-30 & 100 & 31 & 13 & 850 & 850 & 465.377 & 465.368 & 8.70 & 11.20 & $2.15 E-09$ & 0.28 & 0.28 & 1 & 1200 & 0.144 & \\
\hline 266 & 45 & $8 / 12 / 2014$ & WG1-30 & 100 & 31 & 25 & 850 & 850 & 465.365 & 465.339 & 11.74 & 20.03 & $1.87 E-09$ & 0.28 & 0.29 & 1 & 1200 & 0.144 & \\
\hline 267 & 45 & $8 / 12 / 2014$ & WG1-30 & 100 & 31 & 39 & 850 & 850 & 465.338 & 465.326 & 20.52 & 24.36 & $1.87 E-09$ & 0.29 & 0.29 & 1 & 1200 & 0.144 & \\
\hline 268 & 45 & $8 / 12 / 2014$ & WG1-30 & 100 & 31 & 0 & 850 & 850 & 465.305 & 465.22 & 26.12 & 28.80 & $1.89 E-08$ & 0.30 & 0.31 & 1 & 1200 & 0.144 & \\
\hline 269 & 45 & $8 / 12 / 2014$ & WG1-30 & 100 & 52 & 0 & 850 & 850 & 465.202 & 465.118 & 29.36 & 31.91 & $1.97 E-08$ & 0.32 & 0.34 & 1 & 1200 & 0.144 & \\
\hline 270 & 45 & $8 / 12 / 2014$ & WG1-30 & 100 & 52 & 39 & 850 & 850 & 465.105 & 465.094 & 33.01 & 35.56 & $2.58 E-09$ & 0.34 & 0.34 & 1 & 1200 & 0.144 & \\
\hline 271 & 45 & $8 / 12 / 2014$ & WG1-30 & 100 & 52 & 25 & 850 & 850 & 465.09 & 465.036 & 36.42 & 45.13 & $3.70 E-09$ & 0.34 & 0.35 & 1 & 1200 & 0.144 & \\
\hline 272 & 45 & $8 / 12 / 2014$ & WG1-30 & 100 & 52 & 13 & 850 & 850 & 465.027 & 464.985 & 46.60 & 51.04 & $5.65 E-09$ & 0.36 & 0.36 & 1 & 1200 & 0.144 & \\
\hline 275 & 46 & $8 / 15 / 2014$ & WG1-31 & 15 & 14 & 25 & 850 & 850 & 469.05 & 469.042 & 12.39 & 18.33 & $7.98 E-10$ & 0.23 & 0.24 & 1 & 1200 & 0.097 & \\
\hline 277 & 46 & $8 / 15 / 2014$ & WG1-31 & so & 52 & 25 & 850 & 850 & 469.037 & 469.019 & 22.48 & 27.74 & $2.03 E-09$ & 0.24 & 0.24 & 1 & 1200 & 0.097 & \\
\hline 278 & 46 & $8 / 15 / 2014$ & WG1-31 & 100 & 105 & 26 & 850 & 850 & 469.01 & 468.938 & 28.50 & 35.88 & $5.78 E-09$ & 0.24 & 0.26 & 1 & 1200 & 0.097 & \\
\hline 279 & 46 & $8 / 15 / 2014$ & WG1-31 & 30 & 30 & 25 & 850 & 850 & 468.937 & 468.911 & 36.89 & 46.14 & $1.67 E-09$ & 0.26 & 0.26 & 1 & 1200 & 0.097 & \\
\hline 280 & 46 & $8 / 15 / 2014$ & WG1-31 & 150 & 150 & 28 & 850 & 850 & 468.881 & 468.786 & 46.99 & 51.82 & $1.17 E-08$ & 0.27 & 0.29 & 1 & 1200 & 0.097 & \\
\hline 281 & 46 & $8 / 15 / 2014$ & WG1-31 & 150 & 154 & 28 & 850 & 850 & 468.786 & 468.703 & 51.82 & 58.44 & $7.43 E-09$ & 0.29 & 0.31 & 1 & 1200 & 0.097 & \\
\hline 282 & 46 & $8 / 15 / 2014$ & WG1-31 & 3 & 5 & 25 & 850 & 850 & 468.721 & 468.706 & 59.62 & 70.73 & $8.00 E-10$ & 0.30 & 0.31 & 1 & 1200 & 0.097 & \\
\hline 283 & 47 & $8 / 25 / 2014$ & WG1-32 & 15 & 15 & 26 & 800 & 800 & 455.577 & 455.569 & 5.83 & 14.08 & 5.91E-10 & 0.26 & 0.26 & 2 & 1200 & 0.15 & \\
\hline 284 & 47 & $8 / 25 / 2014$ & WG1-32 & 15 & 15 & 26 & 850 & 850 & 455.496 & 455.472 & 14.89 & 24.11 & $1.59 E-09$ & 0.27 & 0.28 & 2 & 1200 & 0.15 & \\
\hline 285 & 47 & $8 / 25 / 2014$ & WG1-32 & 15 & 15 & 26 & 900 & 900 & 455.393 & 455.365 & 25.13 & 34.36 & $1.85 E-09$ & 0.30 & 0.30 & 2 & 1200 & 0.15 & \\
\hline 286 & 47 & $8 / 25 / 2014$ & WG1-32 & 15 & 15 & 26 & 950 & 950 & 455.285 & 455.207 & 34.99 & 44.46 & $5.03 E-09$ & 0.32 & 0.34 & 2 & 1200 & 0.15 & \\
\hline 287 & 48 & $9 / 3 / 2014$ & WG1-33 & 30 & 30 & 25 & 800 & 800 & 462.61 & 462.59 & 6.36 & 14.26 & $1.44 E-09$ & 0.239 & 0.243 & 2 & 1200 & 0.207 & \\
\hline 288 & 48 & $9 / 3 / 2014$ & WG1-33 & 30 & 30 & 25 & 850 & 850 & 462.53 & 462.49 & 15.17 & 24.17 & $2.74 E-09$ & 0.256 & 0.265 & 2 & 1200 & 0.207 & \\
\hline 289 & 48 & $9 / 3 / 2014$ & WG1-33 & 30 & 30 & 25 & 900 & 900 & 462.42 & 462.35 & 25.08 & 34.45 & 4.36E--09 & 0.279 & 0.294 & 2 & 1200 & 0.207 & \\
\hline 290 & 48 & $9 / 3 / 2014$ & WG1-33 & 30 & 30 & 25 & 950 & 950 & 462.28 & 462.10 & 35.04 & 44.59 & $1.16 E-08$ & 0.309 & 0.349 & 2 & 1200 & 0.207 & \\
\hline 291 & 49 & $12 / 30 / 2014$ & WG1-34 & 30 & 30 & 0 & 800 & 800 & 468.207 & 468.247 & 10.34 & 15.33 & $6.30 E-09$ & 0.020 & 0.01 & 1 & 1200 & 0.063 & \\
\hline 292 & 49 & $12 / 30 / 2014$ & WG1-34 & 30 & 30 & 0 & 850 & 850 & 468.235 & 468.143 & 15.82 & 25.31 & $9.81 E-09$ & 0.014 & 0.03 & 1 & 1200 & 0.063 & \\
\hline 293 & 49 & $12 / 30 / 2014$ & WG1-34 & 30 & 30 & 0 & 900 & 900 & 468.226 & 468.067 & 26.13 & 35.55 & $1.47 E-08$ & 0.016 & 0.05 & 1 & 1200 & 0.063 & \\
\hline 294 & 49 & $12 / 30 / 2014$ & WG1-34 & 30 & 30 & 0 & 950 & 950 & 468.225 & 467.903 & 35.88 & 45.69 & $2.40 E-08$ & 0.016 & 0.08 & 1 & 1200 & 0.063 & \\
\hline 295 & 50 & 1/1/2015 & WG1-34 & 12 & 12 & 0 & 850 & 850 & 468.307 & 468.226 & 9.69 & 14.45 & $9.22 E-09$ & 0.00 & 0.02 & 1 & 1200 & 0.06 & \\
\hline 296 & 50 & 1/1/2015 & WG1-34 & 12 & 12 & 0 & 900 & 900 & 468.233 & 468.191 & 14.78 & 19.51 & $1.37 E-08$ & 0.01 & 0.02 & 1 & 1200 & 0.06 & \\
\hline 297 & 51 & $1 / 5 / 2015$ & WG1-34 & 3 & 3 & 0 & 800 & 800 & 468.273 & 468.253 & 4.42 & 9.45 & $5.54 E-09$ & 0.01 & 0.02 & 1 & 1200 & 0.092 & \\
\hline 298 & 51 & $1 / 5 / 2015$ & WG1-34 & 3 & 3 & 0 & 850 & 850 & 468.237 & 468.22 & 9.81 & 14.48 & $1.02 E-08$ & 0.01 & 0.02 & 1 & 1200 & 0.092 & \\
\hline
\end{tabular}




\begin{tabular}{|c|c|c|c|c|c|c|c|c|c|c|c|c|c|c|c|c|c|c|c|}
\hline \multirow{3}{*}{$\begin{array}{l}\text { Test Data } \\
\text { Number }\end{array}$} & \multirow{3}{*}{$\begin{array}{l}\text { Day } \\
\text { Number }\end{array}$} & \multirow{3}{*}{ Test Date } & \multirow[b]{2}{*}{ Specimen ID } & \multicolumn{2}{|c|}{ Water Pressure } & \multirow{2}{*}{$\begin{array}{c}\text { H2 } \\
\text { Pressure }\end{array}$} & \multicolumn{2}{|c|}{ Temperature } & \multicolumn{2}{|c|}{ Weight } & \multicolumn{2}{|c|}{ Time in the Test } & \multirow{2}{*}{$\begin{array}{l}\text { Oxidation } \\
\text { Rate }\end{array}$} & \multicolumn{2}{|c|}{ Burn off \% } & \multicolumn{2}{|c|}{ Sample Preparaton } & \multirow{2}{*}{\multicolumn{2}{|c|}{$\begin{array}{l}\text { Weight Loss on } \\
\text { Outgasing }\end{array}$}} \\
\hline & & & & target & actual & & target & actual & before & after & before & after & & before & after & duration & temperature & & \\
\hline & & & & $\mathrm{Pa}_{\mathrm{a}}$ & $\mathrm{Pa}$ & $\mathrm{Pa}$ & ${ }^{\circ} \mathrm{C}$ & $o C$ & $\mathrm{mg}$ & $\mathrm{mg}$ & $\mathrm{hr}$ & $\mathrm{hr}$ & $s^{-1}$ & $\%$ & $\%$ & $h$ & ${ }^{\circ} \mathrm{C}$ & $\mathrm{mg}$ & \\
\hline 299 & 51 & 1/5/2015 & WG1-34 & 3 & 3 & 0 & 900 & 900 & 468.233 & 468.197 & 14.81 & 19.63 & $1.27 E-08$ & 0.01 & 0.02 & 1 & 1200 & 0.092 & \\
\hline 300 & 51 & 1/5/2015 & WG1-34 & 3 & 3 & 0 & 950 & 950 & 468.229 & 468.181 & 19.93 & 24.60 & $1.51 E-08$ & 0.01 & 0.02 & 1 & 1200 & 0.092 & \\
\hline 301 & 52 & 1/7/2016 & WG1-34 & 3 & 3 & 0 & 800 & 800 & 468.686 & 468.276 & 5.33 & 9.94 & $3.09 E-09$ & 0.01 & 0.02 & 1 & 1200 & 0.081 & \\
\hline 302 & 52 & 1/7/2016 & WG1-34 & 3 & 3 & 0 & 850 & 850 & 468.239 & 468.228 & 10.25 & 14.95 & $9.09 E-09$ & 0.01 & 0.02 & 1 & 1200 & 0.081 & \\
\hline 303 & 52 & 1/7/2016 & WG1-34 & 3 & 3 & 0 & 900 & 900 & 468.234 & 468.188 & 15.26 & 20.05 & $1.39 E-08$ & 0.01 & 0.02 & 1 & 1200 & 0.081 & \\
\hline 304 & 52 & $1 / 7 / 2016$ & WG1-34 & 3 & 3 & 0 & 950 & 950 & 468.229 & 468.165 & 20.32 & 25.18 & $1.65 E-08$ & 0.01 & 0.02 & 1 & 1200 & 0.081 & \\
\hline
\end{tabular}

\section{REECTED DATA}

\begin{tabular}{|c|c|c|c|c|c|c|c|c|c|c|c|c|c|c|c|c|c|c|c|}
\hline 239 & 40 & $6 / 30 / 2014$ & WG1-24 & 500 & 530 & 0 & 1100 & 1100 & 455.242 & 441.4 & 19.41 & 22.27 & $2.95 E-06$ & 2.11 & 5.08 & 2 & 1200 & 0.25 & $\mathrm{~N} 1$ \\
\hline 245 & 41 & $7 / 1 / 2014$ & WG1-25 & 1000 & 702 & 0 & 1100 & 1100 & 453.542 & 442.934 & 19.95 & 21.74 & $3.63 E-06$ & 2.51 & 4.79 & 2 & 1200 & 0.18 & N1 \\
\hline 246 & 41 & $7 / 1 / 2014$ & WG1-25 & 1000 & 1447 & 0 & 1100 & 1100 & 442.934 & 430.093 & 21.74 & 22.84 & $7.32 E-06$ & 4.79 & 7.55 & 2 & 1200 & 0.18 & N1 \\
\hline 163 & 28 & $3 / 5 / 2014$ & AG3-15 & 30 & 15 & 26 & 800 & 800 & 462.756 & 462.756 & 4.82 & 7.36 & $0.00 E+00$ & 0.18 & 0.18 & 2 & 1200 & 0.16 & N2 \\
\hline 169 & 29 & $3 / 6 / 2014$ & AG3-16 & 30 & 30 & 26 & 800 & 800 & 470.752 & 470.749 & 4.68 & 7.34 & $6.65 E-10$ & 0.17 & 0.17 & 2 & 1200 & 0.12 & N3 \\
\hline 170 & 29 & $3 / 6 / 2014$ & AG3-16 & 30 & 15 & 25 & 850 & 850 & 470.696 & 470.7 & 7.73 & 10.41 & $-8.81 E-10$ & 0.18 & 0.18 & 2 & 1200 & 0.12 & N4 \\
\hline 175 & 30 & $3 / 7 / 2014$ & AG3-17 & 50 & 52 & 26 & 800 & 800 & 466.475 & 466.491 & 4.60 & 7.36 & $-3.45 E-09$ & 0.19 & 0.18 & 2 & 1200 & 0.15 & N4 \\
\hline 188 & 32 & $3 / 25 / 2014$ & AG3-20 & 150 & 151 & 26 & 850 & 850 & 452.259 & 452.272 & 7.67 & 10.43 & $-2.89 E-09$ & 0.24 & 0.24 & 2 & 1200 & 0.22 & N4 \\
\hline 193 & 33 & $4 / 1 / 2014$ & WG1-17 & 100 & 102 & 26 & 800 & 800 & 467.009 & 466.98 & 5.13 & 7.39 & $7.63 E-09$ & 0.20 & 0.21 & 2 & 1200 & 0.17 & N5 \\
\hline 194 & 33 & $4 / 1 / 2014$ & WG1-17 & 100 & 101 & 25 & 850 & 850 & 466.953 & 466.985 & 7.70 & 10.46 & $-6.90 E-09$ & 0.22 & 0.21 & 2 & 1200 & 0.17 & N4 \\
\hline 199 & 34 & $4 / 2 / 2014$ & WG1-18 & so & 51 & 26 & 800 & 800 & 463.408 & 463.386 & 5.51 & 7.42 & $6.90 E-09$ & 0.20 & 0.20 & 2 & 1200 & 0.18 & N5 \\
\hline 200 & 34 & $4 / 2 / 2014$ & WG1-18 & so & 51 & 26 & 850 & 850 & 463.34 & 463.361 & 7.70 & 10.55 & $-4.42 E-09$ & 0.21 & 0.21 & 2 & 1200 & 0.18 & N4 \\
\hline 205 & 35 & $4 / 3 / 2014$ & WG1-19 & 30 & 30 & 26 & 800 & 800 & 463.123 & 463.123 & 5.53 & 7.38 & $0.00 E+00$ & 0.20 & 0.20 & 2 & 1200 & 0.17 & N2 \\
\hline 206 & 35 & $4 / 3 / 2014$ & WG1-19 & 30 & 30 & 26 & 850 & 850 & 463.075 & 463.114 & 7.68 & 10.47 & $-8.39 E-09$ & 0.21 & 0.20 & 2 & 1200 & 0.17 & N4 \\
\hline 207 & 35 & $4 / 3 / 2014$ & WG1-19 & 30 & 30 & 26 & 900 & 900 & 463.063 & 463.066 & 10.75 & 13.55 & $-6.43 E-10$ & 0.21 & 0.21 & 2 & 1200 & 0.17 & N4 \\
\hline 209 & 35 & $4 / 3 / 2014$ & WG1-19 & 30 & 30 & 26 & 1000 & 1000 & 465.219 & 462.71 & 16.95 & 19.80 & $5.26 E-07$ & -0.25 & 0.29 & 2 & 1200 & 0.17 & N3 \\
\hline 211 & 36 & $4 / 4 / 2014$ & WG1-20 & 150 & 152 & 26 & 800 & 800 & 464.249 & 464.24 & 4.88 & 7.39 & $2.15 E-09$ & 0.19 & 0.19 & 2 & 1200 & 0.15 & N3 \\
\hline 212 & 36 & $4 / 4 / 2014$ & WG1-20 & 150 & 150 & 26 & 850 & 850 & 464.191 & 464.215 & 7.81 & 10.49 & $-5.36 E-09$ & 0.21 & 0.20 & 2 & 1200 & 0.15 & N4 \\
\hline 223 & 38 & $4 / 8 / 2014$ & WG1-22 & 15 & 22 & 26 & 850 & 850 & 456.287 & 456.317 & 7.67 & 10.43 & $-6.62 E-09$ & 0.23 & 0.22 & 2 & 1200 & 0.17 & N4 \\
\hline 224 & 38 & $4 / 8 / 2014$ & WG1-22 & 15 & 8 & 26 & 900 & 900 & 456.266 & 456.283 & 10.74 & 13.59 & $-3.63 E-09$ & 0.23 & 0.23 & 2 & 1200 & 0.17 & N4 \\
\hline 229 & 39 & $4 / 9 / 2014$ & WG1-23 & 30 & 4 & 96 & 850 & 850 & 469.615 & 469.638 & 7.69 & 10.45 & $-4.93 E-09$ & 0.11 & 0.10 & 2 & 1200 & 0.26 & N4 \\
\hline 230 & 39 & $4 / 9 / 2014$ & WG1-23 & 30 & 4 & 96 & 900 & 900 & 469.638 & 469.655 & 10.79 & 13.46 & $-3.77 E-09$ & 0.10 & 0.10 & 2 & 1200 & 0.26 & N4 \\
\hline 231 & 39 & $4 / 9 / 2014$ & WG1-23 & 30 & 4 & 96 & 950 & 950 & 469.634 & 469.655 & 13.89 & 16.62 & $-4.55 E-09$ & 0.10 & 0.10 & 2 & 1200 & 0.26 & N4 \\
\hline 273 & 46 & $8 / 15 / 2014$ & WG1-31 & 3 & 4 & 85 & 850 & 850 & 469.07 & 469.062 & 3.49 & 9.17 & $5.21 E-10$ & 0.23 & 0.23 & 1 & 1200 & 0.097 & N3 \\
\hline 274 & 46 & $8 / 15 / 2014$ & WG1-31 & 3 & 4 & 85 & 850 & 850 & 469.062 & 469.064 & 9.17 & 11.04 & $-6.33 E-10$ & 0.23 & 0.23 & 1 & 1200 & 0.097 & N4 \\
\hline 187 & 32 & $3 / 25 / 2014$ & AG3-20 & 150 & 152 & 26 & 800 & 800 & 452.311 & 452.31 & 5.38 & 7.39 & $3.06 E-10$ & 0.23 & 0.23 & 2 & 1200 & 0.22 & N3 \\
\hline 219 & 37 & $4 / 7 / 2014$ & WG1-21 & 300 & 296 & 26 & 900 & 900 & 464.84 & 464.828 & 10.74 & 13.56 & $2.54 E-09$ & 0.24 & 0.25 & 2 & 1200 & 0.19 & N1 \\
\hline 276 & 46 & $8 / 15 / 2014$ & WG1-31 & 15 & 8 & 25 & 850 & 850 & 469.042 & 469.041 & 18.33 & 21.72 & $1.75 E-10$ & 0.24 & 0.24 & 1 & 1200 & 0.097 & N3 \\
\hline 171 & 29 & $3 / 6 / 2014$ & AG3-16 & 30 & 29 & 26 & 900 & 900 & 470.671 & 470.67 & 12.67 & 13.59 & $6.41 E-10$ & 0.19 & 0.19 & 2 & 1200 & 0.12 & N6 \\
\hline 228 & 39 & $4 / 9 / 2014$ & WG1-23 & 30 & 4 & 96 & 800 & 800 & 469.592 & 469.613 & 4.56 & 7.26 & $-4.60 E-09$ & 0.11 & 0.11 & 2 & 1200 & 0.26 & N3 \\
\hline 232 & 39 & $4 / 9 / 2014$ & WG1-23 & 30 & 4 & 96 & 1000 & 1000 & 469.65 & 469.601 & 16.96 & 19.63 & $1.09 E-08$ & 0.10 & 0.11 & 2 & 1200 & 0.26 & N3 \\
\hline 233 & 39 & $4 / 9 / 2014$ & WG1-23 & 30 & 4 & 96 & 1100 & 1100 & 469.581 & 469.517 & 20.15 & 22.85 & $1.40 E-08$ & 0.12 & 0.13 & 2 & 1200 & 0.26 & N3 \\
\hline 181 & 31 & $3 / 14 / 2014$ & AG3-19 & 100 & 101 & 26 & 800 & 800 & 459.769 & 459.772 & 5.30 & 7.25 & $-9.29 E-10$ & 0.19 & 0.19 & 2 & 1200 & 0.22 & N4 \\
\hline 43 & 8 & $1 / 9 / 2014$ & WG1-12 & 15 & 15 & 0 & 800 & 800 & 463.377 & 463.249 & 4.13 & 6.72 & $2.96 E-08$ & 0.18 & 0.21 & 2 & 1200 & 0.14 & N5 \\
\hline
\end{tabular}

N1 = unstable weight readings; N2 = apparent “zero” rate; N3 = experimental errors; N4 = apparent "negative” rate; N5 = uncommon trend; N6 = unsteady state 
Table A-3: $\quad$ Fitted parameter estimates and standard errors provided by SAS

\begin{tabular}{|c|c|c|c|c|c|c|c|c|c|}
\hline \multirow{2}{*}{$\begin{array}{c}\text { SAS } \\
\text { Parameters }\end{array}$} & \multirow{2}{*}{ Estimate } & \multirow{2}{*}{$\begin{array}{c}\text { Standard } \\
\text { Error }\end{array}$} & \multicolumn{2}{|c|}{ Confidence intervals } & \multirow{2}{*}{ Gradient } & \multirow{2}{*}{$\begin{array}{c}\text { L-H } \\
\text { Parameters }\end{array}$} & \multirow[b]{2}{*}{ Estimate } & \multicolumn{2}{|c|}{ Confidence intervals } \\
\hline & & & Lower & Upper & & & & Lower & Upper \\
\hline \multicolumn{10}{|c|}{ All Temperatures $\left(800-1100^{\circ} \mathrm{C}\right)$} \\
\hline a1 & -12.468 & 1.3374 & -15.1542 & -9.7819 & $3.45 \mathrm{E}-06$ & A1 & $3.85 E-06$ & $2.62 E-07$ & $5.65 E-05$ \\
\hline b1 & -7.3964 & 1.7409 & -10.8932 & -3.8996 & $4.76 \mathrm{E}-06$ & A2 & $4.00 E-08$ & $1.06 \mathrm{E}-09$ & $1.51 \mathrm{E}-06$ \\
\hline a2 & -17.0341 & 1.8085 & -20.6667 & -13.4016 & $-5.90 E-06$ & A3 & 5.79E-07 & $2.74 E-08$ & $1.22 \mathrm{E}-05$ \\
\hline b2 & 22.4502 & 2.2377 & 17.9558 & 26.9447 & $-5.18 \mathrm{E}-06$ & E1 & 61,494 & 90,566 & 32,421 \\
\hline a3 & -14.3624 & 1.5182 & -17.4118 & -11.313 & $-3.62 \mathrm{E}-06$ & E2 & $-186,651$ & $-149,285$ & $-224,018$ \\
\hline b3 & 14.7806 & 1.9233 & 10.9175 & 18.6436 & $-4.77 \mathrm{E}-06$ & E3 & $-122,886$ & $-90,768$ & $-155,003$ \\
\hline$s 2 u$ & 0.1952 & 0.04352 & 0.1078 & 0.2826 & 0.00001 & & & & \\
\hline$s 2$ & 0.4514 & 0.02187 & 0.4074 & 0.4953 & -0.00004 & & & & \\
\hline \multicolumn{10}{|c|}{ Low Temperatures $\left(800-950^{\circ} \mathrm{C}\right)$} \\
\hline a1 & -25.6475 & 9.2171 & -44.1605 & -7.1345 & $8.66 \mathrm{E}-06$ & A1 & $7.27 \mathrm{E}-12$ & $6.63 E-20$ & $7.97 E-04$ \\
\hline b1 & 8.9619 & 11.2904 & -13.7156 & 31.6394 & $7.76 \mathrm{E}-06$ & A2 & $1.08 \mathrm{E}-10$ & $7.11 \mathrm{E}-19$ & $1.64 \mathrm{E}-02$ \\
\hline a2 & -22.9484 & 9.3798 & -41.7883 & -4.1085 & -0.00002 & A3 & 4.73E-10 & $3.65 E-18$ & $6.13 E-02$ \\
\hline b2 & 30.5303 & 11.4679 & 7.4963 & 53.5643 & -0.00002 & E1 & $-74,509$ & 114,031 & $-263,050$ \\
\hline a3 & -21.4714 & 9.2997 & -40.1505 & -2.7923 & $4.70 \mathrm{E}-06$ & E2 & $-253,829$ & $-62,324$ & $-445,334$ \\
\hline b3 & 24.3938 & 11.3949 & 1.5065 & 47.281 & $4.91 E-06$ & E3 & $-202,810$ & $-12,525$ & $-393,094$ \\
\hline$s 2 \mathrm{u}$ & 0.2623 & 0.04052 & 0.1809 & 0.3437 & 0.000027 & & & & \\
\hline$s 2$ & 0.3265 & 0.01981 & 0.2867 & 0.3663 & 0.00022 & & & & \\
\hline \multicolumn{10}{|c|}{ High Temperatures $\left(900-1100^{\circ} \mathrm{C}\right)$} \\
\hline a1 & -12.6576 & 1.3106 & -15.2972 & -10.018 & -0.00009 & A1 & $3.18 \mathrm{E}-06$ & $2.27 \mathrm{E}-07$ & $4.46 \mathrm{E}-05$ \\
\hline b1 & -7.445 & 1.766 & -11.0019 & -3.8882 & -0.00006 & A2 & $8.95 \mathrm{E}-13$ & $6.24 E-15$ & $1.28 \mathrm{E}-10$ \\
\hline a2 & -27.7424 & 2.4654 & -32.7079 & -22.7768 & -0.0002 & A3 & $3.99 \mathrm{E}-10$ & $1.55 \mathrm{E}-11$ & $1.03 E-08$ \\
\hline b2 & 35.6533 & 3.055 & 29.5002 & 41.8064 & -0.00016 & E1 & 61,898 & 91,470 & 32,326 \\
\hline a3 & -21.6432 & 1.6127 & -24.8913 & -18.3951 & 0.000223 & E2 & $-296,422$ & $-245,265$ & $-347,578$ \\
\hline b3 & 23.6152 & 2.1001 & 19.3854 & 27.845 & 0.000167 & E3 & $-196,337$ & $-161,170$ & $-231,503$ \\
\hline$s 2 \mathrm{u}$ & 0.2305 & 0.03632 & 0.1574 & 0.3037 & 0.000439 & & & & \\
\hline$s 2$ & 0.2874 & 0.01868 & 0.2498 & 0.325 & -0.00137 & & & & \\
\hline
\end{tabular}

Units: $A_{1}\left(P a^{-1} s^{-1}\right) ; A_{2}(P a-0.5) ; A_{3}(P a-1) ; E_{1}, E_{2}, E_{3}(J / m o l)$ 
ORNL/TM-2015/142 


\section{DISTRIBUTION LIST}

\section{Oak Ridge National Laboratory}

Timothy Burchell

Peter Tortorelli

Yutai Katoh

Cristian Contescu

Weiju Ren

John Hunn

Nidia Gallego

Sam Sham

\section{Idaho National Laboratory}

David Petti

William Windes

Laurence Hull

Rebecca Smith

Robert Bratton

David Jensen

Joshua Kane

\section{Department of Energy}

William Corwin

Thomas O’Connor

Carl Sink burchelltd@ornl.gov

tortorellipf@ornl.gov

katohy@ornl.gov

contescuci@ornl.gov

renw@ornl.gov

hunnjd@ornl.gov

gallegonc@ornl.gov

shamt@ornl.gov

David.Petti@inl.gov

William.Windes@inl.gov

Laurence.Hull@inl.gov

Rebecca.Smith@inl.gov

Robert.Bratton@inl.gov

David.Jensen@inl.gov

Joshua.Kane@inl.gov

William.Corwin@Nuclear.Energy.gov

Tom.OConnor@Nuclear.Energy.gov

Carl.Sink@Nuclear.Energy.gov 